\title{
Supervision, compliance and societal effects : impact assessment of the Tobacco Legislation : effects of the workplace-smoking ban and the tobacco sales ban to minors
}

Citation for published version (APA):

Verdonk-Kleinjan, W. M. I. (2014). Supervision, compliance and societal effects : impact assessment of the Tobacco Legislation : effects of the workplace-smoking ban and the tobacco sales ban to minors. [Doctoral Thesis, Maastricht University]. Datawyse / Universitaire Pers Maastricht. https://doi.org/10.26481/dis.20141113wv

Document status and date:

Published: 01/01/2014

DOI:

10.26481/dis.20141113wv

Document Version:

Publisher's PDF, also known as Version of record

Please check the document version of this publication:

- A submitted manuscript is the version of the article upon submission and before peer-review. There can be important differences between the submitted version and the official published version of record. People interested in the research are advised to contact the author for the final version of the publication, or visit the DOI to the publisher's website.

- The final author version and the galley proof are versions of the publication after peer review.

- The final published version features the final layout of the paper including the volume, issue and page numbers.

Link to publication

\footnotetext{
General rights rights.

- You may freely distribute the URL identifying the publication in the public portal. please follow below link for the End User Agreement:

www.umlib.nl/taverne-license

Take down policy

If you believe that this document breaches copyright please contact us at:

repository@maastrichtuniversity.nl

providing details and we will investigate your claim.
}

Copyright and moral rights for the publications made accessible in the public portal are retained by the authors and/or other copyright owners and it is a condition of accessing publications that users recognise and abide by the legal requirements associated with these

- Users may download and print one copy of any publication from the public portal for the purpose of private study or research.

- You may not further distribute the material or use it for any profit-making activity or commercial gain

If the publication is distributed under the terms of Article 25fa of the Dutch Copyright Act, indicated by the "Taverne" license above, 
Supervision, compliance and societal effects

\section{IMPACT ASSESSMENT OF THE TOBACCO LEGISLATION \\ Effects of the workplace-smoking ban \\ and the tobacco sales ban to minors}

Wendy Verdonk-Kleinjan 
Nederlandse Voedsel- en

Warenautoriteit

Ministerie van Economische Zaken

Dit proefschrift is mede tot stand gekomen dankzij de steun van de NVWA

(C) Wendy Verdonk-Kleinjan, Maastricht 2014

Druk en layout: Datawyse | Universitaire Pers Maastricht

Cover photo: Wendy Verdonk

ISBN 978-94-6159-370-2 


\title{
Supervision, compliance and societal effects
}

\section{IMPACT ASSESSMENT OF THE TOBACCO LEGISLATION \\ Effects of the workplace-smoking ban and the tobacco sales ban to minors}

\author{
PROEFSCHRIFT \\ ter verkrijging van de graad van doctor aan de Universiteit Maastricht, \\ op gezag van de Rector Magnificus, Prof. dr. L.L.G. Soete, \\ volgens het besluit van het College van Decanen, \\ in het openbaar te verdedigen, \\ op donderdag 13 november 2014, om 14.00 uur \\ door \\ (Wendy) Maria Izabella Verdonk-Kleinjan
}

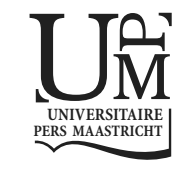




\section{Promotoren}

Prof. dr. R.A. Knibbe

Prof. dr. H. de Vries

\section{Beoordelingscommissie}

Prof. dr. N.K. de Vries (voorzitter)

Prof. dr. R.C.M.E. Engels (Radboud Universiteit Nijmegen)

Dr. G.E. Nagelhout

Prof. dr. P.B.M. Robben (Erasmus Universiteit Rotterdam)

Prof. dr. ir. C.P. van Schayck 


\section{Contents}

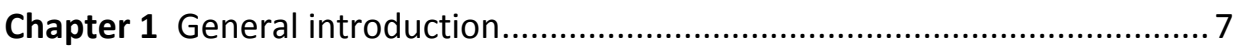

Chapter 2 Compliance with the workplace-smoking ban in the Netherlands

Chapter 3 Agreement between self-reports and on-site inspections of compliance with the workplace-smoking ban

Chapter 4 Does the workplace-smoking ban eliminate differences in risk for environmental tobacco smoke exposure at work?

Chapter 5 Effect of a workplace-smoking ban in combination with tax increases on smoking in the Dutch population

Chapter 6 The tobacco sales ban and tobacco purchases by adolescents: a general population study in the Netherlands

Chapter 7 Supervisory bodies and impact assessment

Chapter 8 General discussion, including valorization 109

Summary

Samenvatting

References

Dankwoord

Curriculum vitae 

CHAPTER 1

General introduction 



\section{Introduction}

This thesis describes the effects of legislation in the Netherlands based on two legal provisions emerging from the Tobacco Act, i.e. the workplace-smoking ban (excluding the hospitality sector) and the tobacco sales ban to minors. This thesis includes studies on the societal effects of this legislation (i.e. smoking behaviour, exposure to secondhand smoke and purchase behaviour) as well as studies on the level of compliance by relevant actors with the legislation, and the factors that influence this compliance. These research themes, compliance assessment and policy impact assessment are the general themes of this thesis, as well as the theme supervision, the relation between legislation, compliance and societal effects.

This introductory chapter starts by describing the history of the discovery of the harms due to active and passive smoking (1.1). This is followed by a historical overview of the (legal) policy measures taken to discourage smoking and decrease the risks due to passive smoking, both internationally as well as in the Netherlands (1.2). We then deal with the relation between legislation, compliance and societal effects (1.3). This chapter ends with an outline of the thesis, including the aims, research questions and the studies performed (1.4).

\subsection{Smoking and health}

\subsubsection{Smoking and health}

In the middle of the 20th century a strong increase was observed in the annual number of deaths attributed to cancer of the lung [Doll \& Hill, 1950; Wynder \& Graham, 1950]. Based on their British doctors' study, Doll and Hill concluded that smoking was an important factor in the incidence of carcinoma of the lung [Doll \& Hill, 1950], and that there was a clear association between the mortality from lung cancer and the smoking of cigarettes [Doll \& Hill, 1956]. In the Netherlands, Wassink was one of the first to investigate the causes of increased lung cancer. In 1948, he concluded that smoking and rooms with tobacco smoke, were the main causes of lung cancer among men in the Netherlands [Wassink, 1948].

Since that time many more studies have investigated the relationship between smoking and several diseases. In 1964, the first 'Report: Smoking and Health' of the Advisory Committee to the Surgeon General [U.S. Department of Health Education and Welfare, 1964] stated that cigarette smoking was causally related to lung cancer in men and that the risk of developing lung cancer increased with the duration of smoking and the number of cigarettes smoked per day, and was diminished by stopping 
smoking. Furthermore this report stated that cigarette smoking was the most important cause of chronic bronchitis and increased the risk of dying from chronic bronchitis and emphysema. It was also established that male cigarette smokers have a higher death rate from coronary artery disease and other cardiovascular diseases than non-smoking males. Overall, the authors concluded that cigarette smoking contributed substantially to mortality due to specific diseases as well as to the overall death rate. A few years before that (1957), the first advice issued by the Dutch Health Council was more reluctant to specify diseases due to smoking. Although the Dutch government was worried about the clear increase in lung cancer, it considered that the causal relationship with smoking was not (yet) proven, even though it had no specific arguments against this assumption [Wester, 1957].

Nowadays, it is accepted worldwide that smoking causes various diseases and that smoking is a major cause of premature death worldwide. It was estimated that in 2000 nearly five million (4.83 million) premature deaths were due to the effects of smoking, whereby the leading causes of deaths from smoking were cardiovascular diseases (1.69 million deaths), chronic obstructive pulmonary disease (0.96 million deaths), and lung cancer (0.85 million deaths) [Ezzati \& Lopez, 2004]. In the Netherlands in 2009, more than 19,000 people died from smoking-related diseases. Most of them died due to lung cancer, followed by chronic obstructive pulmonary disease, cardiovascular diseases and cancers other than lung cancer [Gelder van, Poos \& Zantinge, 2011].

\subsubsection{Second-hand smoke and health}

In 1971 the US Surgeon General stated that: "non-smokers have as much right to clean indoor air ... as smokers have to their so-called right to smoke" [International Agency for Research on Cancer (IARC), 2009, p. 63]. A few years later, in 1975, the first WHO Expert Committee report on smoking and its effects on health suggested a harmful concentration of smoke among non-smokers who were exposed to second-hand smoke in ill-ventilated small places [IARC, 2009]. At the same time an Australian report came to similar conclusions [IARC, 2009]. It took until 1986 (20 years after the first report of the Surgeon General) for a report which provided convincing evidence for a causal relation between second-hand smoke and lung cancer. This report described the causal relation between the exposure of non-smokers to environmental tobacco smoke and lung cancer, as well as the relationship between parental smoking and the respiratory health of infants and children. Furthermore, the report advised to explore the relationship between environmental tobacco smoke and cancers other than lung cancer and cardiovascular diseases [U.S. Department of Health and Human Services, 1986]. Later, the relationship between passive smoking and cardiovascular diseases, asthma among children, cot death and decreased birth weight was established [Knol, 
Hilvering, Wagener \& Willemsen, 2005]. In 1990 and again in 2003 the Dutch Health Council reported on the health risks of second-hand smoke [Gezondheidsraad, 1990; Gezondheidsraad, 2003].

\subsection{History of anti-smoking policy}

Once governments accepted that smoking and passive smoking were very harmful for a person's health, they started to give shape to an anti-smoking policy. Below, we present a historical overview of the development of the anti-smoking policy and the (legal) measures taken on the international level and in the Netherlands. The effects of the various legal measures are discussed in Chapters 2 to 6.

\subsubsection{International policy measures to discourage smoking}

Since the 1960s, various strategies were introduced to reduce the use of tobacco. After the Surgeon General's report on smoking in 1964, and the UK report 'Smoking and Health' by the Royal College of Physicians of London in 1961, several countries started to discourage smoking. In the beginning the discouragement was mainly focused on getting smokers to quit smoking and on adolescents to prevent the onset of smoking. Later, after the risks of second-hand smoke were proven (mid-1980s), the policy was expanded to protect non-smokers by restrictions on smoking in general. Besides the discouragement policy of the individual countries, in 1995 there was an international initiative by the World Health Organization (WHO) to develop an international instrument for tobacco control. In 2003, this resulted in the WHO Framework Convention on Tobacco Control (FCTC), which demonstrated a global political will to strengthen tobacco control. The following section outlines the development and working of the FCTC, and the development of various legal measures on the international and national level.

\section{WHO Framework Convention on Tobacco Control (FCTC)}

Apart from the single policy measures enacted by the individual countries, in 1995 the World Health Assembly initiated the idea of an international instrument for tobacco control. This resulted in the adoption of Resolution EB97.R8, 'International framework convention for tobacco control' and in a request to the WHO to draft a feasibility study to develop an international instrument for tobacco control. After years of negotiations and working groups, on 21 May 2003 the $56^{\text {th }}$ World Health Assembly unanimously adopted the WHO Framework Convention on Tobacco Control (FCTC) [WHO, 2003]. In the following year, the FCTC opened for ratification and entered into force on $27 \mathrm{Fe}-$ bruary 2005. In 2011 the treaty had 173 signatories by Member States and is the most 
widely embraced treaty in the history of the United Nations. The FCTC is a legally binding global legislation treaty that provides the foundation for countries to implement tobacco control programmes [WHO, 2011]. The FCTC consists of 38 articles addressing a wide variety of measures concerning price and tax; protection from exposure to tobacco smoke; packaging and labelling; education, communication, training and public awareness; tobacco advertising, promotion and sponsorship; tobacco dependence and cessation; illicit trade in tobacco products; and sales to and by minors [WHO, 2003]. To support countries to implement the FCTC, in 2008 the WHO introduced the MPOWER policy package. MPOWER consists of six, evidence-based, tobacco control measures (Table 1) that helps countries to fight tobacco use. The MPOWER document provides information on the importance, best practices, characteristics of effective implementation, and information about the opposition they might receive from the tobacco industry [WHO, 2008]. To follow the implementation process, the WHO periodically collects data to evaluate the existing policies and compliance [WHO, 2011].

Table 1: The MPOWER policy package [WHO, 2008].

Monitor tobacco use and prevention policies

Protection of people from tobacco smoking

Offer help to quit tobacco use

Warn about the dangers of tobacco

Enforce bans on tobacco advertising, promotion and sponsorship

Raise taxes on tobacco

\section{Adoption of various (legal) policy measures}

The following section describes various policy measures undertaken by different governments to reduce the use of tobacco.

\section{Legislation on labelling}

The first laws to discourage smokers from smoking were focused on labelling. The labelling legislation required health warnings to be placed on cigarette packages to inform smokers of the harmfulness of smoking: i.e. in the US in 1965 [Jabobson \& Wasserman, 1997], Canada in 1973 [De Beyer \& Waverley Brigden, 2003] and in Australia in 1986 [Netherlands School of Public Health (NSPH), 1998]. The European Union (EU) regulated labelling of tobacco products in 1989; a general warning 'Smoking damages health' and a changing health warning (1 out of 14) were obliged to be placed on packages of cigarettes [European Parliament and the Council, $1989^{\text {b }}$ ]. A few years later, the EU introduced a legal maximum limit on tar and extended the regulation of labelling to 
other tobacco products [European Parliament and the Council, 1990; 1992]. A decade later the regulation was extended to include maximum limits for tar, nicotine and carbon monoxide, to a ban on descriptions such as 'light', and to the establishment of a library of pictures that EU countries can use to reinforce the warning messages [European Parliament and the Council, 2001].

Currently, the majority of countries worldwide have regulations about health warnings, although they still vary in the position, size and general strength of these messages [Hammond, 2011]. To increase the effects of health warnings, in 2001 Canada started with pictorial warnings and increased the size of the warnings to cover $50 \%$ of the principal display area. The FCTC has taken over this initiative and, since 2008, recommends pictorial warnings that cover at least half of the package as one of the MPOWER policy measures [WHO, 2008]. These recommendations have now been adopted in more than 30 countries [Hammond, 2011]. In 2014, the Council of the European Union adopted a revision of the regulation and reguires a combined pictorial and text warning that cover $65 \%$ of the package [European Parliament and the Council, 2014]. To enhance the effectiveness of the warnings various countries are exploring new methods, such as increasing the size of the warnings to $80 \%$ of the front and back of packages (Uruguay), maximizing the negative emotional arousal (Brazil), testimonial warnings that depict real people (Chile), and engaging cessation/supportive information by adding 'quit line' numbers and by organising mass media campaigns with themes similar to the pictorial warnings (Australia) [Fong, Hammond \& Hitchman, 2009; Hammond, 2011].

\section{Ban on tobacco advertisement and sponsoring}

The tobacco industry claims that they use advertising activities not to attract new users or increase the total consumption, but to communicate with (adult) consumers to maintain or increase the relative market shares [Cummings, Morley, Horan, Steger \& Leavell, 2002; Pollay, 2000]. However, industry documents show that advertising and promotion efforts actually encourage current smokers to smoke more and decrease their motivation to quit and, furthermore, urge potential users to become long-term customers [Cummings et al., 2002; Pollay, 2000; Mackenbach \& McKee, 2013; WHO, 2008; Willemsen \& Zwart de, 1999]. It is probably because of these effects that the tobacco industry is so strongly opposed to government bans on advertising and sponsoring. Advertising bans are in fact effective in reducing smoking [WHO, 2008].

In 1969, the US started with a ban on cigarette advertising on television and radio [Jabobson \& Wasserman, 1997]. In the 1970s some countries (Norway in 1975; Finland in 1977) banned all cigarette advertising and sponsoring and, a decade later, other countries followed (Canada in 1989; New Zealand in 1990) [NSPH, 1998]. In 1989 the EU started a ban on tobacco advertising on television only [European Parliament and 
the Council, $1989^{\mathrm{a}}$ ]. A decade later another EU regulation proposed a ban on all types of tobacco advertising and sponsoring [European Parliament and the Council, 1998]. However, this regulation was cancelled by the European High Court after a legal process initiated by the tobacco industry and the German government. In 2003 the EU regulation was adjusted, leading to a ban on tobacco advertising in the press, on the radio and internet, as well as banning tobacco sponsoring of cross-frontier cultural and sports events [European Parliament and the Council, 2003].

A new strategy to ban advertisements is 'plain' packaging. This originated in Australia in 2012 and requires all cigarette packaging to be generic. This should prevent the tobacco industry from using packaging to promote their products, which should reduce the attractiveness and appeal of tobacco [Freeman, Chapman \& Rimmer, 2008; Wakefield, Hayes, Durkin \& Borland, 2013]. New Zealand plans to be the second country to implement this strategy, but is waiting to see what the verdict is of the court case the tobacco industry brought against the Australian government [Hefler, 2013; Sweet, 2013].

\section{Smoking restrictions and regulation}

In the 1970s various countries started to introduce restrictions on smoking in public places (US, Bulgaria, Singapore) [IARC, 2009]. In 1986, when the relation between second-hand smoke and lung cancer was considered to be proven [U.S. Department of Health and Human Services, 1986], more countries started to ban smoking in public places and to introduce smoking restrictions at worksites. Initially, however, many governments preferred voluntary agreements rather than legal measures to prevent second-hand smoke exposure. This was mostly due to the political power of the tobacco industry [IARC, 2009]. It took some time before evaluation studies of these voluntary agreements indicated that the exposure to second-hand smoke was not eliminated and, at best, was only reduced [Siegel, 2002].

In the late 1980s, smoking bans on airlines were adopted by the US, Canada and Norway, after a lawsuit by an employee in the US. Under pressure from a lobbying campaign for smoke-free skies, this resulted in a resolution to eliminate smoking on international commercial flights by 1 July 1996 [IARC, 2009].

In 1990, New Zealand introduced a Smoke-free Environments Act, which also enforced partial restrictions in the hospitality sector. A few years later, in 1995, California (USA) approved the California Smoke-Free Workplace Law which, in 1998, came to include the hospitality sector. From then onwards, California was the first state (and for a long time the only one) with a comprehensive Smoke-Free Workplace Law. It took almost a decade before Ireland (2004), Norway (2004) and New Zealand (2004) implemented comprehensive smoke-free laws at the national (rather than at the state) level [IARC, 2009]. Since the adoption of the FCTC (article 8: 'Protection from exposure 
to tobacco smoke') and the second recommendation of the MPOWER package (Protection of people from tobacco smoking), many more countries have enacted smoke-free legislation and this will probably continue in the future. The treaty states that the parties shall adopt and implement effective legislation 'providing for protection from exposure to tobacco smoke in indoor workplaces, public transport, indoor public places and, as appropriate, other public places' [IARC, 2009]. The 2011 WHO report on the global tobacco epidemic stated that about half of the countries now have smokefree legislation covering more than two types of public places, of which 31 countries have comprehensive smoke-free legislation (giving the highest level of protection). The remaining countries have legislation on only one or two types of public places or have no laws at all [WHO, 2011].

A positive side-effect of the smoke-free legislation is that it also encourages families to make their homes smoke-free [WHO, 2008]. Moreover, the legal smoking ban is often expanded to include cars with very young passengers (various US states and Bahrein), or with children below 12 years of age (South Africa, United Arabic Emirates), or children below 16 years (Australia, Canada, Cyprus), or passengers in general (Mauritius). In addition, smoking bans in open air areas, like beaches (California, France) or parks (New York), have also been enacted [IARC, 2009].

\section{Control access}

Control access measures make it more difficult for users to access tobacco products; well-known examples include legal age limits, restrictions related to vending machines, and forbidding displays of tobacco products in shops [WHO, 2003].

The majority of smokers initiated smoking or became a habitual smoker prior to the age of 18 years. Therefore, adolescents are the most important target population to prevent the uptake of smoking. One of the strategies of control access is a legal age limit, to prevent young people from buying, smoking and developing addiction to tobacco products [Fichtenberg \& Glantz, 2002 ${ }^{\text {; }}$; Richardson et al., 2009; Stead \& Lancaster, 2008]. A legal age limit makes it illegal for retailers to sell cigarettes to adolescents. This sales ban to minors was adopted by the FCTC (article 16: 'Sales to and by minors') and has been implemented by many countries, i.e. they set the minimum age for buying tobacco at 16 or 18 years of age [WHO, 2003; Willemsen \& Zwart de, 1999].

Besides age limits, some countries adopted legal rules forbidding teenagers to possess tobacco, or introduced a licensing system for tobacco sales, or restricted the sale of tobacco via tobacconists only. Moreover, some countries have bans or restrictions related to vending machines, e.g. to be placed in locations not visited by youth, or with technical obligations to lock the machines [Willemsen \& Zwart de, 1999]. 
A relatively new policy measure to control access is to ban displays in selling points, so that packets of cigarettes will 'disappear' from the shelves of the shops [Paynter \& Edwards, 2009; Lee, Hendriksen, Myers, Dauphinee \& Ribisl, 2013]. Various countries have already banned displays, including Iceland (2001), Canada (2004), Thailand (2005), Ireland (2009), Norway (2010), the UK (2012) and Finland (2012) [Boseley, 2012; Joossens \& Raw, 2011].

\section{Taxation}

In the $17^{\text {th }}$ century, England was probably the first country that excised duty for health reasons, whereby the tobacco tax increased from 2 to 82 pence per pound, making tobacco more expensive than silver [Townsend, 1996]. Although this is no longer the case, increasing the tobacco tax to regulate the retail price has been introduced everywhere. The FCTC recommends to set the tobacco tax to at least $75 \%$ of the retail price, to minimize the aim of the tobacco industry to make more profit. In addition, regular tax increases are needed to compensate for inflation and increases in wage levels, which can make tobacco more affordable. Research in 2010 on the implementation of the WHO MPOWER recommendations shows that 26 countries and one State set tobacco tax at more than $75 \%$ of the retail price. That study also shows that the retail price for a package of 20 cigarettes in the EU ranges from $€ 2.04$ in Estland to $€ 8.50$ in Ireland [WHO, 2011; Joosens \& Raw, 2011].

\subsubsection{Policy measures to discourage smoking in the Netherlands}

This section outlines developments in the anti-smoking policy in the Netherlands; Table 2 presents an overview of the most important (legal) measures taken to date.

In the Netherlands it took some time before a more comprehensive tobacco policy was implemented. The first official recommendation of the Dutch Health Council in 1957 was somewhat indecisive about the risks of smoking, and was limited to a warning aimed at youth not to get used to smoking [Wester, 1957]. In 1975, the second official recommendation included specific recommendations for legislation, such as restrictions on tobacco advertising and restrictions on the use and sales of tobacco products in public places [Knol et al., 2005]. However, only small tax increases, some anti-smoking campaigns and warnings on cigarette packs were implemented.

This situation lasted until 1990 when the first Tobacco Act came into force, which was relatively late compared with other countries (USA: 1965 labelling, and 1969 ban on advertising on television and radio; Canada: 1973 labelling; Australia: 1986 labelling; Norway: 1975 advertising and sponsoring) [Staatsblad van het Koninkrijk der Nederlanden, 1989]. This law was partly the result of the European anti-smoking policy, committing the Netherlands to implement this European regulation in its national legislation. The two European Directives contained rules about the labelling of ciga- 
rette packages, e.g. health warnings, and a ban on advertising on television and radio [European Parliament and the Council, $1989^{\mathrm{ab}}$ ]. The legislation resulting from the Dutch anti-tobacco policy included a ban on sales, and on smoking tobacco in public places: public spaces in government buildings, in health and welfare services, buildings for education, social-cultural services and sport facilities. The regulation of this new Tobacco Law was entrusted to the (former) Netherlands Food and Consumer Product Safety Authority, Nederlandse Voedsel en Warenautoriteit (NVWA). However, there was no possibility to apply sanctions or fines in case of non-compliant behaviour. This, of course, minimised both enforcement power and compliance with these new rules and, thereby, the effects of these measures on smoking.

Table 2: Overview of Dutch anti-tobacco policy since the 1950 s.

\begin{tabular}{|c|c|c|}
\hline Year & Dutch political developments & (Legal) policy measures \\
\hline 1957 & $1^{\text {st }}$ Advise of Dutch Health Council & informing young people \\
\hline 1964-1976 & & annual anti-smoking campaigns \\
\hline \multirow[t]{2}{*}{1975} & $2^{\text {nd }}$ Advise of Dutch Health Council & small tax increases \\
\hline & & legal health warnings \\
\hline \multirow[t]{3}{*}{1990} & $1^{\text {st }}$ Tobacco Act & legal health warnings \\
\hline & & ban on advertisement (television \& radio) \\
\hline & & ban on sales and smoking in public places \\
\hline \multirow[t]{2}{*}{1996} & Anti-tobacco policy & self-regulation (restrictions on advertisement) \\
\hline & & self-regulation (imposing an age limit of 16 years) \\
\hline 2002 & Changed Tobacco Act & ban on advertisement and sponsoring \\
\hline \multirow[t]{2}{*}{2003} & & ban on smoking in transport \\
\hline & & sales ban to minors (age limit of 16 years) \\
\hline \multirow[t]{2}{*}{2004} & & ban on smoking in workplaces \\
\hline & & tax increase \\
\hline 2005 & Ratification WHO FCTC & \\
\hline \multirow[t]{2}{*}{2008} & & ban on smoking in hospitality sector \\
\hline & & tax increase \\
\hline 2013 & & tax increase \\
\hline 2014 & & increase of the age limit to 18 years \\
\hline 2015 & & undo the exception for small pubs without employees \\
\hline
\end{tabular}

In 1996 the government intensified the Dutch Tobacco discouragement policy. Two main objectives were formulated: 1) to reduce the percentage of smokers by discouraging smoking onset among youth and increasing the number of quitters among 
smokers; and 2) to protect the non-smoker against tobacco smoke. The envisaged instruments were restrictions on advertising based on self-regulation, further restrictions on smoking and the possibility to impose fines, a sales ban to minors, tax increases, labelling of roll-your-own tobacco, and prevention and education [Tweede Kamer der Staten-Generaal, 1996]. However, this did not result in legislation but in a covenant with the industry about self-regulation in relation to advertising and imposing an age limit.

Finally, six years after the publication of the Dutch Tobacco discouragement policy and twelve years after the first Tobacco Act, in 2002 the government adopted the revised Tobacco Act with four important themes. Changes in health warnings and an expansion of the advertising ban were based on European Directives [European Parliament and the Council, 1998; 2001]. On the national level there was a sales ban to minors, implemented in 2003, whereby the seller of tobacco products had to verify that the buyer had a minimum age of 16 years before selling them tobacco. Moreover, for vending machines there were technical obligations to lock them, and not to locate the machines out of doors but only within sight of the seller. In addition to the sales ban, the existing smoking ban for public places (1990) was expanded to include public transport (since 2003), and the workplace with employees (since 2004). Employers were obliged to take measures to ensure that employees could work without 'nuisance and inconvenience' from tobacco smoke. This implied the implementation of a smoking ban at the worksite, whereby lockable, designated smoking rooms were allowed. This workplace-smoking ban was accompanied by a mass media campaign together with support to the employers to implement this ban. The hospitality sector was not included in this ban, but was allowed to regulate themselves as to how to reduce smoking and exposure to tobacco smoke in cafés, restaurants, hotels, etc. Furthermore, the NVWA became legally liable to check compliance with this law and was given the authority to impose fines in case of non-compliance [Staatsblad van het Koninkrijk der Nederlanden, 2002].

After two years of failed self-regulation, in which the hospitality sector should be smoke free [Tweede Kamer der Staten-Generaal, 2007; Diepen van, 2007], in July 2008 the government decided to expand the smoke-free legislation to this sector. This legislation was accompanied by a mass media campaign and enforcement. From the beginning, the hospitality entrepreneurs resisted, covertly supported by the tobacco industry [Gonzalez \& Glantz, 2011; Nagelhout et al., 2012]. First, entrepreneurs filed for a court case against the government to allow an exception for entrepreneurs without employees, an action that failed [Stichting Red de Kleine Horeca Ondernemr v. Staat der Nederlanden, 2008]. Later, after an initial high compliance in the entire sector, there was an organised protest against this ban by funding court appeals, an organised demonstration, and media attention. This triggered a media hype for many months 
and resulted in a decrease in compliance in cafés and bars [Gonzalez \& Glantz, 2011; Intraval \& nVWA), 2011; Nagelhout et al., 2012]. In the meantime, the Minister ordered use of the criminal law. This resulted in several court cases; these ended in the Supreme Court in June 2010 which ruled in favour of the Dutch government. However, in July 2011, the government changed the law and made an exception for hospitality entrepreneurs working without employees and with just one space (a floor surface $<70$ $\mathrm{m}^{2}$ ) and focused on selling (alcoholic) beverages; also, there was a doubling of the fines [Staatsblad van het Koninkrijk der Nederlanden, 2011]. In reaction, in 2012 'Clean Air Nederland' (an interest group) started a lawsuit against the government based on the FCTC. The last verdict in the higher court, based on the WHO FCTC, is that the existing exception is not legal [Nederlandse Nietrokersvereniging CAN v. de Staat der Nederlanden, 2013]. In reaction, the government appealed against this verdict, but then announced it was repealing this exception by changing the Tobacco Act, expected in January 2015 [Rijn, M.J. van. 2013 ${ }^{\mathrm{a}}$, 2013 ${ }^{\mathrm{a}}$; Tweede Kamer der Staten-Generaal, 2014].

In January 2014, the government also increased the age limit of the tobacco sales ban from 16 to 18 years of age. This now makes it in line with the legislation on drugs, with the raising of the age limit for selling alcoholic beverages from 16 to 18 years in January 2014, and with the changes in societal norms [Rijn, M.J. van, $2013^{\mathrm{a}}$ ].

Another legal measure, not yet mentioned, is taxation on tobacco products. The tax is calculated each year and is based on the retail price of the previous year. However, in some years the taxation rules are changed to allow for a larger increase in tax and in the price of tobacco products. The most important tax increases occurred in 2004 and 2008, simultaneously with the implementation of the workplace-smoking ban for worksites and the hospitality industry, respectively. In an overview of the MPOWER recommendations, it was calculated that in 2010 in the Netherlands the tax was $73 \%$ of the retail price, thus below their recommendation of more than $75 \%$ [WHO, 2011]. However, in 2011 and 2013 there were two additional tax increases which resulted in a tax of over $75 \%$ of the retail price [Staatsblad van het Koninkrijk der Nederlanden, 2010, 2012; European Commission, 2011; 2013].

Overall we can conclude that the Dutch anti-smoking policy started relatively late in comparison with the United States and other industrialized countries such as Canada, Australia and Norway. It seems that international initiatives are often the trigger for the Netherlands to implement new legislation. On the one hand the EU initiates regulation about cross-border activities of the tobacco industry like advertising, labelling and composition of tobacco products; on the other hand there is the anticipation of the FCTC that obliged the Netherlands to adopt and implement measures. In the last evaluation of measures implemented by European countries in 2014, it appears that the Netherlands is around the middle of the ranking order (number 13 out of 34) [Joossen \& Raw, 2014]. The government and politicians in the Netherlands may have 
been relatively more responsive to the tobacco lobby than in other European countries [Bouma, 2013]; this may explain the relatively late adoption of effective measures.

\subsection{Legislation, compliance and societal goals}

\subsubsection{Legislation, compliance and societal goals}

The international literature on tobacco legislation mainly focuses on the question as to whether the policy measures have led to the expected effect (goal achievement evaluation), for example, a decrease in smoking due to the workplace-smoking ban [Fichtenberg \& Glantz, 2002 ${ }^{\text {b }}$; Nagelhout, Willemsen \& Vries de, 2011]. In this thesis we also present three studies in which we investigate whether these expected effects have been achieved after introduction of the workplace-smoking ban, and the tobacco sales ban to minors. However, in this type of studies, an important aspect of the policy remains under-researched. Legal provisions require that certain actors, such as employees (introduction of the smoking ban) or tobacco sellers (identification of the minimum age) comply with the norms expressed in these provisions. It is clear that a better and more complete picture of the (lack of) policy impact requires a model that provides insight into the degree of compliance and working mechanism of the enforcement interventions (e.g. on-site inspections). Such studies, focusing on the implementation of legislation and the optimisation of compliance, are performed much less frequently. This is also observed by the Court of Audit which has conducted various studies on the work of enforcement agencies in the Netherlands. The conclusion of the studies in 1990 and 2001 was that the goal achievement evaluation by the agencies was lacking [Algemene Rekenkamer, 1990; 2002]. The studies in 2005 and 2008 showed improvement in knowledge on the degree of compliance and priorities based on risks, although the knowledge on the additional value of enforcement to compliance and/or to the societal problem was under-researched [Algemene Rekenkamer, $2005 ; 2008$ ]. Also, a study by the Court of Audit on the NVWA concluded that there is a lack of knowledge about the effects of its enforcement interventions [Algemene Rekenkamer, 2013].

\subsubsection{Effect chain}

A more comprehensive model of the process of supervision is the 'effect chain' (Figure 1) which describes the relationship between the (introduction of) legislation, the degree of compliance by target groups and the intended societal goals. 
Figure 1: Effect chain outlining the relationship between legislation, compliance and societal goals [Jansen \& Smits, 2011].

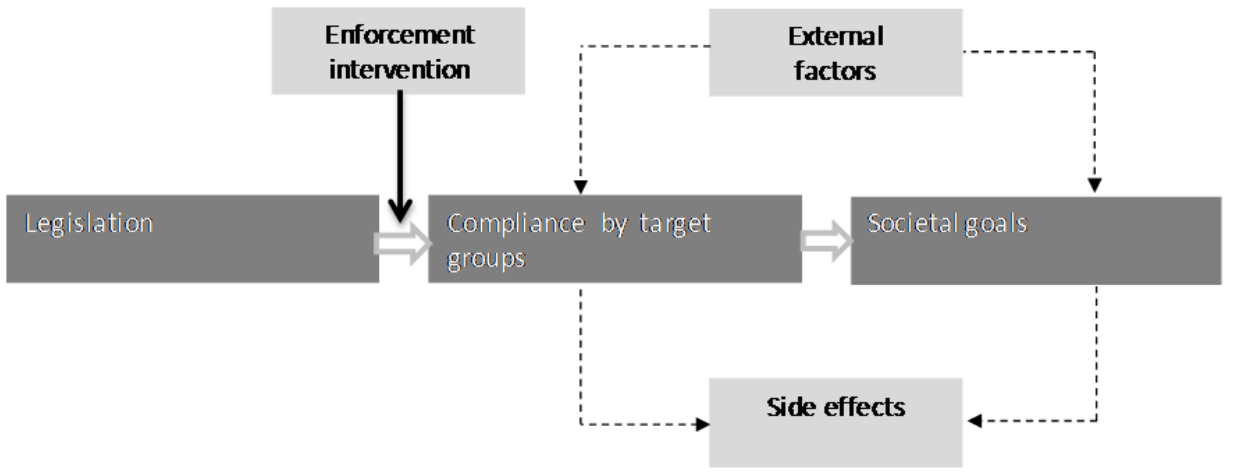

This model allows to distinguish between two levels of evaluation research; 'compliance assessment' and 'policy impact assessment'. Assessment of compliance investigates effects among target groups, more specifically their compliance with the norms. The analysis of compliance effects involves, for example, the extent to which drivers adhere to the speed limit. Policy impact assessment examines effects on the final (societal) goal that the legislature wants to achieve with the law; these effects are called societal or policy effects. In the framework of road safety, a policy impact can, for example, be a decrease in the number of victims of road accidents. Agencies responsible for regulation aim to promote compliance through enforcement intervention(s) and, in that way, contribute to the solution of the societal problem. In addition to the enforcement intervention(s), other factors may also influence compliance with regulations or the size of the societal problem, these are called external factors. An example is the use of new techniques in cars (e.g. airbags), making the use of cars safer and contributing to road safety by means of less serious injuries in traffic accidents. Finally, some side-effects might occur: i.e. unintended effects of the enforcement intervention(s) which can be positive or negative. An example is an enforcement intervention aimed at wearing a seat belt. One possible side-effect that is the compensatory behaviour of the motorist who, by wearing a seat belt, feels safer but drives in a more risky way, which has a negative affect on the societal purpose, i.e. traffic safety.

In this thesis we focus on two legal provisions, the workplace-smoking ban and the tobacco sales ban to minors, and describe the effect chains for these two bans.

\section{Workplace-smoking ban}

Introduction of the workplace-smoking ban means that employers with employees have to take measures to ensure that employees can work without the inconvenience of tobacco smoke (Figure 2). In practice, this means that employers must set up a 
smoking ban at the worksite. However, designated and lockable smoking rooms are allowed. Compliance assessment examines the extent to which employers have instituted a smoking ban. The target groups that the Dutch government hoped to influence with the introduction of the workplace-smoking ban were both non-smokers and smokers. The societal goal for non-smokers was that the smoking ban would prevent them from exposure to second-hand smoke from their colleagues. For smokers the societal goal of the smoking ban was that, because of the restrictions of smoking in time and place at work, they would decrease the number of cigarettes and more often attempt to quit [Tweede Kamer der Staten-Generaal, 1996]. Again, the additional societal goals are further away in the effect chain, such as the reduction of health-related harm by (second-hand) smoke, and a decrease in the number of avoidable deaths from tobacco use, both as a result of implementation of the workplace-smoking ban. However, these goals fall outside the scope of this thesis. External factors to think of are other policy measures, such as tax-increases. Possible side-effects are the encouragement to families to make their home smoke-free (positive) or compensation of smoking at home (negative) [WHO, 2008].

Figure 2: Effect chain of the workplace-smoking ban.

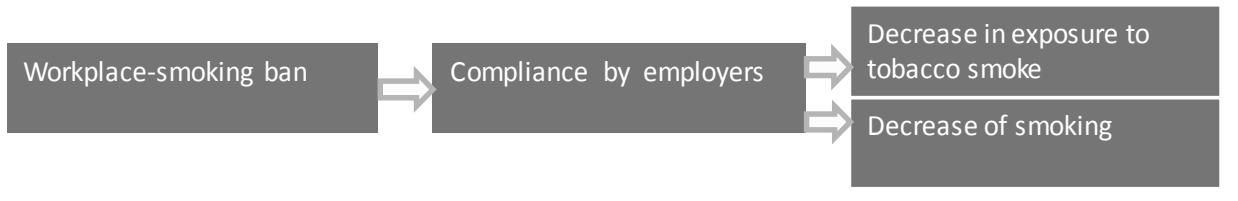

\section{Sales ban to minors}

The legal age limit is aimed on the sellers of tobacco (Figure 3). They are required to demand a proof of identity to check whether an adolescent is at least 16 years of age before selling them tobacco (since 2014: 18 years). In the Netherlands, the adolescent is not punishable. Compliance assessment focuses on the degree of compliance by the sellers of tobacco. Assessment of the impact of legal provisions focuses on societal goals of the age limit. Setting the legal age limit makes it more difficult for minors aged under 16 years to buy tobacco. The first objective is that fewer adolescents under age 16 will buy tobacco. A decrease in purchases will lead to the second goal, which is that adolescents smoke less and that the age at which adolescents start with (daily) smoking will rise [Tweede Kamer der Staten-Generaal, 1996; NSPH, 1998]. Other societal goals, such as the reduction of health-related harm by smoking and the reduction of avoidable deaths from tobacco use, are additional and more long-term goals. These two goals also fall outside the scope of this thesis. Also here it might be that other policy measures (i.e. tax-increases or the advertisement ban) influence compliance of 
retailers or purchase and smoking behaviour of minors. A side-effect might be illegal purchases.

Figure 3: Effect chain of the sales ban to minors.

Sales ban to minors

( $<16$ years)
Compliance by

tobacco retailers
Decrease in pur-

chases among

minors $<16$ years
Decrease in (onset)

smoking by minors

$<16$ years

Increase in the age of onset smoking among minors

\subsection{Objective and outline of this thesis}

The aim of this thesis is to determine the effects of the Tobacco Act of 2002. As shown in Figure 1 (section 1.3.) the effects can be examined on two levels 1) compliance assessment with the legislation by target groups, and 2) impact assessment of legal policy provisions, related to the societal goals aimed at by the government with the legislation. Besides, we describe the role of supervisory bodies in relation to impact assessment.

In this thesis, this results in three main themes:

\section{Compliance assessment}

To what extent is implementation of legislation followed by compliance with the (new) norms of the target groups and which factors are associated with this compliance? This theme addresses the measurement and monitoring of the level of compliance with the workplace-smoking ban and the factors which influence this compliance.

\section{Policy impact assessment}

To what extent does legislation lead to the intended societal goals (final-outcome)? This theme addresses the impact of the workplace-smoking ban and the tobacco sales ban to minors on the societal aim of these two provisions.

\section{Supervision}

To what extent do the results of the studies in this thesis contribute to optimize supervision and to account for supervision carried out and the impact achieved.

This theme addresses the role of supervisory bodies in relation to the increased attention for impact assessment, barriers in practice and the need to account for their added value of supervision to the increase of compliance and to the achievement of societal goals. 
The structure of this thesis is as follows (Table 3):

Table 3: Overview: the three research themes and related legislation and studies in this thesis.

\begin{tabular}{|c|c|c|c|}
\hline Research theme & Workplace-smoking ban & Sales ban to minors & General \\
\hline $\begin{array}{l}\text { Compliance } \\
\text { assessment }\end{array}$ & $\begin{array}{l}\text { Compliance with the workplace- } \\
\text { smoking ban in the Netherlands } \\
\text { (Chapter 2) } \\
\text { Agreement between self-reports and } \\
\text { on-site inspections of compliance } \\
\text { with a workplace-smoking ban } \\
\text { (Chapter 3) }\end{array}$ & & \\
\hline $\begin{array}{l}\text { Policy impact } \\
\text { assessment }\end{array}$ & $\begin{array}{l}\text { Does the workplace-smoking ban } \\
\text { eliminate differences in risk for } \\
\text { environmental tobacco smoke } \\
\text { exposure at work? (Chapter 4) } \\
\text { Effects of a workplace-smoking ban } \\
\text { in combination with tax increases } \\
\text { on smoking in the Dutch population } \\
\text { (Chapter 5) }\end{array}$ & $\begin{array}{l}\text { The tobacco sales ban and } \\
\text { tobacco purchases by } \\
\text { adolescents: a general } \\
\text { population study in the } \\
\text { Netherlands (Chapter } 6 \text { ). }\end{array}$ & \\
\hline Supervision & & & $\begin{array}{l}\text { Supervisory bodies and } \\
\text { impact assessment } \\
\text { (Chapter } 7 \text { ) }\end{array}$ \\
\hline
\end{tabular}

Chapters $\mathbf{2}$ and $\mathbf{3}$ are related to the first theme of this thesis, compliance assessment. In Chapter $\mathbf{2}$ compliance assessment of the workplace-smoking ban was monitored in the period 2004-2008, whereby differences in the level of compliance over time and between different sectors are examined. In addition, this study describes associations between changes in the level of compliance and changes in factors indicating awareness and motivation. Chapter 3 reports on whether the use of self-reporting is a valid method to measure the level of compliance with the workplace-smoking ban. In this study the results of self-reported compliance are compared with the results of on-site inspections, carried out by supervisors at the same worksites.

Chapters 4 to 6 describe evaluation studies on the assessment of the impact of legal provisions, i.e. the second theme of this thesis; policy impact assessment Chapter 4 explores the exposure to environmental tobacco smoke before and after introduction of the workplace-smoking ban. This study also focuses on differences in risks for exposure between subgroups of non-smoking employees. Chapter $\mathbf{5}$ evaluates the impact of the combination of the workplace-smoking ban and two tax increases on the smoking behaviour of those with and without paid work. Chapter 6 focuses on changes in the purchasing behaviour of adolescents before and after implementation of the 
tobacco sales ban to minors; also, the composition of the categories of buyers in terms of gender, age and smoking status are compared. Furthermore, the categories of buyers in terms of the frequency and distribution of purchases over different types of commercial outlets are examined.

Chapter 7 concerns the third theme, supervision, and presents the discussion over the last decennia on the regulation, enforcement and role of supervisory bodies and describes why the focus on impact assessment by supervision has increased. This chapter also describes the way supervisory bodies deal with their professional responsibilities to evaluate the effects of their work.

Finally, Chapter 8 summarizes the most important results emerging from this thesis related to the two themes, compliance assessment and policy impact assessment, and discusses the significance of these findings. 



\section{CHAPTER 2}

\section{Compliance with the workplace-smoking ban in the Netherlands}

Published as:

Verdonk-Kleinjan W.M., Rijswijk P.C., de Vries H. \& Knibbe R.A. (2013). Compliance with the workplace-smoking ban in the Netherlands. Health Policy, 109(2), 200-206. 


\section{Abstract}

\section{Introduction}

In 2004 the Dutch government instituted a workplace-smoking ban. This study focuses on differences in compliance over time and between occupational sectors, and describes the background variables.

\section{Methods}

Telephone interviews were conducted with company employees across industry, public and service sectors in $2004(n=705), 2006(n=2201)$ and $2008(n=2034)$. The questions concerned smoking policy, aspects of awareness and motivation to implement this ban.

\section{Results}

Compliance rates increased between 2006 (83\%) and 2008 (96\%) after an initial stagnation in the rate of compliance between 2004 and 2006. The increase in compliance was accompanied by a less negative attitude and an increase in confidence in one's ability to comply (self-efficacy). Differences in compliance between sectors with the highest compliance (public sector) and the lowest compliance (industry) decreased from about $20 \%$ to nearly $4 \%$. Simultaneously, in the industry there was a stronger increase for risk perception of enforcement, social influence and self-efficacy.

\section{Discussion}

The initial stagnation in increase of compliance might be due to the lack of a (new) coherent package of policy measures to discourage smoking. Over the entire period there was a stronger increase in compliance in the industry sector, probably due to the intensification of enforcement activities and additional policy like legislation, which might increase awareness and social support. 


\subsection{Introduction}

The main aim of a legal smoking ban for public places and workplaces is to protect non-smokers from the dangers of environmental tobacco smoke (ETS). Additionally, such a ban contributes to the reduction of smoking prevalence and number of cigarettes consumed by smokers [Fichtenberg \& Glantz, 2002; Hopkins et al., 2001; Levy, Chaloupka \& Gitchell, 2004; Verdonk-Kleinjan, Candel, Knibbe, Willemsen \& Vries de, 2011].

In 1990 the Dutch government introduced the workplace-smoking ban for the public sector only (e.g. schools, hospitals, public administration, social services). At that time no extra activities were undertaken to increase the adoption and implementation of the smoking ban. For the remaining workplaces, the smoke-free workplace legislation was implemented on January $1^{\text {st }} 2004$, with the exception of the hospitality sector, where the ban was implemented in July 2008. The act bans smoking inside, but allows designated smoking rooms. In 2004 the new law was accompanied by mass media campaigns to inform the public and enhance compliance, together with considerable media attention about the new law. A similar approach was seen in 2008 when the workplace-smoking ban was extended to the hospitality industry.

In 2002 the Netherlands Food and Consumer Product Safety Authority, Nederlandse Voedsel en Warenautoriteit (NVWA). became legally liable to check compliance and was given authority to impose fines in case of non-compliance. These fines start at 300 euro and increase to a maximum of 2400 euro in case of continued noncompliance.

In this paper we focus on compliance with the general smoking ban from the start of the implementation in 2004 until 2008. The term compliance refers to actions of actors required by the implementation of the general smoking ban. In this case we focus on what is required from the employers and the extent to which they complied with those requirements and factors related to this compliance.

Several studies have assessed levels of compliance of general workplace-smoking bans, and reported increased compliance after its implementation, with follow-up periods ranging from 6 months [Goodin \& McAllister, 1997], to one year [Haw \& Gruer, 2007] up to several years [Gilpin, Farkas, Emery, Ake \& Pierce, 2002; Heloma \& Jaakkola, 2003]. Studies also focused on explaining differences in compliance between occupational groups and found, for instance, higher levels of exposure to ETS at the workplace in blue-collar and service groups [Heloma \& Jaakkola, 2003; Gerlach, Shopland, Hartman, Gibson \& Pechacek, 1997; Jenkins \& Counts, 1999; Wortley, Caraballo, Pederson \& Pechacek 2002]. A few studies assessed factors facilitating or hindering compliance with the general workplace-smoking ban. For example, Levy and colleagues (2004) found that government enforcement and media publicity may facilitate compli- 
ance, whereas a lack of public support and perceived negative economic impact hindered compliance. More qualitative cross-sectional studies in the hospitality sector reported the following to be facilitating conditions: low cost to comply [Montini \& Bero, 2008; Miller, Wakefield, Kriven \& Hyland, 2002], enforcement and prosecution [Montini \& Bero, 2008; Edwards et al., 2008], a positive attitude towards the ban, competence and skills of the management [Eadie et al., 2008], and clear legislation and definitions, without exemptions and loopholes [Montini \& Bero, 2008; Edwards et al., 2008]. The most frequently mentioned obstruction to comply was fear of economic loss [Montini \& Bero, 2008; Hilton et al., 2007]. However, studies showed an absence of economic loss in bars that complied [Hilton et al., 2007; Eriksen \& Chaloupka, 2007; Scollo, Lal, Hylan \& Glantz, 2003]. Other factors obstructing compliance were negative norms in the community [Eadie et al., 2008], non-compliance in other bars [Montini \& Bero, 2008], bars in rural areas and smaller bars with a high proportion of smokers [Edwards et al., 2008].

The first objective of this paper is to describe overall trend in time concerning compliance rates of the general workplace-smoking ban. The second objective is to study differences in compliance rates between the three occupational sectors. Our last objective is to assess the role of awareness and motivational factors to further understand the reasons for (non)compliance with the general workplace-smoking ban. The data are derived from cross-sectional surveys among businesses in 2004, 2006 and 2008.

Concerning changes over time, as in other studies we expect increased levels of compliance over time [Hilton et al., 2007; Eriksen \& Chaloupka, 2007]. Concerning differences between occupational sectors we expect higher compliance rates in the public sector, because in this sector implementation started (earlier) in 1990. In addition, other studies reported higher compliance rates in white-collar occupational groups [Scollo, Lal, Hyland \& Glantz, 2003] and in offices [Eriksen \& Chaloupka, 2007].

\subsection{Methods}

\subsubsection{Study design and setting}

Telephone surveys were done in the period September through November in 2004, 2006 and 2008. The employee who was responsible for the implementation of and compliance with the workplace-smoking ban was identified during the first contact with the company; once identified, an interview (lasting 25 minutes) was held. The sampling frame was defined as Dutch companies with at least five employees. We used the Dutch database of registered companies, which is almost complete, to take a random sample for each survey, stratified according to type of economic activity (i.e. agri- 
culture, industry, education) and number of employees, (5-9, 10-99, 100>). The study samples and response rates for the surveys were $n=705$ (38\%) in 2004, $n=2,201$ (56\%) in 2006 and $n=2,034$ (75\%) in 2008. For the present study we excluded the hospitality sector, as that sector was, until July 2008, excluded from the workplace-smoking ban; we distinguish 3 categories: public sector, service sector and industry sector. Table 2 shows the number of respondents in each sector per year.

\subsubsection{Questionnaire}

The dependent variable, compliance with the workplace-smoking ban, was measured by the question 'Which of the following descriptions reflects the current smoking regulation in your company?' The answers were a) 'complete smoking ban', b) 'general smoking ban with lockable smoking rooms, avoidable for non-smokers', c) 'general smoking ban with non-lockable smoking areas', d) 'limited smoking ban, whereby smoking is prohibited in some places within the company' and e) 'no smoking regulation'. Afterwards we recoded the answers into $1=$ compliance (answers a and b) and $0=$ non-compliance (answers $c, d$, and e).

The validity of this self-reported compliance was investigated by means of a separate study of 360 companies who participated in the telephone interview in 2006. Directly after the survey, Inspectors from the NVWA made systematic observations which included control of the smoking policy and observational checks on smoking by employees to classify the workplaces into those complying and not complying with the smoking ban. Comparison between the self-reported compliance and compliance based on the on-site inspections showed considerable agreement (77.5\%) and indicated self-reported compliance to be a valid method to assess compliance of the workplace-smoking ban [Verdonk-Kleinjan, Rijswijk, Candel, Vries de \& Knibbe, 2012].

To measure awareness and motivation we used an extended version of the 'Integrated Model of Change' [Vries de et al., 2003; Vries de, Kremers, Smeets, Brug \& Eijmael, 2008] by including also constructs specifically aimed at assessing the importance of enforcement and sanctions in case of (non)-compliance.

Table 1 provides a detailed description of the scales, gives 2 or 3 examples of the items used in a scale, the total number of items of a scale, and the answering categories used. We follow the distinction of the I-change model into variables indicating 'awareness' and factors indicating 'motivation'. Awareness factors are indicated by knowledge of the law; clarity of the law; cues to action (specific events, experiences possible leading to compliance); risk perception of smoking; risk perception of enforcement and risk perception of sanction severity. Motivational factors are indicated by the variables positive and negative attitude towards the ban, social influence and pressures of various others, and self-efficacy, indicating the perceived skills to comply in all situations and circumstances. Most of these questions were adopted from the 
Law Enforcement Expertise Centre (2004). Moreover, these factors correspond with factors mentioned in the literature as obstructing compliance e.g. lack of support or negative norms [Levy et al. 2004; Eadie et al. 2008], fear of economic loss [Montini \& Bero, 2008; Hilton et al. 2007], or as facilitating compliance e.g. clear legislation [Montini \& Bero, 2008; Edwards et al., 2008], enforcement and prosecution [Levy et al., 2004, Montini \& Bero, 2008; Edwards et al., 2008], a positive attitude [Eadie et al., 2008], and competence and skills [Eadie et al., 2008]. Table 1 presents examples of the questions used in the present study.

Scales were made for items with more than one question (Table 1); for cues to action to implement the workplace-smoking ban an index was created. The alphas of all scales (Table 1) were acceptable, i.e. higher than 0.70 [Field, 2005]. Respondents with missing values on more than $25 \%$ of the items of a scale were excluded from the analysis. High scores on the index and scales are favorable and indicate more awareness and motivation to comply with the ban.

\subsubsection{Statistical analyses}

In order to assess changes over time in the level of compliance pair-wise Chi-square tests were performed for all respondents and for the separate sectors between 2004 and 2006, and between 2006 and 2008. To assess differences in the level of compliance between the three sectors per year, pair-wise Chi-square tests were performed per year between public sector and service sector, between public sector and industry, and between service sector and industry.

In order to assess changes over the years in awareness and motivational factors Ttests were performed between 2004 and 2008. Furthermore, to assess differences in awareness and motivational factors between the different sectors per year, ANOVA tests were conducted, followed by Bonferronni tests to evaluate pair-wise differences per year between public sector and service sector, between public sector and industry, and between service sector and industry.

For all analyses, a significance level of $p<0.05$ was used. Data were analyzed using SPSS 17.0 for Windows. 
Table 1: Questionnaire on awareness factors and motivational factors.

\begin{tabular}{|c|c|c|c|c|c|}
\hline Factors & Examples of used items & Response options & $\begin{array}{l}\text { Number } \\
\text { of items }\end{array}$ & $\begin{array}{l}\text { Score } \\
\text { calcu- } \\
\text { lation }\end{array}$ & $\begin{array}{l}\text { Cron- } \\
\text { bach's } \\
\alpha\end{array}$ \\
\hline \multicolumn{6}{|l|}{ Awareness factors } \\
\hline $\begin{array}{l}\text { Knowledge of } \\
\text { the law }\end{array}$ & How much do you know about the smoking ban? & $\begin{aligned}-2 & =\text { very little } \\
2 & =\text { very much }\end{aligned}$ & 1 & - & - \\
\hline Clarity of the law & How clear is the smoking ban to you? & $\begin{aligned}-2 & =\text { very obscure } \\
2 & =\text { very clear }\end{aligned}$ & 1 & - & - \\
\hline Cues to action & $\begin{array}{l}\text { Did an on-site inspection by the NVWA influence the } \\
\text { implementation of the law? } \\
\text { Did complaints of employees about smoking col- } \\
\text { leagues influence the implementation of the law? }\end{array}$ & $\begin{array}{l}0=\text { of no influence } \\
1=\text { of influence }\end{array}$ & 8 & $\begin{array}{l}\text { Sum } \\
\text { score }\end{array}$ & n.a. \\
\hline $\begin{array}{l}\text { Risk perception } \\
\text { of smoking }\end{array}$ & $\begin{array}{l}\text { Does smoking cause harm to one' health? } \\
\text { Does second-hand smoking cause harm to one's } \\
\text { health? }\end{array}$ & $\begin{aligned}-2= & \text { definitely not } \\
& \text { causing harm } \\
2= & \text { definitely causing } \\
& \text { harm }\end{aligned}$ & 2 & Mean & $\alpha=0.79$ \\
\hline $\begin{array}{l}\text { Risk perception } \\
\text { of enforcement }\end{array}$ & $\begin{array}{l}\text { What is the likelihood that the NVWA: } \\
\text { - will inspect your establishment to check compli- } \\
\text { ance with the ban? } \\
\text { - knows the level of compliance in all establishments. }\end{array}$ & $\begin{array}{l}-2=\text { very small } \\
2=\text { very large }\end{array}$ & 6 & Mean & $\alpha=0.72$ \\
\hline $\begin{array}{l}\text { Risk perception } \\
\text { of sanction } \\
\text { severity }\end{array}$ & $\begin{array}{l}\text { First violation will carry a fine of } 300 \text { euro and will in- } \\
\text { crease to } 2400 \text { euro with continued non-compliance: } \\
\text { what is your opinion about this sanction? }\end{array}$ & $\begin{aligned}-2 & =\text { very low } \\
2 & =\text { very high }\end{aligned}$ & 1 & - & - \\
\hline \multicolumn{6}{|c|}{ Motivational factors } \\
\hline Positive attitude & $\begin{array}{l}\text { The ban: } \\
\text { - protects employees against exposure to ETS. } \\
\text { - contributes to a good image of our company. }\end{array}$ & $\begin{aligned}-2 & =\text { totally disagree } \\
2 & =\text { totally agree }\end{aligned}$ & 10 & Mean & $\alpha=0.75$ \\
\hline $\begin{array}{l}\text { Negative atti- } \\
\text { tude }\end{array}$ & $\begin{array}{l}\text { The ban: } \\
\text { - decreases productivity of the smoking employees. } \\
\text { - causes a lot of resistance from clients / visitors. }\end{array}$ & $\begin{aligned}-2 & =\text { totally agree } \\
2 & =\text { totally disagree }\end{aligned}$ & 6 & Mean & $\alpha=0.74$ \\
\hline Social influence & $\begin{array}{l}\text { Employees / the board of directors / friends and } \\
\text { family think the smoking ban is reasonable. }\end{array}$ & $\begin{aligned}-2 & =\text { totally disagree } \\
2 & =\text { totally agree }\end{aligned}$ & 3 & Mean & $\alpha=0.75$ \\
\hline Self-efficacy & $\begin{array}{l}\text { I will be able to maintain the smoking ban even: } \\
\text { - when employees keep on smoking. } \\
\text { - when there is a celebration at the company. }\end{array}$ & $\begin{aligned}-2 & =\text { sure not } \\
2 & =\text { sure yes }\end{aligned}$ & 6 & Mean & $\alpha=0.81$ \\
\hline
\end{tabular}




\subsection{Results}

\subsubsection{What are the trends over time?}

In the period 2004-2006 there were no differences in compliance for all the sectors together, or within each sectors considered separately. Between 2006 and 2008 there were some changes. The overall compliance for all companies together increased from $83.0 \%$ to $95.8 \%$. Also, within each sector a significant increase in compliance was observed, the largest in the industry sector (from 69.9\% to $94.0 \%$ ), and the smallest (but still significant) in the public sector (from $94.7 \%$ to $97.7 \%$ ) (Table 2 ).

Table 2: Self-reported compliance for different sectors in the three surveys.

\begin{tabular}{|c|c|c|c|c|c|c|c|}
\hline & \multicolumn{2}{|c|}{ Compliance 2004} & \multicolumn{2}{|c|}{ Compliance 2006} & \multicolumn{2}{|c|}{ Compliance 2008} & \multirow{2}{*}{$\begin{array}{l}\text { Pairwise } \\
\text { differences }\end{array}$} \\
\hline & $\%$ & $\mathrm{n}$ & $\%$ & $\mathrm{n}$ & $\%$ & $\mathrm{n}$ & \\
\hline \multicolumn{8}{|l|}{ Sector } \\
\hline Public sector & 94.0 & 218 & 94.7 & 490 & 97.7 & 346 & '04, ${ }^{\prime} 06<{ }^{\prime} 08^{* *}$ \\
\hline Service sector & 84.6 & 279 & 84.8 & 964 & 96.2 & 923 & ${ }^{\prime} 04,,^{\prime} 06<{ }^{\prime} 08^{* *}$ \\
\hline Industry & 74.5 & 137 & 69.9 & 564 & 94.0 & 596 & ${ }^{\prime} 04,{ }^{\prime} 06<{ }^{\prime} 08^{* *}$ \\
\hline Pairwise differences & \multicolumn{2}{|c|}{ Ind.<Serv. $<$ Publ ${ }^{*}$} & \multicolumn{2}{|c|}{ Ind. $<$ Serv. $<$ Publ. ${ }^{*}$} & \multicolumn{2}{|c|}{ Ind. $<$ Serv. $=$ Publ. ${ }^{*}$} & \\
\hline Total & 84.9 & 634 & 83.0 & 2,018 & 95.8 & 1,865 & '04, ${ }^{\prime} 06<{ }^{\prime} 08^{* *}$ \\
\hline
\end{tabular}

${ }^{*} p<0.05,{ }^{* *} p<0.01$

Table 2 also shows the differences in compliance between the sectors. In all years, compliance in the industry sector was lower than in the public and service sector. However, this does not mean that the differences between the sectors are stable over time. In fact there is some convergence in the rate of compliance, indicated by the fact that in 2004 the difference between the industry and respectively public sector (20\%) and service sector (10\%) was much larger than in 2008 ranging from $3.7 \%$ (industry vs public sector) to $2.2 \%$ (industry vs. service sector).

\subsubsection{Role of awareness and motivation for implementing the workplace-smoking ban}

Table 3 presents data on self-reported compliance awareness and motivation over time to comply with the workplace-smoking ban. These results allow conclusions to be made on three subjects: 1) the overall increase in compliance, 2) the decreasing differences in compliance between the sectors, and 3) the remaining differences in compliance in 2008 between the sectors. 


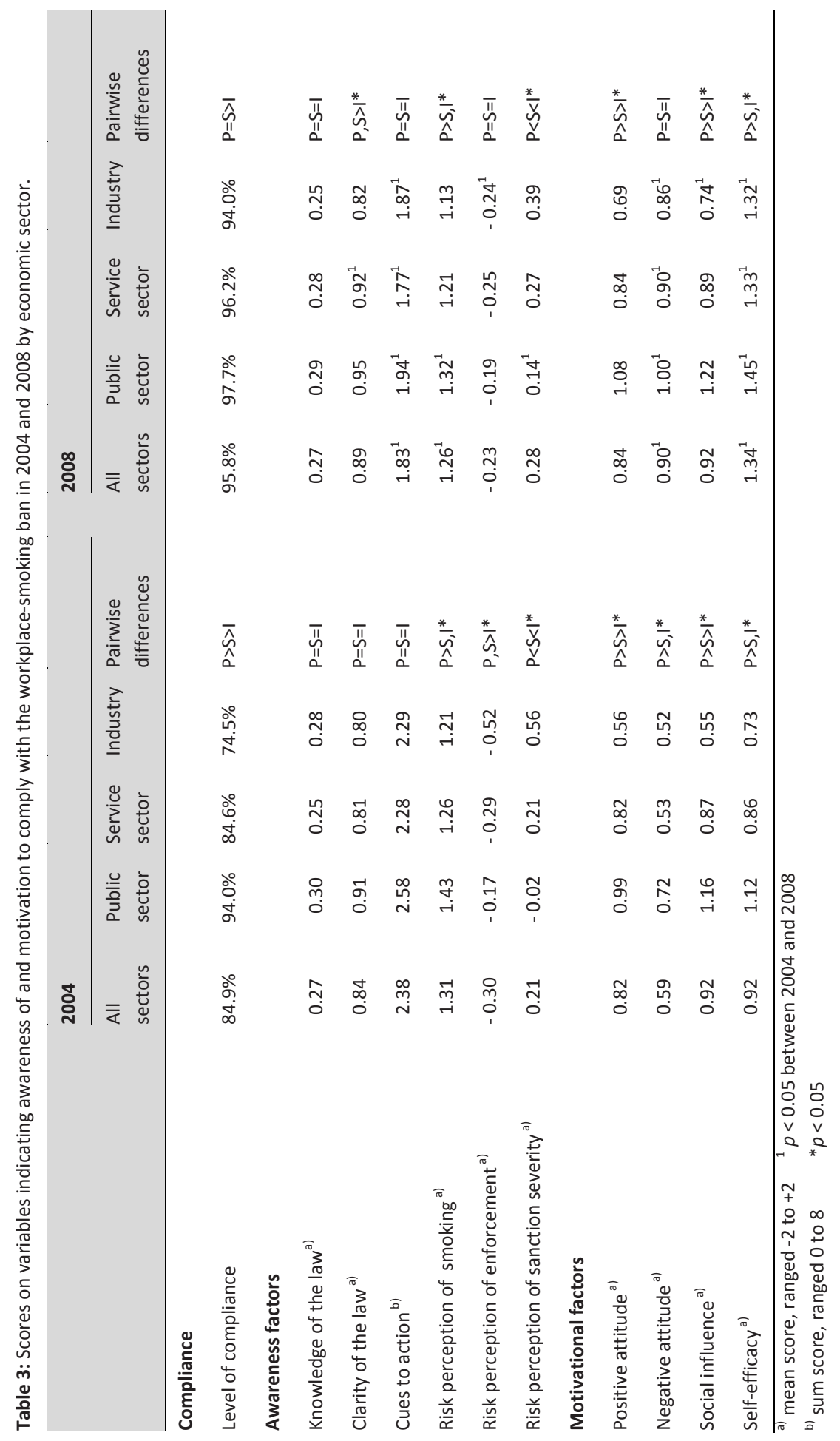


Concerning the overall trend of increased compliance, in all sectors this was accompanied by a decrease in negative attitude (showing an increase in score) between 2004 and 2008, and an increase in self-efficacy. In addition, we found a decrease in cues to action, and in risk perception of smoking.

Concerning the decreasing differences between sectors, some factors increased more in the industry than in the service sector or the public sector. For risk perception of enforcement (industry: +0.28 ; service: +0.04 ; public: -0.02 ), social influence (industry: +0.19 ; service: +0.02 ; public: +0.06 ) and self-efficacy (industry: +0.59 ; service: +0.47 ; public: +0.33 ) stronger increases in the industry were found compared to the other sectors.

Factors which might allow to interpret the lower compliance in the industry (also in 2008) are probably those factors which are consistently lower in 2004 and 2008, or show much less change in the industry sector than in the other sectors. Table 3 shows that the largest significant differences among sectors, in both 2004 and 2008, occur on scores of social influences, positive attitude and risk perception of sanction severity, whereby the score on social influence has significantly increased in the industry sector.

\subsection{Discussion}

This study shows, as expected, that the level of compliance indeed increased over time. However, the rate of compliance did not increase in the first two years, but started to increase two years after implementation of the workplace-smoking ban. When considering the different sectors, we note a strong decrease in differences in compliance over time. In 2004 the compliance rate in the industry was about $20 \%$ lower than in the public sector, whereas in 2008 the difference had reduced to nearly 4\%. Nevertheless, in 2008 the compliance in the industrial sector (94.0\%) was still significantly lower than in the service $(96.2 \%)$ and public $(97.7 \%)$ sector.

The factors most likely associated with the overall increase in compliance are a less negative attitude towards the ban and an increase in skills to comply with the ban. In addition, the importance of cues to action and risk perception apparently decreases once there is a trend of increasing compliance. Factors probably contributing to the decreasing differences between sectors are a stronger increase in the industry sector than in the service and public sector, in risk perception of enforcement, social influence and self-efficacy. Finally, factors possibly contributing to continued lower compliance in the industrial sector are less social influence, a less positive attitude, and a higher score on risk perception of sanction severity. 


\subsubsection{Compliance with the workplace-smoking ban over time}

The lack of an increased compliance between 2004 and 2006 was not expected, since other compliance studies found increased compliance after introduction of the law [Gilpin et al., 2002; Heloma \& Jaakkola, 2003]. However, these latter studies made their first measurement before the legal obligation to implement such a ban. In our study the first measurement was made about 9-11 months after the legal obligation to implement the ban. Another Dutch study showed that in 2003 only $32 \%$ of the companies complied with the new legislation [Segaar \& Willemsen, 2003]. Therefore, also in the Netherlands, the legal obligation to implement a workplace-smoking ban has led to an increase in compliance. It is likely that this increase is due to the mass-media campaign, which was noticed by $75 \%$ of the smokers [Putte van den, Yzer, Ten Berg \& Steevels, 2005]; the campaign focused on employers and the media attention during the introduction of the law.

Nevertheless, it remains an open question as to why, after an initial increase in compliance, no further increase was observed between 2004 and 2006. Similar to this stagnation in compliance, there was also a stagnation in the decrease of smokers (2002-2004: 31\%-28\%; 2004-2006: 28\%-28\%; 2006-2008: 28\%-27\%) [Stivoro, 2012; Astma Fonds, KWF Kankerbestrijding, Nederlandse Hartstichting \& Stivoro 2007]. A possible explanation for both types of stagnation is that, in the period after 2004, a (new) coherent package of policy measures to discourage smoking was lacking [Astma Fonds et al., 2007]. Another cue for the remaining companies not complying might have as its background that, at that time, there was a more general dispute between enterprises and politicians about the burden of all kinds of regulations. It is possible that (a part of) non-complying companies were not interested in complying with yet another rule that, in their opinion, had little to do with their core business. However, the absence of an increase in compliance between 2004 and 2006 does not mean that nothing happened. Another study [Bieleman \& Kruize, 2007] shows that among the companies complying, many more companies (63\% in 2006 vs $39 \%$ in 2004) chose for the option of a total smoking ban instead of the more permissive option of a smoking ban with designated lockable smoking rooms. Unfortunately no other studies have a follow-up period comparable to ours. However, Heloma et al. (2003) found that $45 \%$ complied before the legislation, compared with $83 \%$ and $87 \%$ at one and three years, respectively, after implementation of the ban. Gilpin et al. (2002) found $46 \%$ compliance two years before the law, compared with a compliance of $91 \%$ and $93 \%$ at three and five years, respectively, after legislation. It is unclear whether such a pattern, i.e. a fast increase in compliance directly after implementation of a ban (within one year), followed by a stable period and then by another increase (in this case a few years after its implementation), is common. The adoption and implementation of the workplacesmoking ban may possibly occur in a stage of adoptions, according to the model of 
diffusion of innovations [Wejnert, 2002], i.e. the innovators and early adopters complied before the legal implementation date (32\%), the early majority complied directly after the act came into effect (85\%) and remained stable (83\%), and the late majority (96\%) needed time (4 years) to comply with the ban, while the laggards did not (yet) comply with the law.

For the late majority in our study, the further increase of compliance took place after the initial resistance against this law until 2006. This increase may have as its background a combination of an intensification of the policy to discourage smoking in the period 2006 - 2010 [Astma Fonds et al., 2007] and enforcement. Additional legislation, which banned smoking in the hospitality sector, was implemented in July 2008. In that period, the Ministry of Health, Welfare and Sport started a mass-media campaign which may have increased the awareness of non-complying companies that they also have an obligation to protect their employees against passive smoking. Furthermore, additional enforcement activities were focused on sectors showing less compliance, resulting in a continuous threat of sanctions if not complying. Levy et al. (2004) indicated both, media publicity and government enforcement as facilitating interventions. This increase was accompanied by a decrease in negative attitude and an increase in skills. These results are supported by studies in the hospitality sector, which found a less negative attitude after complying with the smoking ban [Hilton et al., 2007] and stated that attitudinal and managerial factors contribute to compliance [Eadie et al., 2008].

\subsubsection{Differences in compliance with the workplace-smoking ban between sectors}

The differences in compliance between the sectors in 2004 were expected, because the ban for the public sector had been in force since 1990 and has been enforced since 2002. Other studies also found differences in the compliance rates between sectors; mainly blue-collar occupational groups and the service or hospitality sector reported the highest exposure to ETS [Gerlach et al., 1997; Jenkins \& Counts, 1999; Wortley et al., 2002]. The convergence in rates of compliance between sectors was also reported by others. This phenomenon also occurred in the study of Heloma et al. (2003), i.e. before the ban there was a difference of $12 \%$ in compliance between the industry and offices, and after 3 years the differences was only $3 \%$.

Three factors increased more in the industry than in the service sector or public sector and may have had an impact on the increased compliance. The awareness factor was a higher risk perception of enforcement, probably due to the intensification of enforcement activities by the NVWA on the industry sector. The two increased motivational factors were a stronger social influence (probably due to observing examples at familiar companies that did comply) and an increase in self-efficacy to comply with the 
law. These three factors are also reported by others to influence compliance [Levy et al., 2004; Eadie et al., 2008].

Despite this convergence, compliance in the industrial sector in 2008 was still significantly lower than in the service and public sector. This lower compliance should be interpreted against the background of the variables on which the industrial sector in 2008 scored differently compared with the other sectors. The industrial sector (also in 2008) had a less positive attitude and scored lower on social influence. The higher risk perception of the severity of sanctions should be interpreted as a consequence of the lower compliance in the industrial sector in 2008 and may mean that, in the future, differences in compliance between the industrial and other sectors will be further reduced.

The strength of the current study is the relatively long follow-up period compared to other studies, and the large sample size. We were able to detect differences between sectors over time. Furthermore, not only was self-reported compliance assessed, but also awareness and motivational factors that indicate the background to the differences in the rates of compliance with the workplace-smoking ban. A limitation of this study is that no measurement was made before the implementation of the workplace-smoking ban.

\subsection{Conclusions}

From a policymaking point of view, our results indicate that a strategy that focuses on removing negative attitudes and increasing skills may contribute the most to compliance with the workplace-smoking ban. Sectors that initially stay behind in compliance may be helped to faster adopt the workplace-smoking ban by strengthening enforcement, mobilizing social support and improvement of skills. 



\section{CHAPTER 3}

\section{Agreement between self-reports and on-site inspections of compliance with the workplace-smoking ban}

Published as:

Verdonk-Kleinjan W.M., Rijswijk P.C., Candel M, de Vries H. \& Knibbe R.A. (2012). Agreement between self-reports and on-site inspections of compliance with the workplace-smoking ban. Nicotine \& Tobacco Research, 14(9), 1121-1125. 


\section{CHAPTER 3}

\section{Abstract}

\section{Introduction}

This study compares self-reports on compliance with a workplace-smoking ban, with on-site inspections of the same workplace, in the Netherlands, to assess the validity of self-reported compliance by employees.

\section{Methods}

A total of 360 companies had participated in the telephone survey (in October and November 2006) and were also visited by inspectors directly after the survey to establish compliance. The sampling frame included companies with 5 or more employees, stratified according to the number of employees and type of economic activity. We calculated the agreement, the under- or overestimation and the predictive values, and explored non-response research.

\section{Results}

The percent agreement on compliance between the two measures was $77.5 \%$, the McNemar test was not significant, and the agreement coefficient with first order correction was 0.68 , indicating moderately strong agreement. Furthermore, the results indicate a slight overestimation of compliance. Concerning the predictive values, we found most variance among the self-reported non-compliance: $55.2 \%$ of those reporting non-compliance did in fact comply.

\section{Conclusions}

This study allows to conclude that self-reports on compliance with a workplacesmoking ban are largely valid and that social desirability is negligible. For agencies enforcing the workplace-smoking ban, these results indicate that a strategy to identify non-compliance among responding companies might be useful. Moreover, such a strategy reduces the burden of inspecting among complying companies. 


\subsection{Introduction}

In the Netherlands the workplace-smoking ban was implemented on January 12004 , with the exception of the hospitality sector. The act banned smoking inside, but allowed to provide designated smoking rooms. The Netherlands Food and Consumer Product Safety Authority, Nederlandse Voedsel en Warenautoriteit (NVWA) became legally responsible to monitor compliance. The NVWA has the authority to impose fines in case of noncompliance. These fines start at 300 euro and increase to a maximum of 2,400 euro in case of continued noncompliance.

For an effective enforcement program, it is necessary to have insight in compliance rates. Although use of self-report is a common method when examining compliance [Borland et al., 2006; Gilpin et al., 2002; Heloma \& Jaakkola, 2003; Hyland et al., 2009], this method can be biased by 'social desirability' [Holbrook, Green \& Krosnick, 2003], which is defined as the tendency of respondents to reply in a manner that will be viewed favorably by others. In this case the avoidance of legal consequences (in case of noncompliance) is part of social desirability. In general, social desirability will take the form of overreporting good behaviour or underreporting bad behaviour. The present study compares self-reports on compliance with a workplace-smoking ban, with on-site inspections of the same workplace.

In 2006, a telephone interview was held with employees responsible for implementation of the workplace-smoking ban regulation. Independent of this survey, inspectors of the NVWA organization conducted on-site inspections of the workplacesmoking ban. The present study uses the outcomes of the on-site inspections to assess the validity of self-reported compliance by employees.

\subsection{Methods}

The sampling frame for the telephone survey included Dutch companies with five or more employees. For the telephone survey a random sample of 4,634 companies, stratified according to the number of employees (5-9, 10-99, 100>), and type of economic activity (i.e. agriculture, industry, education) was taken from the Netherlands database of registered companies. From the telephone survey sample, a second random sample was taken for on-site inspections, with the exception of companies in the hospitality industry as that sector was, at that time, excluded from the workplacesmoking ban. This second sample was smaller than the first because non-response was not expected, since companies are obliged to cooperate with the inspections performed by the NVWA. During October and November 2006 the telephone survey was performed by a commercial market research organization. Directly after this survey the NVWA conducted on-site inspections up to February 2007. Anonymity of the compa- 
nies that participated in the telephone survey was guaranteed, and it was unknown to the NVWA which companies had participated in the telephone survey. Of the 4,634 companies 3,925 companies were reached by telephone and 2,201 (56.1\%) were willing to complete an interview; this was reduced to 2,018 (55.0\%) companies after excluding the hospitality industry. Those companies not willing to participate were asked the same question about their smoking policy. Of the 2,018 companies which completed an interview, 360 were also visited by inspectors to establish compliance with the workplace-smoking ban. For the present study we made 3 categories of companies: public sector (e.g. schools, hospitals, public administration, social services), service sector and industry. We use the general term 'company' to cover both public and forprofit enterprises. This sample of 360 companies shows a similar distribution in terms of the size of the company, that is, $31.9 \%$ (5-9 employees), $54.7 \%$ (10-99 employees) and $13.3 \%$ (>100 employees), and economic activity, that is $17.2 \%$ (public sector), $50.3 \%$ (service sector) and $32.5 \%$ (industry sector), to the companies selected for onsite inspections ( $n=1.389$ ), that is, $35.4 \%$ (5-9 employees), $54.8 \%$ (10-99 employees) and $9.8 \%$ (>100 employees), and $22.6 \%$ (public sector), $46.6 \%$ (service sector) and $30.8 \%$ (industry sector), as well as to the companies which completed an interview ( $n=2.018$ ), 33.9\% (5-9 employees), 54.1\% (10-99 employees) and 12.0\% (>100 employees), and $24.3 \%$ (public sector), $44.7 \%$ (service sector) and $31.0 \%$ (industry sector).

In the telephone interview compliance with the workplace-smoking ban was measured by the question "Which of the following descriptions reflect the current smoking policy in your company?". The answers 'complete smoking ban' and 'general smoking ban with lockable smoking rooms, avoidable for non-smokers' indicate compliance with the legislation and all other answers (i.e. 'general smoking ban with nonlockable smoking areas', 'limited smoking ban, whereby smoking is prohibited in some places within the company' and 'no smoking regulation') indicate non-compliance. The inspectors used systematic observation, which includes control of the smoking policy (such as having no-smoking rules and having no-smoking signs) and checks on nonsmoking (such as there being no smokers and no ashtrays) to classify the workplaces into those complying and not complying with the smoking ban.

To validate the accuracy of self-reported compliance, we used the combined dataset of 360 companies. First, we calculated the percent agreement, McNemar's test and the agreement coefficient with first order correction $\left[\mathrm{AC}_{1}\right]$ for the whole group and stratified according to company size (5-9 employees, 10-99 employees and $>100$ employees) and economic activity (public sector, service sector and industry). The $\mathrm{AC}_{1}$ coefficient expresses the agreement between the two collection methods but, contrary to the percent agreement, corrects for agreement due to chance. Furthermore, compared to the traditional kappa measure, which also corrects for agreement due to chance, the $\mathrm{AC}_{1}$ coefficient gives less biased estimates of the true intermethod agree- 
ment, when the prevalence of an event is high or low [Gwet, 2008]. In these cases the kappa clearly underestimates the true agreement. Since we expected the compliance to be much more than $50 \%$, we preferred to calculate the $A_{1}$ coefficient instead of the kappa. For the $A C_{1}$ coefficient, the following cut-offs were used: a score of $\geq 0.8$ is very strong agreement; 0.6-0.8 indicates moderately strong agreement, 0.3-0.6 is fair agreement, and a score of $\leq 0.3$ is poor agreement [Chan, 2003]. To test whether the percent agreement was different for companies of different size and for companies categorized according to economic activity chi-square tests were performed, each time comparing two types of companies in terms of agreement.

Second, we compared the compliance based on the self-reports and compliance based on the on-site inspections to determine under- or overestimation. Finally, we calculated the predictive values, indicating the probability that self-reported compliance or non-compliance has been confirmed by on-site inspections [Altman \& Bland, 1994]. The predictive values also allow to estimate whether the error of overreporting compliance or underreporting compliance dominates non-agreement.

In relation to the non-response research, we used the companies willing to answer only one question as a proxy for non-responders. Differences in compliance according to self-report and on- site inspection between companies answering all questions and those answering only one question are presented. Furthermore, we analysed differences in on-site inspections between companies which participated in the whole interview and companies which did not. We also calculated the percent agreement, McNemar's test, the $A C_{1}$ and the predictive values for those companies $(n=120)$ which answered only the question about their smoking policy. Data were analysed using SPSS 16.0 for Windows.

\subsection{Results}

Table 1 presents the results of the 360 companies: the raw percent agreement between the two data collection methods was $77.5 \%$. In $70.3 \%$ of the cases self-reported compliance matched with compliance based on the on-site inspections, and in $7.2 \%$ of the cases self-reported non-compliance matched with on-site inspection. The McNemar test was not significant ( $p>0.05)$, which indicates no difference between the self-reported and observed compliance by on-site inspections. The agreement coefficient with first order correction $\left[\mathrm{AC}_{1}\right]$ is 0.68 , indicating moderately strong agreement [Chan, 2003]. When focusing on companies of different size (Table 1), there is no significant difference in percent agreement. The McNemar test found no differences between self-reported compliance and compliance assessed by the NVWA. For a stratification of companies according to the type of economic activity we assessed a significantly higher percent agreement among the public sector, compared with the industry. 
Only for the service sector did McNemar's test turn out to be significant, which indicates that the self-reported compliance is higher than the observed compliance for this type of company.

Table 1: Data on agreement between compliance ratings $\mathrm{n}(\%)$

\begin{tabular}{|c|c|c|c|c|c|c|c|}
\hline & Self-reports & $\begin{array}{l}\text { Inspection } \\
\text { Compliance } \\
(\%)\end{array}$ & $\begin{array}{l}\text { Non- } \\
\text { compliance (\%) }\end{array}$ & $\begin{array}{l}\text { Total } \\
\text { (\%) }\end{array}$ & $\begin{array}{l}\text { Percent } \\
\text { agreement }\end{array}$ & $\begin{array}{l}\text { McNemar's } \\
\text { test } p \text {-value }\end{array}$ & $\mathrm{AC}_{1}{ }^{2)}$ \\
\hline \multirow{3}{*}{$\begin{array}{l}\text { Overall } \\
(n=360)\end{array}$} & Compliance & 70.3 & 13.6 & 83.9 & \multirow[t]{3}{*}{77.5} & \multirow[t]{3}{*}{0.075} & \multirow[t]{3}{*}{0.68} \\
\hline & Non-compliance & 8.9 & 7.2 & 16.1 & & & \\
\hline & & 79.2 & 20.8 & 100 & & & \\
\hline
\end{tabular}

\begin{tabular}{|c|c|c|c|c|c|c|c|}
\hline \multicolumn{8}{|c|}{ Size of the companies } \\
\hline 5-9 employees & Compliance & 67.0 & 14.8 & 81.7 & 75.7 & 0.345 & 0.64 \\
\hline \multirow[t]{2}{*}{$(n=115)$} & Non-compliance & 9.6 & 8.7 & 18.3 & & & \\
\hline & & 76.5 & 23.5 & 100 & & & \\
\hline $10-99$ & Compliance & 71.6 & 13.2 & 84.8 & 79.2 & 0.118 & 0.70 \\
\hline employees & Non-compliance & 7.6 & 7.6 & 15.2 & & & \\
\hline$(n=197)$ & & 79.2 & 20.8 & 100 & & & \\
\hline$>100$ & Compliance & 72.9 & 12.5 & 85.4 & 75.0 & 1.000 & 0.67 \\
\hline employees & Non-compliance & 12.5 & 2.1 & 14.6 & & & \\
\hline$(n=48)$ & & 85.4 & 14.6 & 100 & & & \\
\hline \multicolumn{8}{|l|}{ Sector } \\
\hline Public sector & Compliance & 87.1 & 8.1 & 95.2 & 87.1 & 0.727 & 0.85 \\
\hline \multirow[t]{2}{*}{$(n=62)$} & Non-compliance & 4.8 & 0.0 & 4.8 & & & \\
\hline & & 91.9 & 8.1 & 100 & & & \\
\hline Service sector & Compliance & 65.7 & 16.6 & 82.3 & 76.7 & $0.009^{1}$ & 0.64 \\
\hline \multirow[t]{2}{*}{$(n=181)$} & Non-compliance & 6.6 & 11.0 & 17.7 & & & \\
\hline & & 72.4 & 27.6 & 100 & & & \\
\hline Industry & Compliance & 68.4 & 12.0 & 80.3 & 73.5 & 0.719 & 0.62 \\
\hline \multirow[t]{2}{*}{$(n=117)$} & Non-compliance & 14.5 & 5.1 & 19.7 & & & \\
\hline & & 82.9 & 17.1 & 100 & & & \\
\hline
\end{tabular}

\footnotetext{
${ }^{1)} p<0.01$

2) cut-offs for $\mathrm{AC}_{1}: \geq 0.8$ very strong agreement; 0.6-0.8 moderately strong agreement, 0.3-0.6 fair agreement, $\leq 0.3$ poor agreement [Chan, 2003].
}

In the telephone survey $83.9 \%$ reported compliance with the smoke-free workplace legislation, whereas during the on-site inspection the NVWA established compliance for $79.2 \%$ of the companies. This result indicates a slight overestimation of compliance by $4.7 \%$ if one uses self-reports rather than on-site inspections. 
Finally, we calculated the predictive values. The positive predictive value, the chance that self-reported compliance is confirmed by on-site inspections, is 0.838 , indicating that $83.8 \%$ of the companies that reported compliance did indeed comply with the workplace-smoking ban legislation and $16.2 \%$ did not. The negative predictive value, the chance that self-reported non-compliance is confirmed by on-site inspections, is 0.448 , which means that for $44.8 \%$ of the companies that reported non-compliance this was confirmed by on-site inspections. However, $55.2 \%$ of the companies reporting non-compliance did in fact comply according to the on-site inspections. This indicates that a higher proportion of reported non-compliance was not confirmed, compared to the proportion of reported compliance.

Non-response analysis showed that there were no significant differences in selfreported compliance between responding companies $(83 \% ; n=2,018)$ and companies willing to answer only one question ( $80.7 \%$; $n=576$ ), nor in reported compliance according to on-site inspections for responding companies $(79.2 \% ; n=360)$ and for companies willing to answer only one question (76.7\%; $n=120)$. Comparing on-site inspections between the groups of full responders and the group of partial and nonresponders showed no significant differences between companies that completed the interview (79.2\%; $n=360$ ) and companies that did not (77.0\%; $n=1029)$. When focusing on agreement measures among the companies which were willing to answer one question we found a raw percentage agreement of $70 \%$ and an $\mathrm{AC}_{1}$ of 0.56 indicating fair agreement [Chan, 2003]. The McNemar test was not significant ( $p>0.05)$, which indicates no difference between the self-reported and observed compliance by on-site inspections in this group. The positive predictive value is 0.780 and is in line with the sample of full responders, and the negative predictive value is 0.300 which is lower than that of the full responders.

\subsection{Discussion}

Our main question was to assess the validity of self-reported compliance. The outcomes show that there is large agreement between compliance according to selfreports and on-site inspections. Further, for all companies together, no significant difference in compliance rates was found between both methods (i.e. self-reports and observations by inspectors of the NVWA) and both yield comparable compliance rates. These results indicate that self-reported compliance by employees is a valid method to assess compliance of the workplace smoking ban.

However, for companies in the service sector the results of the self-reported compliance did not agree with the observed compliance. Furthermore, we have to take into account that, compared with the original sample of all interviewed companies $(n=2,018)$ and all on-site inspections $(n=1,389)$, companies in the public sector were 
underrepresented in the sample for which both self-reports and on-site inspections $(n=360)$ were available. As the $A_{1}$ is higher in the public sector $(0.85)$ than in the service sector (0.64) and industry (0.62), this probably means that for the total population of enterprises the $\mathrm{AC}_{1}$ is somewhat underestimated.

Finally, non-response analysis showed comparable levels of compliance between the responding and partial responding groups, and between the responding group and the non-responding and partial responding groups. Furthermore, McNemar's test of partial responders showed that self-reported compliance did not differ significantly from the observed compliance. These results do not indicate that, among nonresponders, differences in compliance according to self-report and on-site inspection are larger than among enterprises fully cooperating with an interview.

We compared the results of our study with two different kind of studies, one that is methodologically comparable and others related to smoking legislation. In the first comparison Hurd et al. (2006) found similar percent raw agreements for compliance with indoor tanning legislation between measures based on self-reports and based on on-site visits: $71.3 \%$ for the frequency allowed to tan and $76.3 \%$ for parentally required consent. However, in that study the $\mathrm{AC}_{1}$ was lower: 0.57 and 0.63 , respectively. In the second comparison we found a validation study of self-reported environmental tobacco smoke, which is used as compliance indicator of worksite smoking policies, indicating a substantial correlation with environmental measures as nicotine $(r=0.65$; $p<0.001$ ) [Willemsen et al., 1997].

Taking the results of the on-site inspections as the more objective measure, the results indicate that the (overall) compliance based on self-reports is somewhat overreported (4.7\%). This is probably due to answers being based on social desirability. Holbrook et al. describe that people attempt to construct favourable images of themselves when the reporting circumstances assure anonymity, such as the telephone interviews used in the present study [Holbrook, Green, \& Krosnick, 2003].

Another interesting and surprising outcome concerns the predictive values, whereby most variance was found among the self-reported non-compliance. According to the on-site inspection, $55.2 \%$ of the companies reporting non-compliance did in fact comply. A possible reason for this is that there might be another mechanism, which is almost the opposite of social desirability, claiming non-compliance whilst complying. Respondents who had insufficient knowledge on this subject, or on how the ban was actually implemented, may have 'played safe' by giving a negative answer. Another explanation could be that companies started to implement the workplace-smoking ban after being reminded by the interview that they did not yet comply. In our nonresponse research this phenomenon was stronger in companies willing to answer only one question. Up to $70 \%$ of those reporting non-compliance did in fact comply, which suggests that the proposed mechanism, i.e. giving a negative answer because they 
believe they have insufficient knowledge, might work even stronger and might influence non-participation in the whole interview.

This study allows to conclude that self-reports on compliance with a workplacesmoking ban are largely valid and that social desirability is negligible. For agencies enforcing the workplace-smoking ban these results indicate that a strategy to identify non-compliance among responding companies might be useful. Table 1 shows that concentrating the inspection on those reporting non-compliance increases the possibility to identify non-compliance, rather than focusing on companies reporting compliance of which only a small percentage do not in fact comply. It is clear that preliminary screening reduces the burden of inspection of the large majority of companies in which the likelihood of non-compliance is comparatively low.

The answer to the question as to how such preliminary screening could be implemented probably lies with the innovation programs in the Netherlands aimed at increasing the effectiveness of enforcement agencies. One such innovation is the use of a web-based survey by enforcement agencies to collect data, which helps to increase risked-based supervision [IGZ, 2010]. However, as soon as companies know about such a strategy, they might try to reduce the chance of on-site inspection by reporting compliance. Whether such behaviour in fact occurs should be investigated. 



\section{CHAPTER 4}

Does the workplace-smoking ban eliminate differences in risk for environmental tobacco smoke exposure at work?

Published as:

Verdonk-Kleinjan W.M., Knibbe R.A., Tan F.E., Willemsen M.C., de Groot H.N. \& de Vries H. (2009). Does the workplace-smoking ban eliminate differences in risk for environmental tobacco smoke exposure at work? Health Policy, 92(2), 197-202. 


\section{Abstract}

\section{Objectives}

A workplace-smoking ban in the Netherlands was introduced on January 1, 2004. Before the ban male and low educated employees were at higher risk for exposure to environmental tobacco smoke (ETS). Effective implementation of the ban should result not only in an overall decline of exposure, but also in the disappearance of systematic differences in exposure between subgroups of employees.

\section{Methods}

Data from a Dutch continuous Internet survey were used. From July 2003 through June 2005200 respondents were randomly selected each week. The sample consisted of 11,291 non-smoking, working respondents, aged 16 to 65 years.

\section{Results}

ETS exposure decreased among all employees and among subgroups at higher risk before the ban. However, also after the ban, males and low educated employees were still most likely to be exposed to ETS.

\section{Conclusions}

The workplace-smoking ban was effective in reducing ETS exposure among employees. However, after the ban still $52.2 \%$ of non-smoking workers reported to be exposed. We did not find the expected stronger effect among employees who were at higher risk. Both before and after implementation of the ban, males and lower educated employees were about two times more likely to be exposed to ETS. 


\subsection{Introduction}

There is abundant evidence for the health hazards of exposure to environmental tobacco smoke (ETS), including increased risk for lung cancer, other cancers, coronary heart disease (CHD), respiratory diseases (such as chronic obstructive pulmonary disease (CODP) and asthma), stroke, and complications of pregnancy such as low birth weight and pre-term delivery [Barnoya \& Glantz, 2005; Brownson, Eriksen, Davis \& Warner, 1997; Ludbrook, Bird, \& Van Teijlingen, 2005; Reynolds, 1999; Steenland, 1999; U.S. Department of Health and Human Services, 1986; Zhong, Goldberg, Parent \& Hanley, 2000]. The main locations for ETS exposure are workplaces and private homes [Cummings et al, 1990; Pirkle, Flegal, Bernert, Brody, Etzel \& Maurer, 1996; Pucci,1991]. Emmons et al. (1992) reported that, in the absence of workplace smoking bans, approximately $50 \%$ of the exposure was at the workplace. Hammond (1999) found that $29 \%$ of the workers were exposed only at work, while $12 \%$ were exposed only at home.

One of the most effective public health policies to reduce ETS exposure of nonsmokers is the implementation of smoking restrictions or total bans at workplaces and public places [Brownson et al. 1997; Ludbrook et al. 2005; Fichtenberg \& Glantz, 2002; Hopkins et al., 2001; Haw \& Gruer, 2007]. In 2007 approximately 50\% of the countries in Europe installed anti-smoking laws for workplaces; other countries have limited or no worksite smoking restrictions [European Network for Smoking Prevention, 2007]. In the Netherlands a full workplace-smoking ban has been in place for all worksites (except in bars, cafés and restaurants) since January 2004. Employers are allowed to provide designated smoking rooms.

An effective implementation of the workplace-smoking ban would imply that after the ban there would be no systematic differences in exposure of non-smokers to ETS at the workplace. This would also mean that the ban would lead to a greater reduction in exposure to ETS among those at higher risk before the ban. Most ETS evaluation studies focused on specific categories of workers like hospitality workers or healthcare staff [Pucci, 1991; Allwright et al., 2005; Eagan, Hetland \& Aarø, 2006; Ellingsen et al., 2006; Farrelly et al., 2005; Mullooly, Schuman, Stevens, Glasgow \& Vogt, 1990; Skogstad, et al.; 2006], or related the level of worksite smoking policy with ETS exposure [Borland, et al., 1992; Moskowitz, Lin \& Hudes, 1999; Patten, Pierce, Cavin, Berry \& Kaplan, 1995; Pickett, Schober, Brody, Curtin \& Giovino, 2006; Pierce, et al. 1994]. Studies in the USA [Brownson, Davis, Jackson-Thompson \& Wilkerson, 1995; McMullen, Brownson, Luke \& Chriqui, 2005], New Zealand [Edwards et al., 2008], UK/Ireland [Fong et al., 2006], Scotland [Haw \& Gruer, 2007], Spain [Galán et. al., 2007] and Finland [Heloma \& Jaakkola 2003], evaluated the impact of a national or state-wide workplace-smoking ban on all types of employees. All seven studies re- 
vealed significant reductions of ETS exposure at work after implementation of worksite bans [Brownson et.al, 1995; Edwards et al., 2008; Fong et al., 2006; Galán et. al., 2007; Haw \& Gruer, 2007; Heloma \& Jaakkola 2003; McMullen et al. 2005;]. However, only one of these studies examined the effects in risk groups most exposed to ETS before the ban and thus at the highest risk of acquiring ETS-related health problems [Edwards et al. 2008]. In the present study, we analyze whether the workplace-smoking ban reduced exposure to ETS among all non-smoking employees. However, we also focus more specifically on whether some categories of employees are still at elevated risk for exposure to ETS after the ban. Previous studies suggest that high ETS exposure at work is related to younger age, lower education, blue collar workers and being male [Borland et.al, 1992; Edwards, 2008; Moussa, Lindström \& Ostergren, 2004; Pickett et al., 2006]. Therefore, we expected that the impact of the ban will be stronger in younger employees, employees with lower education, and male employees. Moreover we expected that, among employees who work more hours, the differences before and after the ban would be larger, because they spend more of their time in an environment that was changed by the introduction of the smoking ban. Specific for the Netherlands is that government-related agencies implemented a workplace-smoking ban as early as 1990. Assuming that this ban had an effect, it is likely that the 2004 national workplace-smoking ban has had less effect on employees working at government-related agencies.

\subsection{Materials and methods}

\subsubsection{Study design and setting}

The Continuous Survey of Smoking Habits (CSSH) monitors smoking prevalence and smoking habits in the Dutch population. Each week 200 respondents are randomly selected from a database of 140,000 respondents representative for the Dutch population aged 15 years and older. To ensure the representativeness, the sample is weighted to region, urbanisation, gender, age, household, education and activity. The subjects were approached by Internet to fill in a questionnaire. For the present study, data collected from July 2003 through June 2005 were used. We selected all 9856 nonsmoking, working ( $\geq 15$ hours a week) respondents, aged 16 to 65 years. We have no information about non-respondents. To check the representativeness of our sample, we compared our sample (smoking and non-smoking) on gender, age and level of education with a sample of the working population from the National Bureau of Statistics. Differences between these two latter samples were small and ranged from $0.5 \%$ to $5.0 \%$. Implementation of the workplace-smoking ban was indicated at the time respondents were interviewed: i.e. either just before the ban (the third and fourth quar- 
ter of 2003; $n=2,092$ ), or after the ban (2004 and the first and second quarter of 2005; $n=7,764)$.

\subsubsection{Characteristics of the participants}

Table 1 presents the characteristics of all respondents in the current study. There were no significant differences in the characteristics of the respondents before (TO) and after (T1) implementation of the ban.

Table 1: Characteristics of the respondents (percentages).

\begin{tabular}{lll}
\hline & $\begin{array}{l}\text { T0 (before the ban) } \\
\mathrm{n}=2,092\end{array}$ & $\begin{array}{l}\text { T1 (after the ban) } \\
\mathrm{n}=7,764\end{array}$ \\
\hline $\begin{array}{l}\text { Gender } \\
\text { Male }\end{array}$ & 56.7 & 55.5 \\
Female & 43.3 & 44.5 \\
Age & & \\
16-29 years & 17.8 & 18.6 \\
30-49 years & 61.3 & 60.7 \\
50-65 years & 20.9 & 20.7 \\
Education level & & 27.7 \\
Low & 26.5 & 39.8 \\
Middle & 39.2 & 32.5 \\
High & 34.3 & 82.9 \\
Type of employer & 36.1 & 17.1 \\
Non-governmental & 63.9 & 64.2 \\
Governmental & 15.8 & \\
Weekly working hours & & \\
15 -34 hours & & \\
35 hours or more & & \\
\hline
\end{tabular}

\subsubsection{Questionnaire}

Exposure to ETS was measured with the question "How often do colleagues smoke in your presence?" with the answers 'never', 'sometimes', 'regular', 'often' and 'always'. In this article we use mainly a dichotomous variable with the categories 'no exposure' (answer 'never') and 'exposure' (answer 'sometimes', 'regular', 'often' or 'always'). In two analyses we use the ordinal variable (never...always). Firstly, to assess whether those reporting to be exposed after the ban reported a lower frequency of being exposed compared with before the ban. Secondly, we used the ordinal variable in a mul- 
ti-variate analysis to check our outcomes with the dichotomous variable. Furthermore, information on gender (male/female), age (16-29, 30-49, 50-65 years), education level (low/middle/high), type of employer (non-governmental/governmental) and weekly working hours (15-34 hours/ $\geq 35$ hours) was acquired using direct questions. The indicator of the implementation of the workplace-smoking ban was before (T0) and after (T1) the ban.

\subsubsection{Statistical analysis}

Chi-square tests were used to analyze differences in characteristics of the respondents before and after the ban, to assess the proportion that reported being exposed to ETS at work, and to assess differences in exposure in risk groups. Multivariable logistic and linear regression analyses were used to analyze the cumulative contribution of gender, age, level of education, type of employer and weekly working hours to exposure to ETS before and after the ban. Furthermore we tested for interaction effects between the implementation of the ban and the five factors related to exposure to ETS. For all analyses we used a significance level of $p<0.05$. Data were analyzed using SPSS 15.0 for Windows.

\subsection{Result}

\subsubsection{Impact of the ban on the general working population}

The first research question addressed the impact of the workplace-smoking ban on self-reported ETS exposure in the general working population. Figure 1 presents the percentages of employees reporting 'being exposed to ETS at work'. Despite rather large fluctuations per week in the proportion of employees reporting to be exposed, the figure shows that after the ban a smaller proportion of the employees reported to be exposed to ETS. In the weeks before the ban $70.7 \%$ of the employees reported being exposed while after the ban this percentage was significantly lower $(51.9 \%$; $\mathrm{p}<0.001)$.

Among those exposed to ETS, the frequency of exposure decreases significantly $(p<0.001)$. The percentage of employees who reported to be exposed sometimes increased from $51.7 \%$ to $58.8 \%$, while reports of being regular, often and always exposed decreased from $31.2 \%$ to $27.0 \%$ (regular), $10.7 \%$ to $8.5 \%$ (often) and $6.4 \%$ to $5.8 \%$ (always), respectively. 
Figure 1: Percentages of employees reporting "to be exposed to ETS at work" before and after the ban (reported per week).

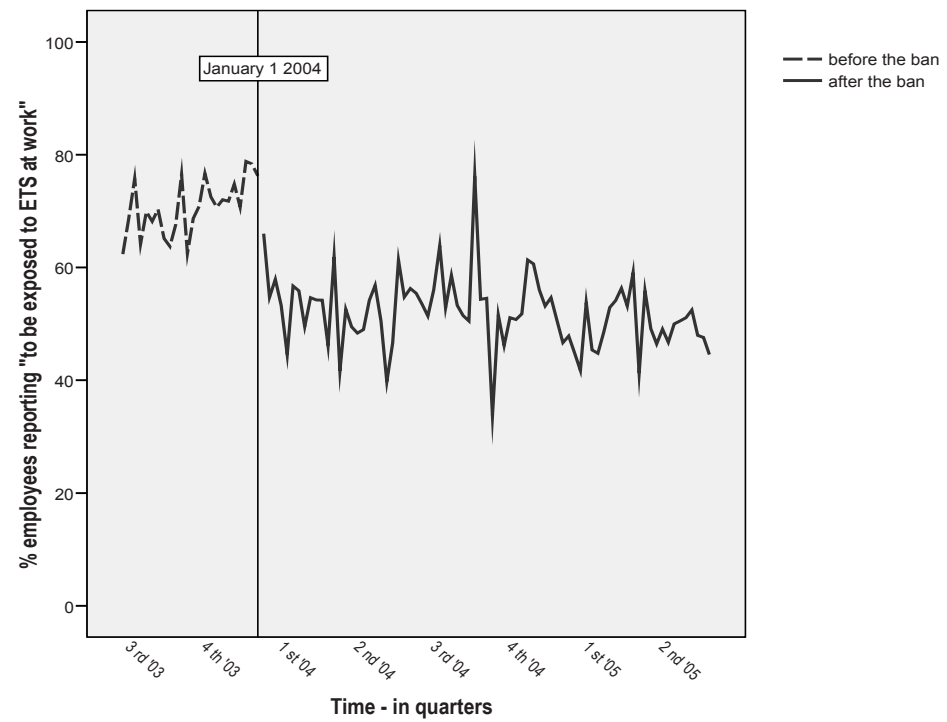

\subsubsection{Impact of the ban on groups at risk for ETS}

Secondly, we focused on specific groups at risk for ETS before the workplace-smoking ban. Table 2 shows that before the ban higher levels of ETS were reported for males $(p<0.001)$, lower educated workers $(p<0.001)$, workers with more weekly working hours $(p<0.001)$ and employees of non-governmental agencies $(p<0.01)$. At baseline, males and lower educated workers most often reported ETS exposure at work: $76.5 \%$ and $79.7 \%$, respectively.

When we examine the effects for these risk groups, significant improvements were found after the ban for all groups at elevated risk (Table 2).

Nevertheless, also after the ban there were significant systematic differences in risk for ETS by gender, level of education, type of employer and weekly working hours (Table 2). The percentages for ETS exposure after the ban were still the highest for males and lower educated employees: $59.8 \%$ and $61.5 \%$, respectively. 
Table 2: Percentage employees reporting "to be exposed to environmental tobacco smoke at work".

\begin{tabular}{|c|c|c|}
\hline & $\begin{array}{l}\text { T0 (before the ban) } \\
n=2,092\end{array}$ & $\begin{array}{l}\text { T1 (after the ban) } \\
\mathrm{n}=7,764\end{array}$ \\
\hline General & 70.7 & $51.9^{3)}$ \\
\hline \multicolumn{3}{|l|}{ Gender } \\
\hline Male & $76.5^{2)}$ & $59.8^{2) 31}$ \\
\hline Female & $63.2^{2)}$ & $42.2^{2) 3)}$ \\
\hline \multicolumn{3}{|l|}{ Age } \\
\hline $16-29$ years & 68.5 & $51.4^{3)}$ \\
\hline $30-49$ years & 72.3 & $51.8^{3)}$ \\
\hline $50-65$ years & 68.0 & $53.0^{3)}$ \\
\hline \multicolumn{3}{|l|}{ Education level } \\
\hline Low & $79.7^{2)}$ & $61.5^{2) 3)}$ \\
\hline Middle & $71.0^{2)}$ & $53.6^{2) 31}$ \\
\hline High & $63.5^{2)}$ & $41.7^{2) 31}$ \\
\hline \multicolumn{3}{|l|}{ Type of employer } \\
\hline Non-governmental & $72.0^{1)}$ & $53.8^{2) 31}$ \\
\hline Governmental & $63.9^{1)}$ & $43.3^{2) 31}$ \\
\hline \multicolumn{3}{|l|}{ Weekly working hours } \\
\hline $15-34$ hours & $64.9^{2)}$ & $44.9^{2) 31}$ \\
\hline 35 hours or more & $74.0^{2)}$ & $55.8^{2) 31}$ \\
\hline
\end{tabular}

${ }^{1)}$ Difference between subgroups $(p<0.01)$

${ }^{2)}$ Difference between subgroups $(p<0.001)$

${ }^{3)}$ Difference between T0 and T1 $(p<0.001)$

\subsubsection{Cumulative contribution to ETS exposure}

Two logistic regression analyses were conducted (one before and one after implementation of the workplace-smoking ban) in order to assess the contribution of factors related to exposure to ETS. Self-reported ETS exposure was regressed on gender, age, education level, type of employer and weekly working hours (Table 3).

Before and after the implementation of the workplace-smoking ban gender and education level were most strongly associated with self-reported ETS exposure. Males were nearly twice more likely to be exposed to ETS than females (OR 1.75 and 1.95, respectively), and lower educated employees were even more than two times more likely to be exposed to ETS than higher educated employees (OR 2.29 and 2.17, respectively). We also found that the ORs for the youngest age group (16-29 years) compared with the middle-aged group (30-49 years) and for the type of employer were significantly increased after the ban. Analysis of interactions of the ban with the independent variables did not show any significant interaction, indicating that in the subpopu- 
lations of workers the effect of the ban was not stronger than in of the other subpopulations.

Linear regression analyses with exposure as an ordinal (never...always) variable yielded similar results. Both gender and education were significant before and after the ban and the change in $\beta$ for gender $(\beta=0.22$ and $\beta=0.26)$ and education ( $\beta=0.46$ and $\beta=0.42$ ) was very limited.

Table 3: Logistic regression for ETS exposure before and after the ban.

\begin{tabular}{|c|c|c|c|c|}
\hline \multirow[b]{2}{*}{ Variable } & \multicolumn{2}{|c|}{ T0 (before the ban) } & \multicolumn{2}{|l|}{ T1 (after the ban) } \\
\hline & OR $[95 \% \mathrm{Cl}]$ & $p$-value & OR $[95 \% \mathrm{Cl}]$ & p-value \\
\hline Gender ( $0=$ male $/ 1=$ female $)$ & $1.75[1.38-2.21]$ & $<0.001^{* * *}$ & $1.95[1.74-2.19]$ & $<0.001 * * *$ \\
\hline Age $(0=16-29 / 1=30-49$ years $)$ & $0.99[0.76-1.28]$ & 0.935 & $1.21[1.07-1.37]$ & $0.003^{* *}$ \\
\hline Age $(0=16-29 / 2=50-65$ years $)$ & $1.43[1.04-1.97]$ & $0.030^{*}$ & $1.30[1.11-1.52]$ & $0.001^{* *}$ \\
\hline Education level ( $0=$ low $/ 1=$ middle) & $1.61[1.23-2.10]$ & $<0.001^{* * *}$ & $1.31[1.16-1.47]$ & $<0.001 * * *$ \\
\hline Education level ( $0=$ low $/ 2=$ high) & $2.29[1.74-3.01]$ & $<0.001 * * *$ & 2.17 [1.91-2.45] & $<0.001^{* * *}$ \\
\hline Type of employer ( $0=$ other $/ 1=$ governmental) & $1.24[0.95-1.65]$ & 0.109 & $1.32[1.17-1.50]$ & $<0.001^{* * *}$ \\
\hline Working hours $(0=15-34 \mathrm{~h} / 1=\geq 35 \mathrm{~h})$ & $0.86[0.68-1.09]$ & 0.205 & $0.93[0.83-1.05]$ & 0.253 \\
\hline
\end{tabular}

$* \mathrm{p}<0.05, * * \mathrm{p}<0.01, * * * \mathrm{p}<0.001$

\subsection{Discussion}

The first conclusion of this study is that the workplace-smoking ban in the Netherlands has led to a decrease in the proportion of employees reporting to be exposed to ETS; however, it should be noted that even after the ban the proportion of non-smoking workers reporting to be exposed $(51.9 \%)$ is still rather high. The decrease also occurred in groups, which before the ban had an elevated risk for exposure to ETS. However, we did not see the expected stronger effect among groups of employees who were at higher risk for ETS before the ban. Therefore, our second conclusion is that both before and after implementation of the workplace-smoking ban, males and lower educated employees are about two times more likely to be exposed to ETS. The significant differences in exposure after the ban according to age and type of employer (see table 3) are mainly due to the larger number of respondents interviewed after the ban rather than to any substantial change in risk due to the ban.

The decrease in ETS exposure after a workplace-smoking ban found in the present study corresponds with results of earlier review studies on ETS exposure [Brownson et al., 1997; Hopkins et al, 2001; Ludbrook et al., 2005], and with national and state-wide reports [Brownson et al. 1995; Edwards et al., 2008; Fong et al., 2006; Galán et. al., 
2007; Haw \& Gruer, 2007; Heloma \& Jaakkola 2003]. In our study, the proportion of Dutch non-smoking employees reporting not to be exposed to smoke at work after the ban (48\%) is somewhat lower than in Finland (54\%) [Heloma \& Jaakkola 2003] and much lower than in Ireland (86\%), Spain (91\%) and New Zealand (92\%) [Edwards et al., 2008; Fong et al., 2006; Haw \& Gruer, 2007]. Apparently there are country differences in how effective a workplace-smoking ban is in protecting non-smoking employees against exposure to ETS. In this case the differences might be partly due to the fact that both the Netherlands and Finland allow designated smoking rooms at the workplace, whereas in Ireland, Spain and New Zealand employers are not allowed to provide such rooms for employees.

We hypothesized that the ban would have the greatest effect on those who were most exposed to ETS before the ban, i.e. males and lower educated employees; this proved not to be the case. The ban did not abolish the systematic differences in exposure to ETS at the workplace. Both before and after the ban male and lower educated employees were at elevated risk for exposure to ETS. Edwards et al. (2008) and Moussa et al. (2004) also analyzed the influence of sociodemographic factors on ETS after implementation of an anti-smoking ban. Both found the risk for ETS at work to be higher among young adults and among those in lower socioeconomic groups, like workers in blue collar jobs [Edwards et al., 2008; Moussa et al., 2004]. A possible reason for the higher exposure to ETS in males and low educated employees (also after the ban) is that males and lower educated persons are overrepresented at worksites known to be least compliant with the smoking ban, e.g. building trade, industry and agriculture [Bieleman \& Kruize, 2007]. Part of the lower compliance might be due to the fact that in some of these sectors most of the work occurs outdoors.

Possible limitations of this study are that the risk of ETS is not necessarily adequately reflected in 'self-reports' about being exposed to tobacco smoke. However, validation studies comparing environmental or biochemical measures indicating exposure to ETS with self-reports show high correlations between self-reports and environmental measures such as nicotine [Coghlin, Hammond, \& Gann, 1989; Willemsen, Brug, Uges \& Vos de-Wael, 1997] or biochemical measures such as cotinine [Cummings et al. 1990; Emmons et al. 1994; Pirkle, Bernert, Caudill, Sosnoff \& Pechacek 2006]. Moreover, reports about exposure might somewhat overestimate the extent to which the workplace-smoking ban is violated. The workplace-smoking ban is principally aimed at securing a smoke-free working place. Because employees might be confronted with smoking colleagues when entering or leaving the building or when passing the designated smoking room inside the building, they may have included these exposures in their report. However, if so, this probably applied to both before and after the implementation of the workplace-smoking ban. Therefore, the change in being exposed is probably a valid indication of the effect of the workplace-smoking ban. 
Another possible limitation is the representativeness of the Internet samples used in the present study. In the Netherlands the proportion of people with access to Internet $(83 \%)$ is relatively high [Linden, 2006]. However, a study comparing estimates of substance use based on an Internet sample and on a sample drawn from the general population register (covering $>98 \%$ of the inhabitants) shows that Internet samples tend to overestimate the prevalence of substance use [Spijkerman, Knibbe, Knoops, Mheen van de Eijnden van den, 2009]. Applied to our study this would mean that the proportion of non-smoking workers may have been underestimated. However, when comparing the total sample (smokers and non-smokers) with a sample of the working population from the National Bureau of Statistics we found little indication of selection effects for gender, age or education. Taken together, we think that there is little indication that the main outcomes concerning the effect of the smoking ban, and risk groups for ETS before and after the ban, are not valid for the general non-smoking working population in the Netherlands.

The last limitation of this study is the relatively low numbers of observations before the ban and, associated with this, the limited seasonal variation before the ban. Concerning the number of observations before the ban, Figure 1 shows enough variation over the period to be confident that the estimates of exposure are rather reliable, also before the ban. Concerning the seasonal variation, both before and after the ban, $50 \%$ of the quarters are in the cold season (first and fourth quarter) and $50 \%$ in the warmer season (second and third quarter). Therefore we think this has little or no effect on the comparison of exposure before and after the ban.

\subsection{Conclusion}

The Dutch workplace-smoking ban led to a decrease in ETS exposure. However, also after the ban still $52 \%$ of the employees report to be exposed to ETS during work, although less frequently than before the ban. It would be worthwhile to explore the specific conditions that influence the effectiveness of the ban to protect the non-smoking workers. Furthermore, it is also clear that the groups at elevated risk (male and loweducated employees) are still more often exposed to smoking colleagues after the ban. For these groups more specific, targeted interventions should be developed to protect the non-smokers in these groups from exposure to ETS during work. 



\section{CHAPTER 5}

\section{Effect of a workplace-smoking ban in combination with tax increases on smoking in the Dutch population}

Published as:

Verdonk-Kleinjan W.M., Candel M., Knibbe R.A., Willemsen M.C. \& de Vries H. (2011). Effect of a workplace-smoking ban in combination with tax increases on smoking in the Dutch population. Nicotine and Tobacco Research, 13(6), 412-418. 


\begin{abstract}
Introduction

In the Netherlands, between 2003 and 2005 three tobacco control measures were implemented: a workplace-smoking ban and two tax increases on tobacco products. This study explores how the combination of measures influences the smoking behaviour of the general population, divided into subpopulations with and without paid work.
\end{abstract}

\title{
Methods
}

Data from the Dutch Continuous Survey of Smoking Habits (CSSH) were used. The total sample consisted of 32,014 respondents (27,150 with paid work and 4,864 without paid work) aged 16 to 65 years. Analyses were done by linear and logistic regression, controlling for relevant factors.

\section{Results}

For respondents with paid work, the combination of a smoking ban and two tax increases led to a decrease in the number of cigarettes per day and in the prevalence of daily smoking. For respondents without paid work there was no significant effect on any of the outcome parameters. In both groups there was no evidence that the effect of the measures on smoking were moderated by the respondent's gender, age or level of education.

\section{Discussion}

The combination of policy measures has influenced the smoking behaviour of respondents with paid work in a positive way. Compared with most other studies, the effect of the workplace-smoking ban alone is smaller. However, the effect of the combined interventions is higher than the effect of tax increases in other studies. Among respondents without paid work who were exposed to tax increases only, no significant effects were found. 


\subsection{Introduction}

In 1996 the Netherlands introduced a tobacco discouragement policy, in line with the WHO Framework Convention on Tobacco Control. Most of the measures related to this policy were implemented after 2002, i.e. a youth access law (2003), an advertising ban (2002), and textual health warnings on cigarette packages (2002). In January 2004 a workplace-smoking ban (from which the hospitality industry was exempt) came into action. One month later, in February 2004, the taxes on tobacco increased by $20 \%$. In January 2005, an additional tax was implemented related to minimum prices of tobacco products, which increased prices by (about) another $4 \%$.

The present study evaluates the impact of the combination of the workplacesmoking ban and the two tax increases on the smoking behaviour of the general population (aged 16-65 years). Subpopulations of those with and without paid work were examined as these two groups differ in their level of exposure to the workplacesmoking ban.

It is generally assumed that a combination of measures has more effect than each of the separate measures [Joossens \& Raw, 2006; Levy, Chaloupka \& Gitchell, 2004; Pierce \& León, 2008]. Three studies [Emont , Choi, Novotny \& Giovino, 1993; Stephens, Pederson, Koval \& Kim, 1997; Stephens, Pederson, Koval \& Macnab, 2001] investigated the impact of the combination of no-smoking laws and increased taxation, but none differentiated the effects for relevant subpopulations. Studies on the impact of a workplace-smoking ban in various countries revealed a decline in the daily cigarette consumption and a reduction in smoking prevalence among working people and in the general population [Brownson, Eriksen, Davis \& Warner, 1997; Chapman et al., 1999;

Fichtenberg \& Glantz, 2002 ${ }^{\text {; }}$ Heloma \& Jaakkola, 2003; Hopkins et al., 2001; Joossens \& Raw, 2006; Levy et al., 2004]. The effect of tax increases is mostly reported in terms of price elasticity. A $10 \%$ increase in price is associated with a $4 \%$ reduction in tobacco consumption (daily cigarette consumption and smoking prevalence) [Fichtenberg \& Glantz, 2002 ${ }^{\text {}}$; Hopkins et al., 2001; Joossens \& Raw, 2006; Guindon, Tobin \& Yach, 2002].

The present study examines the influence of both the workplace-smoking ban and tax increases on persons with paid work, whereas the effect of the tax increases alone was studied in those without paid work. The dataset used covers smoking behaviour in the general population for 36 months. This specific study period covers implementation of the three measures and allows a more comprehensive examination of the cumulative effects of the measures (Fig. 1). For both subpopulations, we expect to see a decline in the intensity of smoking, an increase in quit attempts, and a decrease in the prevalence of smoking. Since the effect of both measures may differ according to age, gender, education [Farrelly, Evans \& Sfekas, 1999; Hopkins et al., 2001; Joossens \& 
Raw, 2006; Levy et al., 2004; Levy, Romano \& Mumford, 2005; Thomas et al., 2008; Townsend, Roderick \& Cooper, 1994] and working hours [Evans, Farrelly \& Montgomery, 1999], these variables were included as moderators. Furthermore, since one of the intervention periods is close to New Year, we also control for possible confounding due to the 'New Year' effect, i.e. taking into account the large number of smokers who start the New Year with an attempt to stop smoking.

\subsection{Methods}

\subsubsection{Study design and setting}

The Continuous Survey of Smoking Habits (CSSH) has continuously monitored smoking behaviour in the Dutch population since 1976. Each week 200 respondents are randomly selected from a database of more than 200,000 respondents representative for the Dutch population aged 15 years and older. To ensure representativeness, the sample is weighted for region, urbanisation, gender, age, household composition, and level of education. The subjects were approached by internet to fill in a questionnaire.

For the present study data collected in 2003, 2004 and 2005 were used, from which we selected all 32,014 respondents aged 16-65 years. Figure 1 shows the timeline of the interventions. Respondents with paid work were exposed to the following interventions: the workplace-smoking ban from 1 January 2004 to 1 February 2004 $(n=601)$, the workplace-smoking ban and the first tax increase from 1 February 2004 to 1 January $2005(n=8,427)$, and the workplace-smoking ban and the first and second tax increase from 1 January 2005 to 31 December $2005(n=8,908)$. Those without paid work were not exposed to an intervention until February $2004(n=1,825)$, they were exposed to the first tax increase from 1 February 2004 to 1 January 2005 ( $n=1,521$ ), and to the first and second tax increases from 1 January 2005 to 31 December 2005 $(n=1,518)$.

\subsubsection{Characteristics of the participants}

Table 1 presents the main socio-demographic characteristics of those with and without paid work. There were significant $(p<0.001)$ differences in gender, age and level of education, when we compared the group of the respondents with paid work with the group without paid work. 
Table 1: Characteristics of the respondents (percentages).

\begin{tabular}{lll}
\hline & $\begin{array}{l}\text { With paid work } \\
\mathrm{n}=27,150\end{array}$ & $\begin{array}{l}\text { Without paid work } \\
\mathrm{n}=4,864\end{array}$ \\
\hline $\begin{array}{ll}\text { Gender } \\
\text { Male }\end{array}$ & 54.7 & 12.3 \\
$\quad$ Female & 45.3 & 87.7 \\
Age group in years & & \\
16-29 & 19.6 & 24.1 \\
$30-49$ & 59.5 & 38.1 \\
50-65 & 20.8 & 37.8 \\
Education level & & \\
Low & 31.5 & 52.5 \\
Middle & 39.8 & 34.4 \\
High & 28.7 & 13.1 \\
\hline
\end{tabular}

\subsubsection{Measurements}

Whether respondents had paid work was assessed by verifying whether their income was derived from paid employment. The outcome measures were intensity of smoking, whether a person made a quit attempt last month and whether a person was a daily smoker. The intensity of smoking was measured by the number of cigarettes per day per smoker. Smoking prevalence was calculated as the percentage of respondents who smoked daily. The variables gender (male, female), age (16-29, 30-49, 50-65 years), educational level (low, middle, high) and number of hours with paid work per week (1-14, 15 hours or more) were measured with direct questions. The variable 'New Year' effect was created by identifying the respondents interviewed in January 2003, 2004 and 2005. The various interventions are operationalized by making dummy variables for the different time intervals, each corresponding to a different set of interventions to which the respondents were exposed (Fig. 1). For employees we made three 'time interval dummies': January 2004 (ban); February 2004 till January 2005 (first tax increase) and 2005 (second tax increase). For non-employees we made two 'time interval dummies': February 2004 till January 2005 (first tax increase) and 2005 (second tax increase). 
Figure 1: Respondents with and without paid work and exposure to interventions.

\begin{tabular}{|c|c|c|c|c|}
\hline Year & 2003 & \multicolumn{2}{|l|}{2004} & 2005 \\
\hline \multirow{4}{*}{$\begin{array}{l}\text { Type of } \\
\text { Intervention }\end{array}$} & \multirow{4}{*}{ No intervention (0) } & \multicolumn{2}{|c|}{ January 1} & January 1 \\
\hline & & \multicolumn{2}{|c|}{ Workplace-smoking ban (1) } & Tax increase (3) \\
\hline & & \multicolumn{3}{|c|}{ February 1} \\
\hline & & \multicolumn{3}{|c|}{ Tax increase (2) } \\
\hline Paid work & (0) & (1) & $(1,2)$ & $(1,2,3)$ \\
\hline$n=27,150$ & $n=9,214$ & $n=601$ & $n=8,427$ & $n=8,908$ \\
\hline No paid work & (0) & & (2) & $(2,3)$ \\
\hline$n=4,864$ & $n=1,825$ & & $\mathrm{n}=1,521$ & $\mathrm{n}=1,518$ \\
\hline
\end{tabular}

\subsubsection{Statistical analysis}

The analyses were stratified for those with $(n=27,150)$ and without $(n=4,864)$ paid work. These categories differ in the measures to which they were exposed, as those not working could not have experienced the workplace-smoking ban. The design of the study implies that, in the period after the workplace-smoking ban, the 'measures' are no longer comparable. For those who are working, the effects of the measure 'first tax increase' are in fact the effects of a tax increase in combination with the workplace smoking ban, while for those without work the effects represent the effects of the tax increase only.

For the two categories of respondents chi-square tests were used to assess differences between baseline and post-intervention measurements in the proportion of respondents that reported to smoke daily and that reported a quit attempt. T-tests were used to assess differences between baseline and post-intervention measurements in the number of cigarettes per smoker per day.

To check whether the analysis of the impact of the measures should be controlled for a variable capturing trends over time, we used the 2003 data. A linear regression (number of cigarettes) or logistic regression analysis (daily smoking and quit attempts) with the month of the year 2003 as independent variable and gender, age, education and New Year as control variables was conducted to detect a possible trend over the 12 months of 2003 . However, neither in the total population, nor separately for those with and without paid work, was a trend found for the smoking prevalence, the proportion of quitters or the number of cigarettes smoked.

Multiple linear and logistic regression analyses were used to analyze the effect of the measures on, respectively, the number of cigarettes per day (among smokers), the proportion of quitters and the proportion of daily smokers, controlling for gender, age, level of education and weekly working hours (only for those who worked) and the 'New Year' effect. Each of the outcome measures were regressed on the variable type 
of intervention. For those with paid work the measures were represented by three dummies (implementation of the ban; implementation of the ban and the first tax increase; and implementation of the ban and first and second tax increase). For those without paid work two dummies (first tax increase; and both the first and second tax increase) were used. Furthermore, we tested for interaction effects between the various interventions and covariates (except for the 'New Year' variable), on each of the outcome variables. We examined all regression analyses for multicollinearity by inspecting the variance inflation factors. The variance inflation factors were between 1.0 and 1.4, indicating no high multi collinearity, By calculating Cook's distance for each subject, all analyses were checked for influential observations. Whenever necessary, analyses were redone after deleting subjects with a Cook's distance larger than 1.

For all analyses, a significance level of $p<0.05$ was used. Data were analyzed using SPSS 15.0 for Windows.

\section{$5.3 \quad$ Results}

\subsubsection{Intensity of smoking}

Among smokers with paid work, the average number of cigarettes decreased from 15.0 cigarettes per day before the interventions to 13.8 cigarettes per day $(p=0.09)$ after implementation of the workplace-smoking ban and to 14.2 cigarettes per day $(p=0.002)$ after the ban and the two tax increases. Among smokers without paid work there were no significant changes in the number of cigarettes per day before the interventions (14.7) and after the two tax increases (14.9). If we combine the decrease in intensity of smoking with the decrease in prevalence of smoking after the ban and the two tax increases (see below), we estimate that the total cigarette consumption among the employed ( $n=27,150$ ) is reduced from 111,994 to 93,684 cigarettes a day, which is a $16.3 \%$ reduction in total cigarette consumption. For those without paid work $(n=4,864)$ we estimate a reduction from 15.158 to 14.495 cigarettes a day, which is a $4.4 \%$ reduction in total cigarette consumption. 
Table 2: Linear regression of the number of cigarettes per day for smoking respondents with and without paid work.

\begin{tabular}{|c|c|c|}
\hline Variable & $\begin{array}{l}\text { Paid work } \\
ß[95 \% \mathrm{Cl}] \\
n=7,334\end{array}$ & $\begin{array}{l}\text { Without paid work } \\
B[95 \% \mathrm{Cl}] \\
n=1,018\end{array}$ \\
\hline Constant & $14.65[13.69-15.61]$ & 13.09 [11.18 - 14.99] \\
\hline Intervention ( $0=$ no interventions / $1=$ the ban) & $-1.28[-2.82-0.26]$ n.s. & \\
\hline Intervention ( $0=$ no interventions $/ 1=$ the ban and first tax increase) & $-0.53[-1.04--0.03] *$ & \\
\hline Intervention ( $0=$ no interventions $/ 1=$ the ban and two tax increases) & $-0.85[-1.33--0.37] * *$ & \\
\hline Intervention ( $0=$ no interventions / $1=$ first tax increase) & & $0.29[-1.12-1.70]$ n.s. \\
\hline Intervention ( $0=$ no interventions / $1=$ two tax increases) & & $0.34[-0.94-1.62]$ n.s. \\
\hline 'New year variable' ( $0=$ other months / $1=$ month January) & $-0.12[-0.69-0.93]$ n.s. & $-1.08[-3.04-0.89]$ n.s. \\
\hline Gender ( $0=$ male $/ 1=$ female) & $-0.77[-1.19--0.35] * * *$ & $0.52[-1.29-2.34]$ n.s. \\
\hline Age group in years $(0=16-29 / 1=30-49 / 2=50-65)$ & $1.67[1.33-2.00]^{* * *}$ & $2.05[1.22-2.88]^{* * *}$ \\
\hline Education ( $0=$ low $/ 1=$ middle $/ 2=$ high $)$ & $-1.94[-2.22--1.67] * * *$ & $-2.19[-3.11-1.27] * * *$ \\
\hline Hours paid work per week ( $0=1-14$ hours $/ 1=\geq 15$ hours) & $0.65[-0.15-0.93]$ n.s. & \\
\hline & F-overall $49.25 * * *$ & F-overall $11.75 * * *$ \\
\hline
\end{tabular}

$* \mathrm{p}<0.05, * * \mathrm{p}<0.01, * * * \mathrm{p}<0.001$, n.s. $=$ non-significant

Table 2 shows the results of the multiple linear regression analysis for smokers with and without paid work. For respondents with paid work only the effect of the smoking ban was not significant. The effects of the first and second tax increases, implemented after the workplace-smoking ban, were significant. It is important to note that the number of respondents interviewed in the month during which the smoking ban only (without additional tax increases) was in force (i.e. January 2004) is much smaller than the number of respondents exposed to both the ban and the tax increase(s). This probably explains why, despite a relatively strong effect of the ban [-1.28 cigarettes per smoker per day], this effect is not significant, whereas the effects of both tax increases $[-0.53 ;-0.85]$ are significant. Furthermore, there were significant differences in the number of cigarettes smoked according to gender, age and education. Women smoked less cigarettes than men [-0.77] and the youngest age group (16-29 years) smoked less cigarettes compared to those aged 30-49 [-1.67] and 50-65 years [-3.34]. Lower educated employees smoked more cigarettes than the middle [1.94] and higher educated employees [3.88]. Analysis of interactions of the different interventions with the relevant factors showed no significant interaction, indicating that subpopulations did not differ in the effect of the interventions. 
Among respondents without paid work there were no significant effects of the tax increases on the number of cigarettes per smoker per day. Because the statistical power for those without paid work is much smaller, it is informative to examine the estimated effect sizes of the tax increases. It appears that these are estimated to be opposite and smaller than for those with work, for the first (0.29 vs -0.53$)$ and second (0.34 vs -0.85$)$ tax increase. The effects of age and education are similar to the effects for those with paid work. Analysis of interactions of the two tax increases with the relevant covariates did not reveal any significant interactions.

\subsubsection{Quit attempts}

Among those with and without paid work there were no significant changes in the percentage of quit attempts. Among those with paid work the percentage of smokers who made an attempt to quit was $1.0 \%$ in the period before the ban and tax increases, and $1.2 \%$ afterwards. In the short period after the implementation of the ban but before the tax increases (i.e. January 2004), the percentage of smokers trying to quit was significantly larger: $5.0 \%(p<0.001)$. Among those without paid work the percentage of smokers making an attempt to quit was $1.3 \%$ before and $0.3 \%$ after both tax increases.

The results of logistic regression analyses showed an acceptable fit of the model to the data: the Hosmer and Lemeshow tests for those with and without paid work were respectively $\chi^{2}(d f=8)=2.725(p=0.95)$ and $\chi^{2}(d f=8)=2.943(p=0.94)$. When controlling for the covariates, the effects of the interventions were not significant among those with or without paid work. For those with paid work associations were found between quit attempts and the period after New Year, number of working hours, and age. Smokers were more likely to attempt to quit smoking in the month after New Year [OR 2.67]. This explains the relatively high percentage of quitters as reported above in the univariate analysis for January 2004. Smokers working more than 15 hours a week were less likely to quit smoking [OR 0.45] and older smokers were also less likely to quit smoking [OR 0.69]. There were no significant differences in quit attempts according to gender or education. Analysis of interaction effects did not reveal any significant interaction.

Among those without paid work none of the covariates were significantly associated with attempts to quit. Removal of a subject without paid work having a Cook's distance clearly larger than 1 , yielded very similar results.

\subsubsection{Prevalence of smoking}

Among those with paid work the percentage of daily smokers decreased from $27.5 \%$ before implementation of the ban and both tax increases to $25.5 \%$ (n.s.) after implementation of the ban and to $24.3 \%(p<0.001)$ after all interventions. Among those 
without paid work the proportion of daily smokers showed no significant change after the interventions: before the interventions $21.2 \%$ were daily smokers compared with $20.0 \%$ after the tax increases. If we examine the prevalence of incidental smokers, we find no significant changes. Among those with paid work, the percentage of incidental smokers was 5.6\% (before the ban), 6.0\% (after the ban) and 5.6\% (after both tax increases). Among those without paid work we found a non-significant decrease from $3.5 \%$ before the tax increases to $2.5 \%$ after both tax increases.

Table 3: Logistic regression of prevalence of daily smoking for respondents with and without paid work.

\begin{tabular}{|c|c|c|}
\hline Variable & $\begin{array}{l}\text { Paid work } \\
\text { OR [95\% Cl] } \\
n=27,067\end{array}$ & $\begin{array}{l}\text { Without paid work } \\
\text { OR }[95 \% \mathrm{Cl}] \\
\mathrm{n}=4,840\end{array}$ \\
\hline Intervention ( $0=$ no interventions / $1=$ the ban) & $0.87[0.70-1.08]$ n.s. & \\
\hline Intervention ( $0=$ no interventions $/ 1=$ the ban and first tax increase) & $0.86[0.80-0.92] * * *$ & \\
\hline Intervention ( $0=$ no interventions $/ 1=$ the ban and two tax increases) & $0.85[0.80-0.91] * * *$ & $-2.19[-3.11-1.27]^{* * *}$ \\
\hline Intervention ( $0=$ no interventions / 1=first tax increase) & & $0.87[0.73-1.04]$ n.s. \\
\hline Intervention ( $0=$ no interventions / 1=two tax increases) & & $0.94[0.79-1.12]$ n.s. \\
\hline 'New year variable' ( $0=$ other months / 1=month January) & $1.04[0.93-1.17]$ n.s. & $0.93[0.71-1.20]$ n.s. \\
\hline Gender $(0=$ male $/ 1=$ female $)$ & $0.88[0.83-0.93] * * *$ & $1.11[0.86-1.42]$ n.s. \\
\hline Age group in years $(0=16-29 / 1=30-49 / 2=50-65)$ & $0.87[0.85-0.93] * * *$ & $0.84[0.75-0.93] * *$ \\
\hline Education ( $0=$ low $/ 1=$ middle $/ 2=$ high) & $0.59[0.57-0.61] * * *$ & $0.54[0.48-0.61] * * *$ \\
\hline Hours paid work per week ( $0=1-14$ hours / $1=\geq 15$ hours) & $1.34[1.20-1.49] * * *$ & \\
\hline & $\begin{array}{l}-2 \text { log likelihood ratio } \\
879.616 * * *\end{array}$ & $\begin{array}{l}-2 \text { log likelihood ratio } \\
114.057 * * *\end{array}$ \\
\hline
\end{tabular}

$* \mathrm{p}<0.05, * * \mathrm{p}<0.01, * * * \mathrm{p}<0.001$, n.s. $=$ non-significant

We conducted multiple logistic regression to establish the effect of the different interventions on daily smoking for those with and without paid work. The analysis models showed a reasonable fit to the data for those with paid work but less for those without paid work. Hosmer and Lemeshow tests for those with and without paid work were respectively $\chi^{2}(d f=8)=13.994(p=0.82)$ and $\chi^{2}(d f=8)=41.015(p<0.01)$. All Cook's distances however were clearly smaller than 1 . Table 3 shows that for paid workers there was no significant change [OR 0.87] in the likelihood of daily smoking among the respondents interviewed in the one month (January 2004) in which the ban without additional tax increases was in force, although the odds ratio was similar to the other interventions. The effects of the first [OR 0.86] and second tax increase [OR 0.85] after the 
ban on daily smoking were significant and in the expected direction. Gender, age, education and hours of paid work per week are related to daily smoking. The likelihood of daily smoking was lower among females [OR 0.88], among the older age groups compared with the younger age groups [OR 0.87], and among the higher educated group compared with the lower educated group [OR 0.59]. For those with more than 15 hours a week paid work a higher likelihood [OR 1.34] was found. No significant interactions were found between the different interventions and the covariates, indicating no differences in intervention effects between the paid workers.

Among those without paid work the tax increases had no significant effect on the likelihood of daily smoking. However, in terms of effect size, there was little difference between those with and without paid work in the effect of the first [OR 0.86 vs. OR 0.87 ] and second [OR 0.85 vs. OR 0.94] tax increase. For the other factors the likelihood of daily smoking was related to age and education. Older and higher educated respondents were less likely to be daily smokers [OR 0.84 and OR 0.54 , respectively]. Analysis of interactions showed no significant intervention effects.

\subsection{Discussion}

The combination of government policies was expected to influence tobacco smoking. For those with paid work the workplace-smoking ban and the two tax increases indeed resulted in a decrease in the number of cigarettes smoked per day and in the prevalence of daily smoking. There were no changes in the prevalence of incidental smoking among workers with or without paid work. For those without work no significant effect of the tax increases was found. For both groups no interaction effects between the interventions on the one hand and gender, age, level of education and working hours on the other were found.

We first discuss the findings related to the influence of the workplace-smoking ban and then discuss the influence of tax increases.

One could argue that, because the effect of the smoking ban alone was not significant, the workplace-smoking ban had no influence on respondents with paid work. However, the very short period (only one month) in which only the smoking ban was in force implies that very few respondents were available to evaluate the effect of this single measure. If we also consider the effect size it appears that the OR for the smoking ban for daily smoking [0.87] was comparable to that for the tax increases [0.86; 0.85]. The effect of the workplace-smoking ban on smoking intensity [-1.28] is estimated to have more than twice the effect of the first tax increase [-0.53]. The effect sizes indicate that the non-significance may have been due to the lack of statistical power. Moreover, one can safely assume that the effect of the workplace-smoking ban lasts 
longer than the one month during which it was the sole measure implemented. Therefore, the influence of the workplace-smoking ban is likely to be incorporated in the effects found for the first and second tax increase.

Although the lack of significance for the workplace-smoking ban may be due to too low statistical power, the effect size of the workplace-smoking ban is smaller than effect sizes found in other studies reporting on a workplace-smoking ban only. Review studies on workplace-smoking ban report a reduction in the number of cigarettes per day ranging from 3.5 [Chapman et al. 1999] or 3.2 [Fichtenberg \& Glantz, 2002 ${ }^{\mathrm{b}}$ ] to 1.2 cigarettes [Hopkins et al., 2001]. A recent WHO study, and European studies, reported a decrease in cigarette use of 2-4 cigarettes per day and concluded that there is strong evidence that smoke-free workplaces decrease the prevalence of smoking [Pierce \& León 2008; IARC, 2009]. These are larger reductions than we found for the workplacesmoking ban (1.2 cigarettes a day). Similarly, the reduction in prevalence of the daily smoking (2.0 percentage points) after the smoking ban is smaller compared with reductions reported for a workplace-smoking ban only in review studies: 5 percentage points [Brownson et al., 1997], 5-5.6 percentage points [Chapman et al., 1999], 3.8 percentage points [Fichtenberg \& Glantz, 2002 ${ }^{\mathrm{b}}$ ], and 1.4-11.4 percentage points [Hopkins et al., 2001]. Most studies on the effect of a workplace-smoking ban had a followup of up to one year [Fichtenberg \& Glantz, $2002^{\text {b }}$; Brownson et al., 1997]. Studies with a longer follow-up show mixed results. During a 4-year follow-up Heloma et al. (2003) found that the effect increased over time, Fichtenberg et al. $\left(2002^{b}\right)$ found in their review that the effects remained stable over time (range 1-24 months), while the review of Brownson et al. (1997) indicated that there might be reductions in the size of the effect over time. The relatively small effect sizes found in the present study may be due to the very short measurement period (1 month). Another reason why the effect of the ban was relatively small is related to limitations of the workplace-smoking ban in the Netherlands. Not only were employees in restaurants, pubs, bars and discotheques excluded from this ban, but employers were also permitted to offer designated smoking rooms at work thereby reducing the potential effect of the workplace-smoking ban on the total tobacco consumption and smoking cessation [Levy et al., 2004, Fichtenberg \& Glantz, $2002^{b}$ ].

The effect of tax increases among employees in our study is somewhat larger than in most other studies. This is perhaps best clarified by comparing the price elasticity in our study, based on the combined effect of the ban and tax increases, with that of other studies. We estimate a $16.3 \%$ decrease in total tobacco consumption (prevalence, and number of cigarettes of smokers) per $24 \%$ tax increase, which corresponds to a $6.8 \%$ decrease in consumption per $10 \%$ price increase. Review studies have indicated that a $10 \%$ increase in tobacco product prices results in a $4 \%$ [Fichtenberg \& 
Glantz, 2002 ${ }^{\mathrm{b}}$ ], 4.1\% [Hopkins et al., 2001], 3-5\% [Levy et al., 2004] or 4.3\% [Gallus, Schiaffino, Vecchia 2006] decrease in tobacco consumption in the general population. In the present study, the effects of the tax increase are estimated to be higher than those found in other studies. Our interpretation is that this is largely due to the fact that the tax increases are combined with a workplace-smoking ban. Therefore, our results seem to support the conclusions from studies in the USA [Emont et al, 1993] and Canada [Stephens et al, 1997, 2001] that a combination of measures focusing on clean indoor air and price of tobacco is likely to result in greater effects than each of these measures separately.

For respondents without paid work we did not find significant effects of the tax increases on prevalence of smoking, the number of cigarettes of smokers per day and the proportion of quitters. The relatively small number of those without paid work implies a relatively low statistical power. In the analysis of the prevalence of smoking, the OR for tax increases found for those with and without work showed hardly any difference. However, in the analysis of the number of cigarettes among smokers it appeared that the effect of the tax increases estimated for those without work was opposite to the effect estimated for those with work. We also estimated the price elasticity among those who had no paid work and found that the tax increase of $24 \%$ was associated with a $4.4 \%$ decrease in cigarette consumption. This means a $1.8 \%$ decrease in consumption per $10 \%$ price increase. This is much lower than estimated for those with paid work (6.8\%). All in all, we think it is safe to conclude that the two tax increases had little to no effect on the tobacco consumption of those without work.

This lack of effect among those without paid work may seem in sharp contrast to studies indicating that in the lower strata the effect of tax measures tend to be stronger [Gallus et al., 2006; Joossens \& Raw 2006, Thomas et al., 2008; Townsend et al., 1994]. However, despite that more than $50 \%$ of those without paid work have a low level education (Table 1), it would be wrong to assume that the non-working population in the present study is homogeneous in terms of social stratification. In the present study, those without paid work represent $36 \%$ of the total population, of which only $4 \%$ is unemployed and seeking work and $32 \%$ is economically inactive in very diverse ways, e.g. (full-time) students, housewives, early retirement, disability pension, etc. [CBS Statline, 2009]. For the majority in this economically inactive group, having no paid work does not mean that they are 'poor' or belong to the lower strata. Therefore our non-working population is possibly more heterogeneous compared to the lower strata as distinguished in other studies. Some subpopulations (e.g. those living on welfare only) may well be very responsive to tax increases, whereas other subpopulations (e.g. women with a large family income who choose not to have paid work) might be less responsive to such increases. 
In general, the prevalence of smoking in the category without work $(21.1 \%$ vs $27.5 \%$ among the working) is much lower than among those with paid work. This relatively low prevalence may explain some of the lack of responsiveness to price measures.

The strength of this population-based study is the large number of respondents $(n=32,014)$, which allowed to differentiate the effect of measures among those with and without paid work. Also, by continuously measuring samples over a 3-year period the main outcomes are less influenced by seasonal variations and indicate the effect of measures over a period of one year or longer. In addition, we could control for several variables that are relatively strongly correlated with differences in smoking.

There are also a number of limitations. One of the limitations concerns the possible lack of representativeness of the Internet sampling frame used. In the Netherlands the proportion of people with access to Internet in 2005 is relatively high (83\%). Among those without work internet access is lower (66\%) than among those with paid work (90\%). However, there is very little difference in financial reasons as a cause for no internet connection between those with (1\%) and without work (5\%) [CBS Statline, 2010]. Although the inclusion of the non-working in the internet sample is less optimal than those who have paid work, there are no indications that this has led to a strong under representation among those not working of persons more responsive to tax measures. Furthermore, a study comparing estimates of substance use based on an Internet sample and a sample drawn from the general population register (covering $>98 \%$ of the inhabitants) shows that Internet samples tend to overestimate the prevalence of substance use (Spijkerman et al., 2009). Applied to the present study this might mean that the proportion of daily smokers and the amount of cigarettes were overestimated. However, if this is the case, this will probably apply both before and after implementation of the different interventions. Therefore, the change in the outcome measures is probably a valid indication of the effect of the interventions applied.

Another limitation is that we have not been able to control for substitution, e.g., people selecting cheaper brands or cheaper types of cigarettes (e.g. hand-rolled instead of factory-made cigarettes) and the effect of inflation. Concerning substitution, most likely some of the smokers switched to cheaper brands/cigarettes. However, the effect of this may have been limited because the last tax increase of $4 \%$ was exclusively aimed at increasing the minimum price of the cheaper brands and cigarettes. Concerning the effect of inflation, the effect sizes of the tax increases might have been smaller had we been able to control for inflation. However, in the Netherlands, the price increases of cigarettes exceed the level of inflation, implying that at least some effects of the tax increases could have been expected.

Finally, we like to emphasize, that the very short period of one month, in which the workplace-smoking ban was in force as only measure, limits the possibility to exa- 
mine the effect of this measure among respondents with paid work. The effects we found among those with paid work in the long run are probably the combined effect of the workplace-smoking ban and tax-increases. 



\section{CHAPTER 6}

\section{The tobacco sales ban and tobacco purchases by adolescents: a general population study in the Netherlands}

Published as:

Verdonk-Kleinjan W.M., Knibbe R.A., Bieleman B., de Groot H.N. \& de Vries H. (2008). The tobacco sales ban and tobacco purchases by adolescents: A general population study in the Netherlands. European Journal of Public Health, 18(5), 498-503. 


\section{Abstract}

\section{Background}

The study aimed to assess the effect of the introduction on January 12003 of a legal tobacco sales ban in the Netherlands on tobacco purchasers by smoking and nonsmoking adolescents aged younger than 16 years.

\section{Methods}

Two cross-sectional surveys were conducted among adolescents aged 13 through 15 years, one at end $1999(n=4,751)$ and the other at end $2003(n=13,298)$.

\section{Results}

The percentage of adolescents buying tobacco decreased significantly from $26.3 \%$ in 1999 to $10.8 \%$ in 2003 ( $p<0.001$ ). Further analysis showed that, after the ban, the proportion of smokers among buyers almost tripled (O.R. 2.9), while the likelihood of nonsmokers buying tobacco decreased strongly (O.R. 0.17). A difference in the pattern of purchasing tobacco also emerged after the ban. In 2003 the proportion of smokers buying at least weekly in commercial outlets was larger than in 1999. For non-smokers there was no difference between 1999 and 2003 in the proportion buying weekly. The variety of commercial outlets in which purchases were made increased among both smoking and non-smoking purchasers of tobacco.

\section{Conclusions}

Implementation of the 2003 tobacco sales ban has had the (intended) effect of lowering tobacco purchases among adolescents. This was mainly due to the decrease in the likelihood of buying tobacco among those who regard themselves as a non-smoker. The decrease in buying tobacco is associated with a decrease in prevalence of smoking. The sales ban has probably contributed to a stronger decrease in prevalence of smoking. 


\subsection{Introduction}

Selling tobacco to adolescents is prohibited by law in most Western countries [Shafey, Dolwick \& Guindon, 2003], thus discouraging smoking (onset). Up to 2003, the Netherlands was one of the few European countries without a legislative tobacco sales ban for adolescents [Staatsblad van het Koninkrijk der Nederlanden, 2002]. The need to discourage smoking among adolescents in the Netherlands is high because $52 \%$ of schoolchildren report to start smoking by the age of 15 years or younger and $28 \%$ report daily smoking by the age of 16 years or younger [Monshouwer, Dorsselaer van, Gorter, Verdurmen \& Vollebergh, 2004]. This study aims to assess the effect of the introduction of a legal tobacco sales ban in the Netherlands for adolescents younger than 16 years, on tobacco purchasing among adolescents aged 13 through 15 years.

Most studies on the effects of a ban on tobacco sales to adolescents have been conducted in the USA and Australia [Lantz et al., 2000; Stead \& Lancaster, 2005]. Comparable studies in Europe have only been conducted in the UK, Finland and Sweden [Bagott, Jordan, Wright \& Jarvis, 1998; Naidoo \& Platts, 1985; Ogilvie, Gruer \& Haw, 2005; Rimpelä \& Rainio, 2004; Sundh \& Hagquist, 2004]. Generally, these studies do not explore the (possible) effect of a new or changed law, but the effect of an intervention in the context of a (existing) law to improve the compliance of tobacco retailers and/or adolescents [Lantz et al., 2000; Stead \& Lancaster, 2005]. The main conclusions from those studies are that interventions based on enforcement or on community interventions tend to be more effective than simply providing information [Lantz et al., 2000; Stead \& Lancaster, 2005; Jacobson, Wasserman \& Anderson, 1997]. The combination of enforcement of the sales ban among retailers with fines for young adolescents in possession of tobacco is possibly even more effective [Stead \& Lancaster, 2005; Mosher 1995; Jason, Pokorny, Muldowney \& Velez, 2005]. A few studies have investigated the implementation of a new or changed law: Rimpelä and Rainio (2004) found a significant decrease in the percentage of smoking adolescents who buy tobacco themselves in regular outlets and a significant increase in other points of sale, Sundh and Hagquist (2004) found that it was more difficult to purchase tobacco, and Hinds (1992) found no significant change in the number of purchasers in stores and vending machines, but found that the use of friends as a source had increased significantly.

With the introduction of the sales ban in the Netherlands in 2003, the Netherlands Food and Consumer Safety Authority - Nederlandse Voedsel en Warenautoriteit (NVWA) became legally liable to check compliance with the tobacco sales ban. Inspectors anonymously observed commercial outlets which adolescents use, to control for compliance, i.e. selling to minors without asking for their identification. In addition, the 
Tobacco Points of Sale Platform provided tobacco retailers with information about the tobacco sales ban.

This study explores the effects of implementing the 2003 tobacco sales ban on the purchasing behaviour in smoking and non-smoking adolescents aged 13 through 15 years. In contrast to most other studies, the current study not only explores the effect of the new law on smokers and how they may get tobacco, but also includes nonsmokers when studying overall purchasing behaviour [Stead \& Lancaster, 2005; Rimpelä \& Rainio, 2004; Hinds, 1992; Cummings, Sciandra, Peckacek, Orlandi \& Lynn 1992]. The main aim was to establish the effect of the tobacco sales ban on the likelihood of buying tobacco, and the composition of the category of buyers in terms of gender, age and smoking status [Rimpelä \& Rainio, 2004, Forster \& Wolfson, 1998; Bieleman \& Kruize, 2003]. The second aim was to determine whether those 13-15 year old adolescents who purchased tobacco after the ban differ in purchasing pattern from those buying tobacco before the sales ban. The two aspects of purchasing included here are the frequency of buying tobacco at commercial outlets, and the distribution of purchases over different types of commercial outlets [Stead \& Lancaster, 2005; Rimpelä \& Rainio, 2004; Castrucci, Gerlach, Kaufman \& Orleans, 2002; Jones, Sharp, Husten \& Crossett, 2002; DiFranza \& Coleman 2001; DiFranza 2003].

\subsection{Methods}

\subsubsection{Respondents}

Two cross-sectional studies were carried out, one before implementation of the tobacco sales ban in 1999 and another 11 months after implementation of the tobacco sales ban in 2003. Telephone interviews lasting 10-15 minutes were held among samples of adolescents aged 13 through 15 years [Bieleman \& Kruize, 2004; Spijkers, Laan van der \& Bieleman, 1999]. The sampling frame was a large database [Wegener, 2004] of more than 4 million households for which the age of the adolescents living at home was known. After selecting the households with children aged 13-15 years, random samples of adolescents in these age groups were approached a maximum of five times to participate in a telephone interview. Response rates in 1999 and in 2003 (81\% and $83 \%$, respectively) were very similar (table 1 ). In both survey years the fieldwork took place in November and December. For the 2003 survey this means that the new law had been in effect for 11 to 12 months. It is important to note that the sample was disproportionately stratified with the purpose to interview 400 tobacco-purchasing adolescents in each age category (table 1). This disproportionate sampling means (among other things) that prevalence figures for both buying and smoking cannot be generalized directly to the general population of 13-15 year olds in 1999 and 2003. 
Table 1: Number of respondents and number of tobacco buyers by age.

\begin{tabular}{|c|c|c|c|c|c|c|c|c|}
\hline & \multicolumn{2}{|l|}{13 year } & \multicolumn{2}{|l|}{14 year } & \multicolumn{2}{|l|}{15 year } & \multicolumn{2}{|l|}{ total } \\
\hline & $\begin{array}{l}1999 \\
\text { n (\%) }\end{array}$ & $\begin{array}{l}2003 \\
\text { n (\%) }\end{array}$ & $\begin{array}{l}1999 \\
\text { n (\%) }\end{array}$ & $\begin{array}{l}2003 \\
\text { n (\%) }\end{array}$ & $\begin{array}{l}1999 \\
\text { n (\%) }\end{array}$ & $\begin{array}{l}2003 \\
\text { n (\%) }\end{array}$ & $\begin{array}{l}1999 \\
\text { n (\%) }\end{array}$ & $\begin{array}{l}2003 \\
\text { n (\%) }\end{array}$ \\
\hline Sampling & 1704 & 6461 & 1729 & 4452 & 1318 & 2385 & 4751 & 13298 \\
\hline Respondents & $1397(82)$ & 4906 (76) & $1463(85)$ & 3771 (85) & $1003(76)$ & 2304 (76) & $3863(81)$ & $10981(83)$ \\
\hline Tobacco buyers ${ }^{\text {a) }}$ & $289(21)$ & $235(5)$ & $345(24)$ & 381 (10) & 349 (35) & $411(35)$ & $983(25)$ & $1027(9)$ \\
\hline
\end{tabular}

${ }^{\text {a) }}$ Purchasing for themselves and/or for others

All respondents are used in the analyses of the effect of the new law on the likelihood of purchasing tobacco. In the analysis of changes in purchasing behaviour among buyers, only tobacco buyers are included (1999: $n=983 ; 2003: n=1,027)$

\subsubsection{Questionnaire}

Age and gender were measured by direct questions. The single question "Do you smoke?" (Yes/No) was used to determine smoking status. Purchasing behaviour was measured with two questions: "Do you ever buy tobacco to smoke yourself?" (Yes/No) and the following question for those who answered "No" was: "Do you ever buy tobacco for others?" (Yes/No). When one of the two questions about purchasing was answered positively, specific questions were asked about the frequency of buying, and the types of outlets where they make their purchases. In 1999 the answers regarding the frequency of buying were reported in terms of the number of times in the past year. In 2003 the answers were reported according to the four categories 'Never', 'Less than once per month', '1-3 times per month' and 'Once or more times per week'. To make the answers comparable we recoded the 1999 answers 0 into 'never', 1-11 times into 'less than once a month', 12-36 times into '1-3 times per month' and $\geq 37$ times into 'once a week or more often'. The last category is not completely comparable with the 'once or more times a week' used in 2003. Closer inspection of the 1999 data showed that on an average only very few respondents ( $n=26 ; 2.6 \%)$ gave 37-51 times a year as an answer in 1999. Therefore the 1999 estimate of the proportion buying once a week might be somewhat overestimated.

The distribution of purchases over types of outlets was calculated by adding up the answers to the four questions about having bought tobacco at the tobacconist, petrol stations, supermarkets, bars and cafeterias. The survey year (before and after the 2003 sales ban) was used as indicator of the sales ban. 


\subsubsection{Statistical analysis}

Adolescents were classified into three groups: those who purchased tobacco for themselves; those who purchased tobacco for others; and those who did not purchase tobacco at all. The Chi-square test was used to analyse differences between 1999 and 2003 in the proportion buying tobacco for themselves, others, or not buying tobacco. Logistic regression was used to analyse the relation of the tobacco sales ban, smoking status, age and gender with the likelihood of purchasing tobacco. For this analysis purchasing tobacco was dichotomised into purchasing tobacco (for themselves or others), and not purchasing tobacco. The regression was performed backwards whereby all independent variables, as well as all interactions between the independent variables, on the likelihood of buying tobacco were tested for significance $(p<0.05)$. The Chi-square-test was used to analyse differences in the frequency of buying at commercial outlets between 1999 and 2003 and the t-test was used to analyse the average distribution of purchases over different type of commercial outlets between 1999 and 2003. All analyses were performed with the statistical program SPSS (version 13).

Table 2: Characteristics of respondents.

\begin{tabular}{|c|c|c|c|c|}
\hline & \multicolumn{2}{|c|}{ Respondents } & \multicolumn{2}{|l|}{ Purchasers } \\
\hline & $\begin{array}{l}1999 \\
(N=3,863)\end{array}$ & $\begin{array}{l}2003 \\
(N=10,981)\end{array}$ & $\begin{array}{l}1999 \\
(N=983)\end{array}$ & $\begin{array}{l}2003 \\
(N=1,027)\end{array}$ \\
\hline \multicolumn{5}{|l|}{ Gender } \\
\hline Boys (\%) & 51.3 & $53.4^{*}$ & 50.9 & $56.0^{*}$ \\
\hline Girls (\%) & 48.7 & $46.6^{*}$ & 49.1 & $44.0^{*}$ \\
\hline \multicolumn{5}{|l|}{ Age } \\
\hline 13 year (\%) & 36.2 & $44.7 * * *$ & 29.4 & $22.9 * *$ \\
\hline 14 year (\%) & 37.9 & $34.3 * * *$ & 35.1 & $37.1^{* *}$ \\
\hline 15 year (\%) & 26.0 & $21.0 * * *$ & 35.5 & $40.0^{* *}$ \\
\hline \multicolumn{5}{|l|}{ Smoking } \\
\hline Yes (\%) & 19.6 & $6.3 * * *$ & 49.8 & $56.8^{* *}$ \\
\hline No (\%) & 80.4 & $93.7 * * *$ & 50.2 & $43.2^{* *}$ \\
\hline \multicolumn{5}{|l|}{ Purchasing } \\
\hline Yes (\%) & 25.4 & $9.4 * * *$ & - & - \\
\hline No (\%) & 74.6 & $90.6 * * *$ & - & - \\
\hline
\end{tabular}

*P<0.05; ** $\mathrm{P}<0.01 ; * * * \mathrm{P}<0.001$ 


\subsection{Results}

\subsubsection{Description of the sample}

All respondents (1999 $n=3,863 ; 2003 n=10,981)$ were used to analyse the effect of the tobacco sales ban on the proportion of adolescents ( $<16$ years) who buy tobacco, and on the differential effects of this ban according to smoking status, age and gender.

Table 2 shows that the percentage buying tobacco decreased from $25.4 \%$ in 1999 to $9.4 \%$ in 2003; similarly, the percentage saying 'Yes' to the question 'Do you smoke' decreased from $19.6 \%$ to $6.3 \%$. However, due to the disproportionate sampling on 400 purchasers in each age group, the composition of the 1999 and 2003 sample in terms of age, and proportion of purchasers is slightly different; this means that the figures in table 2 on decrease in smoking and purchasing cannot be generalized to all 13 to 15 year-olds in the Netherlands. Census data of the National Bureau of Statistics were used to weigh the data for age. It appears that the proportion of purchasers among the $13-15$ year olds decreased from $26.3 \%$ in 1999 to $10.8 \%$ in 2003 . The age-weighted proportion of smokers decreased from $20.3 \%$ in 1999 to $7.4 \%$ in $2003(p<0.001)$.

Among the purchasers, the proportion of smokers increased significantly from $51.3 \%$ to $59.4 \%$. Surprisingly, however, in both years a considerable proportion of the purchasers consider themselves to be a non-smoker. If we analyse this for the smokers (data not shown), the proportion of smokers buying tobacco for themselves increased significantly from $66.5 \%$ in 1999 to $86.4 \%$ in 2003 ( $p<0.01)$. However, this increase in the proportion of smokers buying tobacco should be placed in the context of a sharp decrease in the prevalence of smoking. For the total population the proportion of smokers buying tobacco for themselves in 1999 was $13.5 \%$ which decreased to $6.4 \%$ in 2003.

\subsubsection{Likelihood of purchasing tobacco and the tobacco sales ban, smoking, age and gender}

To evaluate the effect of the smoking ban on size and composition of the category of buyers a multivariate logistic regression was done with purchasing behaviour (Yes/No) as dependent variable and survey year, age, gender, and smoking status as independent variables. We found a significant interaction effect of implementation of the ban with smoking status $(p<0.001)$ indicating that the influence of the ban on the likelihood of buying differed for smokers and non-smokers. Table 3 presents the outcomes of analyses for the smokers and the non-smokers showing that, after the ban, smokers were about 3 times (OR: 2.94) more likely to buy tobacco while non-smokers were far less likely (OR: 0.17) to buy tobacco. Both before and after the ban older smokers were more likely to purchase tobacco. Among the non-smoking buyers the interaction effect 
of the ban with age indicates that there was no age difference in the likelihood of buying before the ban; after the ban, however, older adolescents were more likely to buy tobacco. Reviewing these results in terms of composition of the category of buyers, it appears that the ban is associated with an increase in the proportion of smokers, and in the proportion of older non-smokers among buyers.

Table 3: Factors associated with purchasing tobacco by smokers and by non-smokers.

\begin{tabular}{|c|c|c|c|c|c|c|c|c|}
\hline \multirow[t]{2}{*}{ Variable } & \multicolumn{4}{|c|}{ Smokers ${ }^{\text {a) }}$} & \multicolumn{4}{|c|}{ Non-smokers ${ }^{b)}$} \\
\hline & $\beta$ & SE $\beta$ & OR $[95 \% \mathrm{Cl}]$ & $p$-value & $\beta$ & SE $\beta$ & OR [95\% Cl] & $\mathrm{p}$-value \\
\hline Legislation & 1.077 & 0.133 & $2.94[2.26-3.81]$ & $<0.001$ & -1.794 & 0.113 & $0.17[0.13-0.21]$ & $<0.001$ \\
\hline Age(13) & & & 1.00 & $<0.001$ & & & 1.00 & ns \\
\hline Age(14) & 0.493 & 0.156 & $1.64[1.21-2.22]$ & $<0,01$ & -0.173 & 0.114 & 0.84 [0.67-1.05] & ns \\
\hline Age(15) & 1.305 & 0.171 & $3.69[2.64-5.16]$ & $<0.001$ & 0.740 & 0.125 & 1.08 [0.84-1.37] & ns \\
\hline Age $(13) *$ legislation & & & & & & & 1.00 & $<0,001$ \\
\hline Age $(14) *$ legislation & & & & & 0.485 & 0.164 & $1.63[1.18-2.24]$ & $<0,01$ \\
\hline Age $(15) *$ legislation & & & & & 0.769 & 0.173 & 2.16 [1.54-3.03] & $<0,001$ \\
\hline Constant & -0.035 & 0.132 & 0.97 & ns & -1.624 & 0.077 & 0.20 & $<0,001$ \\
\hline
\end{tabular}

a) Smokers: $R^{2}=0,14^{\text {b) }}$ Non-smokers: $R^{2}=0,09$

\subsubsection{Changes in purchase patterns of tobacco in commercial outlets}

The second aim was to establish changes in purchasing patterns after the tobacco sales ban: i.e. the frequency of buying and the spread of purchases over various commercial outlets. There was a relatively large and systematic difference between smokers and non-smokers buying tobacco once a week or more often (table 4).

Table 4 shows that, compared with 1999, in 2003 the percentage of smokers buying once a week or more often has increased. For non-smoking adolescents the percentage buying once a week or more often is also somewhat higher in 2003 (differ-rence not significant). This pattern of non-significant differences in proportion of nonsmokers buying at least weekly and a significant increase in proportion of smokers buying at least weekly is also found in each age category $(13,14$ and 15 years) separately. 
Table 4: Proportion of purchasers buying tobacco weekly before (1999) and after (2003) the sales ban according to smoking status in different selling points.

\begin{tabular}{|c|c|c|c|c|c|c|}
\hline & \multicolumn{2}{|c|}{ Non-smokers } & \multicolumn{2}{|c|}{ Smokers } & \multicolumn{2}{|l|}{ Total } \\
\hline & $\begin{array}{l}1999 \\
n=494\end{array}$ & $\begin{array}{l}2003 \\
n=483\end{array}$ & $\begin{array}{l}1999 \\
n=521\end{array}$ & $\begin{array}{l}2003 \\
n=707\end{array}$ & $\begin{array}{l}1999 \\
n=1,015\end{array}$ & $\begin{array}{l}2003 \\
n=1,190\end{array}$ \\
\hline Tobacconist (\%) & 1.0 & 2.5 & 6.3 & $21.4^{*}$ & 3.7 & $13.7^{*}$ \\
\hline Petrol station (\%) & 1.2 & 1.9 & 6.3 & $16.4^{*}$ & 3.8 & $10.5^{*}$ \\
\hline Supermarket (\%) & 3.2 & 3.7 & 9.8 & $23.1^{*}$ & 6.6 & $15.2^{*}$ \\
\hline Bar/cafeteria (\%) & 1.0 & 0.4 & 3.3 & $15.6^{*}$ & 2.2 & $9.4^{*}$ \\
\hline
\end{tabular}

$* p<0.001$

The distribution of purchases over different outlets also increased significantly $(p<0.001)$ from 1.7 types of outlets in 1999 to 1.9 types in 2003. Among smokers the variety of outlets in which they bought tobacco was significantly higher both in 1999 (2.07 vs. 1.28) and 2003 (2.24 vs. 1.45). However, the differences between smokers and non-smokers were similar in 1999 (0.79) and 2003 (0.79).

\subsection{Discussion}

The present study explored the effect of the tobacco sales ban on the number of adolescents who purchase tobacco, on the composition of the category of purchasers in terms of smoking status and age, and on changes in frequency of buying and distribution of purchases over different types of outlets. There was a significant overall decrease from $26.3 \%$ to $10.8 \%$ in the proportion of $13-15$ year old adolescents buying tobacco. Surprisingly, the proportion of adolescents who purchased for others (rather than for themselves) was relatively high both before (48.7\%) and after (40.6\%) the tobacco sales ban. Furthermore, the ban had a differential effect on the likelihood of buying of both smokers and non-smokers. In 2003 the likelihood of non-smokers purchasing tobacco was much lower than in 1999. However, among smokers the likelihood of buying tobacco was higher in 2003 compared with 1999. The ban seems to have led to an increase in age differences in purchasing tobacco. The outcomes show that, after the ban, older non-smokers were more likely to buy tobacco. However, among smokers, the age differences in buying tobacco were similar before and after the ban. In 2003 the proportion of smokers buying tobacco at least weekly was significantly higher; this difference might be somewhat greater than shown in table 4 because the 1999 estimate of weekly buying might be slightly overestimated. Among non-smokers there was no increase in the proportion buying at least weekly. Also, in 2003 buyers of tobacco spread their purchases over more commercial outlets than in 
1999. In both 1999 and 2003 smokers use more types of outlets to buy their tobacco; however, the difference between smokers and non-smokers in the distribution of purchases over different types of outlets was the same in both years.

The rather large effect of the sales ban on the proportion of adolescents buying tobacco is probably partly due to how the law was introduced and enforced. Before the start of the ban all tobacco retailers were frequently informed about what was expected from them under the new law, how compliance with the new law would be inspected, and what fines to expect when not complying with the new law. The main element of the new law was that all young customers buying tobacco should be asked for identification before selling the tobacco. Inspection data show that, of the total 1347 inspections in 2003 in which young people were present as (potential) customer, in only $2 \%$ of the cases were fines given because the seller did not ask for identification [Tweede Kamer der Staten-Generaal, $2005^{c}$ ]. Also, those who controlled for compliance could themselves immediately fine the seller when observing that the retailer had failed to ask for identification. This is known to be more effective in promoting the compliance of sellers than having to report non-compliance to the local police or administration who may then decide to fine the seller [Rimpelä \& Rainio, 2004]. The outcomes show that the law was comparatively less effective in discouraging older non-smokers from buying tobacco. This is most likely due to the fact that the obligation of a seller to ask for identification is specified for 'customers younger than 16 year'. Sellers might more often refrain from asking 15 -year-olds for their identification because, in their eyes, they may (already) look like 16-year-olds. From this viewpoint it would probably be more effective to increase the age at which sellers are obliged to ask for identification (for example, to 18 or 20 years) in order to encourage better compliance.

After the sales ban the increase in the likelihood of smokers to buy tobacco, although not expected, is not the most surprising outcome. Other studies have shown that the introduction of such laws does not always lead to a decrease in the buying behaviour of smokers [Stead \& Lancaster, 2005; Hinds, 1992]. Those who started or continued to smoke after the sales ban are probably comparatively more 'deviant' in terms of unlawful behaviour (including buying tobacco) than smokers before the sales ban. However, most surprising was that a large proportion of the buyers of tobacco consider themselves to be a non-smoker, and that the overall decrease in tobacco buying among 13-15 year olds is mainly due to a sharp decrease in the likelihood of buying among non-smokers. As far as we know, no other studies have reported that the main effect of a tobacco sales ban is a decrease in the likelihood of buying among non-smoking adolescents.

Another important point is how to accurately interpret 'non-smoking'. It is unknown whether those who answered 'No' to our question "Do you smoke?" have nev- 
er smoked, or have stopped smoking, or smoke only very occasionally (e.g. $\leq$ once a month). However, one would expect that if some of the 'non-smokers' smoke very infrequently or have stopped smoking in the last year, this group might have answered 'Yes' to the question about whether they bought tobacco for themselves. It appears that both in $1999(0 \%)$ and in $2003(0.5 \%)$ none or very few of the non-smokers who reported to buy tobacco indicated to buy it for themselves. Of course this does not exclude that many of the non-smokers who reported to buy for others may occasionally experiment with tobacco themselves. However, it does indicate that the two main ways in which a tobacco sales ban may influence adolescent smoking are: 1) discouraging non-smokers (i.e. experimental and infrequent smokers) to start and from continuing to buy tobacco, and 2) decreasing the availability of tobacco for more regular smokers because after the ban non-smokers are far less likely to buy for 'others'. The decrease in the likelihood of non-smokers buying for others after the ban might be due, for example, a parent or an older sibling no longer asking the non-smoker to buy cigarettes/tobacco for them; however, it is most likely that non-smokers purchase for their peers. The significant increase in the frequency of buying of smokers after the sales ban supports that smokers have to increase their own efforts to be able to smoke. Another question is the extent to which the ban has changed the sources for tobacco for non-smokers who intend to start smoking. Our study indicates that they are less likely to buy tobacco themselves. However, we do not know the extent to which the decrease in buying tobacco themselves is compensated for by a supply from other sources: for example, by offers from smoking peers, brothers, sisters or parents. Further study is required to specify for non-smokers intending to start smoking to what extent a sales ban is compensated for by additional/different sources of tobacco.

In terms of prevalence, our study indicates a decrease in smoking among adolescents aged 13 through 15 years. This seems to be in line with many Western European countries [Hibell et al., 2003]. From a health point of view the main question is whether a decrease in tobacco purchases will lead to a lower prevalence of smoking. Two major points need to be discussed before drawing conclusions about the possible contribution of the sales ban to a decrease in smoking prevalence. One point concerns the prevalence of smoking as measured in the present study. It is clear that a prevalence based on the single question ('Do you smoke?') is not comparable with prevalence estimates based on a more elaborate and standardized set of questions about smoking [Mudde, Willemsen, Kremers \& de Vries, 2000]. The other point concerns our study design; this design does not allow to attribute all changes in smoking prevalence directly to the one (major) event, i.e. the introduction of the sales ban. Other factors possibly influencing young people's smoking may have occurred in the 4-year period covered in this study and should be taken into account when estimating the possible influence of a tobacco sales ban. Concerning the prevalence of smoking, our study 
shows a strong decrease in smoking among 13 to 15 -year-olds from 20.3\% in 1999 to $7.4 \%$ in $2003(p<0.01)$. Other studies using more elaborate measures to measure smoking only provide estimates for 12 to 18-year-olds [Monshouwer et al. 2004]; in this latter age group the decline in the prevalence of smoking at least monthly was $27 \%$ in 1999 to $18 \%$ in 2003 among boys ( $<<0.01$ ) and $27 \%$ to $22 \%$ among girls (difference not significant). For boys and girls together the prevalence of monthly smoking declined from $27 \%$ in 1999 to $20 \%$ in 2003 ( $p<0.05$ ). There are no indications that the composition of the category of smokers in terms of type of school and ethnic background has changed between 1999 and 2003 [Monshouwer et al. 2004]. Another Dutch study using a more elaborate set of questions to measure smoking shows that in 2005 (the first time that the whole cohort aged 13-15 years in that year were exposed to the sales ban of 2003) the prevalence of smoking in the last month had further decreased to $17.8 \%$ [TNS-NIPO, 2006]. Our study indicates a larger decline in smoking than other studies. However, all studies report a significant decrease in prevalence of smoking between 1999 and 2003, a decrease which continued into 2005.

An important point remains: to what extent did the introduction of the sales ban contribute to the decrease in the prevalence of smoking? Other developments including a period effect on the prevalence of smoking by adolescents in Western European countries may have influenced the prevalence of smoking. Some indication of whether the sales ban has contributed to the decrease in prevalence of smoking after 1999 can be acquired by comparing the period 1999-2003 with that of the preceding period (1996-1999) in terms of changes in prevalence of smoking and major changes in factors known to influence smoking. Price increases are associated with a decrease in the prevalence of smoking [Chaloupka \& Wechsler 1997; Hopkins et al. 2001; Jamrozik, 2004; Lewit, Hyland, Kerrebrock \& Cummings, 1997; Sargent \& DiFranza, 2003; US Community Task Force report, 2003]. The price increase of (on average) 5\% per year between 1999 to 2003 is only marginally higher than the $4.5 \%$ price increase per year in the period 1996-1999 [Tweede Kamer der Staten-Generaal, 2005 ${ }^{\mathrm{b}}$ ]. The decrease in prevalence of smoking among 12-18 year olds [Monshouwer et al., 2004] was, however, much smaller (difference not significant) between 1996 (29.5\%) and 1999 (27\%) than between $1999(27 \%)$ and $2003(20 \%)(p<0.05)$. The further decrease in prevalence between 2003 and 2005 (17.8\%) is likely partly due to a higher increase of price in 2004 (26\%) [Tweede Kamer der Staten-Generaal, 2005 ${ }^{\mathrm{b}}$ ]. A higher budget for and more effective methods of health education initiatives to discourage smoking among adolescents may also influence prevalence of smoking. However, there were no major changes in the budget for health education or methods used before and after 1999. Therefore, in our opinion, the 2003 sales ban has contributed to a decrease in buying of tobacco and prevalence of smoking. 
CHAPTER 7

Supervisory bodies and impact assessment 



\subsection{Introduction}

Compliance with legislation is an important factor in achieving the objectives of the legislators. Supervisory bodies are installed to promote and if necessary enforce compliance. Until the end of the previous century, supervisory bodies were largely left to perform their duties in silence. Since then, however, the role of supervisory bodies has increasingly been discussed, and the task of supervision has become more problematic. There are various reasons for this, such as political pressure to minimise burdens on businesses by reducing the regulatory burden and making cutbacks in the supervisory bodies. At the same time, society's expectations are high, and expect the supervisory bodies to ensure maximum safety and the highest quality of service [WRR, 2013]. This means that supervisory bodies are asked to make supervision more efficient and effective while using fewer resources. In addition they are expected to account for the supervision carried out and the results achieved, by providing insight into their impact on compliance and on society [ARK, 2008; WRR, 2013].

In this chapter we focus on evaluation and impact assessment of supervision and on the accountability of the supervision carried out. Based on the available literature we give closer consideration to the problems outlined and discuss the reasons for the growing interest in impact assessment over the past decades (7.2). Next we consider the response of the supervisory bodies. We describe both their reaction to the debate about supervision, and the performance of impact assessment in practice, identifying both arguments and barriers (7.3). Finally we offer solutions that recognise the importance of evaluating supervision, but take account of difficulties experienced by supervisory bodies in practice (7.4).

\subsection{Problems in supervision: closer consideration}

The context in which supervisory work of organizations such as the Netherlands Food and Consumer Product Safety Authority, Nederlandse Voedsel en Warenautoriteit (NVWA) has to be realized has changed strongly in recent decades. On the one hand, supervision has to address increasingly stronger demands to minimize the administrative burden of regulation and supervision. On the other hand, supervisory work has to meet high expectations of the society that expects maximum safety and highest quality of service. In this section we look more closely at this changing context and describe the current debate on the role of supervision. 


\subsubsection{Administrative burdens}

From the start of the 21st century there has been a perception that regulation and supervision involve unnecessary administrative burdens and extra costs, and that regulation limits the freedom of business and individuals. This perception is not restricted to the Netherlands, as shown by research by Hampton into reducing administrative burdens in the UK [Hampton, 2005] or by the survey on supervision in 25 countries (2012) carried out by the Organisation for Economic Co-operation and Development (OECD) [Monk, 2012]. Since then the international debate has turned to the issue of which enforcement strategy produces the greatest possible compliance at the least possible administrative cost [Department for Business Innovation \& Skills, 2013; OECD, 2014]. The assumption is that this will increase public confidence in a well-functioning society and government, and so promote economic growth [OECD, 2014].

Box 1: Six principles for good supervision [Tweede Kamer der Staten-Generaal, 2005].

Six principles for good supervision from Framework Visions on Supervision I and II:

1. Independence: supervisors reach a judgement objectively.

2. Transparency: public accountability for the effectiveness and efficiency of the decisions made

3. Professionalism: separation between the functions of policy and supervision.

4. Selectiveness: available capacity is used effectively by tailoring the form and scope of supervision to the risks of non-compliance.

5. Readiness to act: those under supervision are encouraged to comply, but supervisors take action if the situation requires, on the principle of "soft if possible, hard where necessary".

6. Cooperation: government reduces the burden of supervision by improving cooperation between supervisory bodies.

\subsubsection{Supervision paradox}

In the Netherlands, partly in response to the Aptroot resolution in 2005, the government has taken action against the undesirable high and sometimes contradictory regulatory burden and any unnecessary burden of supervision [Pechtold \& Brinkhorst, 2006]. The government position on supervision, expressed in the 2001 Framework Vision on Supervision, was revised in 2005 under the title 'Minder last, meer effect' (Smaller burden, greater impact). The government was focused on encouraging personal responsibility in society and limiting the burden of supervision. Three new principles of good supervision were added to the existing three (see box 1) [Tweede Kamer der Staten-Generaal 2001; $2005^{c}$ ]. The Government launched targeted programmes, 
such as 'Eenduidig Toezicht: Minder, Beter, Duidelijker (Uniform Supervision: Less, better, clearer') and 'Vernieuwing Toezicht (Supervision Reform) 2008-2011', to reduce the burden of supervision by $25 \%$ and promote a more effective and efficient process [Tweede Kamer der Staten-Generaal 2005, 2008]. The current program 'Regeldruk Bedrijven (The Regulatory Burden on Business) 2011-2015' is also designed to reduce administrative burdens and compliance costs and improve the implementation of rules and regulations [Tweede Kamer der Staten-Generaal, 2011]. The supervisory bodies have also been subject to severe cutbacks and mergers [ARK, 2013; Ministerie BZK, 2012; Morawski, Leeuw \& Ottow 2013; Winter, 2012].

At the same time we observe an opposite reflex, a call for stricter supervision, particularly in response to incidents and disasters. These vary from abuses in health care (e.g. the neurologist Jansen Steur, who, after dismissal due to dysfunction in 2004 worked in various German clinics, before he was prosecuted in 2013) [Schippers, 2013], to incidents in the chemical and food industries (e.g. the fire at Chemie Pack in Moerdijk [Opstelten, 2011] or the horse meat fraud, in which horse meat was found in beef products [Tweede Kamer der Staten-Generaal, 2013, Dijksma \& Schippers, 2013]. Supervisory bodies are also more often considered to be (partly) responsible, as they should have foreseen and prevented the incident. This may be due to the rising expectations of consumers, media and politics that the supervisory bodies will ensure maximum safety (e.g. food or environment) and the highest quality in services such as education and care [Mertens, 2011; Twist, Klijn \& van der Steen, 2013; WRR, 2013].

In conclusion, the supervisory work of organisations is increasingly characterized by two factors that causes a paradox, also referred to as the "enforcement or supervision paradox". When no incidents occur, supervision is regarded as "a burden" for businesses. Yet, when incidents do occur, the supervisory body is blamed for not preventing it, resulting in calls for increased supervision [Department for Business Innovation \& Skills, 2013; Mertens, 2011; WRR, 2013].

\subsubsection{Impact assessment of supervision}

The tension caused by the supervision paradox has increased the need for evaluation of public bodies in charge of supervision. The report of the Scientific Council for Government Policy, Wetenschappelijke Raad voor het Regeringsbeleid (WRR) includes similar recommendations: "Ensure that supervisory bodies are held publicly accountable for the capacity and instruments deployed and for the results achieved," (WRR, 2013, p.157) and "Encourage a culture that focuses on benefits and improve the knowledge infrastructure so that supervision can be properly evaluated and backed by scientific evidence" [WRR, 2013, p.153]. 
However, research into the use and contribution of supervisory interventions is seen as complex by inspectorates. This is clear from studies carried out by the Netherlands Court of Audit, Algemene Rekenkamer (ARK) which states that there is a lack of research into the extent to which enforcement contributes to increasing compliance, such as systematically requiring proof of age for sales of tobacco to adolescents, or what societal effect is achieved, such as reduction in the number of smokers as a result of enforcement of the smoke-free workplace [ARK, 2008] and by the WRR which indicates that research into the effectiveness of various interventions is still in its infancy [WRR, 2013]. Also international research indicates that monitoring of compliance varies by region and authority, and that there are still many countries that do not perform evaluations or measure compliance [Monk, 2012], while supervision should be based more on evidence and measurement [OECD, 2014].

In sum, despite pressures to conduct evaluation and impact assessment, supervisory bodies have not realized a structural integration of evaluation as part of their regular work.

\subsection{Response of supervisory bodies and supervisory practice}

This section describes the response of supervisory bodies to pressures to take accountability for the results reached and to improve supervision. First a number of activities are described that were aimed to encourage evaluation. We then discuss the implementation of this impact assessment in practice. We describe both the arguments for evaluation of supervision and the difficulties facing the inspectorates, which may form a barrier to structural integration of evaluation.

\subsubsection{Activities of (government) inspectorates}

This section describes which activities (government) inspectorates have undertaken to respond to the requirement to make supervision more efficient and effective with fewer resources, and to account for the results achieved.

Since 2000 there has been informal cooperation between the Inspectors General of the government inspectorates. In 2007 this cooperation formalised in the Inspection Council, which became the contractor for the government-wide programme 'Eenduidig Toezicht (Uniform Supervision)', (see 7.2.2) and gave substance to the $2^{\text {nd }}$ second Framework Vision on Supervision [Tweede Kamer der Staten-Generaal, 2005]. The subject of impact assessment has always been under consideration and several activities have been conducted to promote and support evaluation of supervision (see box 2). In 2012 the final evaluation of the multi-annual programme 'toezicht met effect (supervision with impact)' showed that the inspectorates responded favourably to the 
use of impact assessment, but that few impact assessments were carried out in practice [Timmerman, Tromp \& Waveren van, 2012]. From 2014 onwards the theme of impact assessment was incorporated into the "Academy of Supervision", in which the Inspection Council hopes to combine supervision-related activities in the field of research, development, training and dialogue. This also means the intention of closer collaboration with the scientific community [Inspectieraad, 2012; Reedijk \& Verdonk, 2013].

Box 2: Internal developments in the Inspection Council in relation to impact assessment (www.inspectieloket.nl/vernieuwing_toezicht).

Cooperating government inspectorates and impact assessment of supervision:

2000 Informal Inspection Council

Aim: to contribute to further professionalization of government supervision.

Method: quality agenda with themes, including impact assessment.

Products: guide 'Effectmeting bij inspecties (Impact assessment in inspectorates)' [Werkgroep Effectmeting, 2005].

2007 Inspection Council

Aim: implementation of the program 'Eenduidig Toezicht (Uniform Supervision)' and the 2nd Framework Vision on Supervision.

Method: multi-annual plan with programs such as professionalization, communication, and domain cooperation. Impact assessment remained a separate focus and was provided for in the program 'Toezicht met effect (supervision with impact)'.

'09-'12 Inspection Council - Multi-annual program 'Toezicht met effect (Supervision with impact)' Aim: raising awareness of the added value of impact assessment in all government inspectorates.

Method: promoting and supporting the implementation of impact assessments.

Products: Guide 'Effecten van toezicht en handhaving meten (Measuring the impact of supervision and enforcement)' [Jansen \& Smits, 2011], workshops, customised advice, inventarisation (scan) of use of impact assessment in government inspectorates. Symposia, knowledge network, literature studies [Timmerman, Tromp \& Waveren van 2012].

In recent years there has been increasing collaboration between supervisory bodies and scientific institutions. Supervisory bodies carried out studies or have studies carried out by e.g. by the Inspection Council, the Enforcement and Behaviour Working Group (www.hetccv.nl/dossiers/Handhaving+en+gedrag/index) or by Vide (www.videnet.nl), the professional association for supervisors, inspectors, enforcement officers and assessors [Profacto, 2010; Schol \& Winter, 2012). Vide has also set up a network of researchers to promote cooperation between supervisory organisations and universities. Since 2010 there has also been a scientific journal on supervision, 'Tijdschrift voor toezicht (Journal of Supervision)' which gathers and publishes knowledge and information on supervision in the broad sense [www.bjutijdschriften.nl/tijdschrift/tijdschrifttoezicht/detail]. 
Various university chairs have been established on supervision in general, and supervision in specific fields, such as education, health care or financial institutions. These (part-time) professorships are largely funded and developed by the supervisory bodies themselves [Mertens, 2011; Reedijk \& Verdonk, 2013]. In parallel with this development, there is more attention to supervision as a scientific discipline. This also applies to specific knowledge in the area of the impact and evaluation of supervision [Reedijk \& Verdonk, 2013].

Finally, the development of sustainable cooperation can be seen in the form of Academic Collaborative Centres. In 2011 the Health Care Inspectorate (IGZ) developed this concept for the health care sector, following recommendations from the Health Council of the Netherlands [Gezondheidsraad, 2011]. The 'Academisch werkplaats Toezicht (Academic Collaborative Centre on Supervision)' carries out research on supervision-related topics [Vedder, 2013]. The Education Inspectorate is also setting up an Academic Collaborative Centre on Education (www.academischewerkplaatsonderwijs.nl).

In sum, since 2000 (government) inspectorates have begun to in cooperate more, to develop scientific knowledge, and have started to support research in order to analyse the impact of supervision on society, and how supervision may contribute to compliance. Yet, a very planned and systematic research approach towards research as an integral part of the work of inspectorates fostering quality control is still missing.

\subsubsection{Impact assessment of supervision in practice}

As outlined above, despite an increasing interest in evaluation and impact assessment, evaluation has not yet been adopted as common practice [Timmerman, Tromp \& Waveren van, 2012; WRR, 2013; Winter, 2012]. In this section we answer two questions: 1) what are the arguments for supervisory bodies to perform evaluation and impact assessment and 2) which difficulties facing inspectorates, which hamper a structural evaluation of supervision.

\subsubsection{The need for evaluation}

Section 7.2 described that supervisory bodies are under increasing pressure to account to the outside world and to improve their supervision. There are a number of reasons that inspectorates have to use evaluation and impact assessment to give substance in order to meet these expectations.

The first reason concerns the external pressure in relation to the debate about the burden of supervision versus the benefits. Welp states that, supervisory bodies can no longer opt out of rendering public account of the use of funds in relation to the performance and impact achieved given the democratically oriented optics and scarce 
public resources available [Welp, 2012]. Additionally, studies carried out by the ARK describe the lack of insight into the added value of supervisory interventions. In response, the government requires that measuring the effects of supervision, including its contribution to societal objectives, forms part of enforcement practice [Winter, 2012].

The second reasons concerns the need for setting priorities, because despite increasing demands, the allotted capacity for supervision has been reduced at the same time. Mergers have reduced the number of state supervisory bodies from 16 in 2006 to 10 in 2012, resulting in a reduction of the capacity by $18.7 \%$ (7086 ftes in 2006; 5765 ftes in 2011) [Ministerie BZK, 2012; Winter, 2012]. This reduction implies that strategic decisions have to be made within the supervisory bodies, to deploy their limited capacity where it is expected to have the greatest impact. The reduction thus requires insight into the risks concerned and the impact of supervisory interventions. Such insight provides useful information for setting priorities, and can reduce the chance that supervision will occur as the result of incidents.

The third reason relates to the potential learning effect that may occur when evaluations are performed. This process is a continuation of evidence-based policy making, which aims to create a relationship between scientific knowledge and policy, with the effectiveness of policy as the central concern. Supervisory interventions can be improved by an understanding of what does and does not work [Welp, 2012]. Robben refers in this context to 'evidence-based' supervision, in which supervision is based on scientific knowledge about supervisory methodology, the available instruments and the direct and indirect effects of supervision [Robben, 2011].

In conclusion, the following arguments outline the need for perform evaluation research in a systematic way as a regular part of the work of supervision bodies: 1) the external pressure to account for the results achieved and to give insight into the added value of supervision, 2) the internal need to know how to deploy capacity and 3) the potential learning effect.

\subsubsection{Barriers}

This section addresses the difficulties that inspectorates face when attempting to integrate evaluation research into the practice of supervision. First, we see a contradiction between the need for evaluation on the one hand, and the limited financial resources and manpower allocated to realize evaluation research, yet, other factors also hinder a systematic incorporation of impact measurement into the supervisory process.

\section{Methodology}

An often mentioned problem of supervisory bodies is the complexity of scientific impact assessments, referring to research that demonstrates a causal relationship be- 
tween the supervisory intervention and the (societal) effect [Welp, 2012; Winter, 2012]. One problem that supervisory bodies encounter is that the use of strong designs such as Randomized Controlled Trials (RCT's) is often infeasible, as random allocation to an experimental condition to assess the impact of policies or compliance methods is not feasible when legislation is implemented nationwide. Furthermore, for legal, ethical or political reasons, it is not always desirable, or even possible, to work with control groups. After all, one cannot refrain from responding to suspected fraud or to complaints about food poisoning because the company concerned is part of a control group, or because there are statutory obligations in relation to monitoring activities. Additionally, existing data sources often lack specificity to answer specific research questions, as the original data collection was not aimed to address them, resulting in a need for further research [Dishoeck van, et al., 2013]. Other factors, such as (the size of) the target group (i.e. how many illegal traders are there) or the measurability of the anticipated effects (i.e. safety or welfare) can also influence the research design [ARK, 2008].

Consequently, given the constraints, the best possible research design should be chosen. Farrington developed, within the science of criminology, the Maryland Scientific Methods Scale in which the burden of proof for causality varies according to the research set-up [Farrington, Gottfredson, Sherman \& Welsh, 2002]. The choice of research design and associated burden of proof therefore depends on the case, the research question and the feasibility. The availability of methodological knowledge, experience and skills to make these decisions and carry out the research varies from one supervisory body to another [Gezondheidsraad, 2011; Dishoeck van, et al., 2013].

In conclusion, although RCTs may be hard to conduct, there are several ways to select relevant alternative research designs. Hence, increasing awareness of these possibilities may be needed in order to stimulate a more research driven approach for quality control by supervision bodies.

\section{Organisational characteristics}

As we explained in section 7.2 the requirements and expectations to supervisory bodies have changed in the last decades. There might be barriers in the current characteristics of the inspectorates to implement structural evaluation of supervision.

The current developments in social science require highly specialized research expertise to deal with the research challenges above. This requires either the appointment of this type of personnel and/or collaboration with specialized institutes to foster evidence based supervision quality control. There are inspection services, such as the Health Care Inspectorate, Inspectie voor de Gezondheidszorg (IGZ) and the Education Inspectorate, Inspectie van het Onderwijs (IvhO), have in-house research departments 
and an Academic Collaborative Centre, so one could assume that the knowledge of social science is available and that the independence of the research is assured. For most inspectorates this often proves more of a problem [Robben, 2011].

Other organisational characteristic that might play a hindering role in embedding evaluation research is the lack of a culture of impact assessment among inspectors. In its recommendations the Health Council wrote that the IGZ should strive for a culture of testability, as research into the effectiveness of supervision will then filter down into practice [Gezondheidsraad, 2011]. In this context Robben outlined that testability starts with the development of such a culture favouring the incorporation of evaluation in the current practice of supervision [Robben, 2011]. According to a survey of inspectors' views on impact assessment Klerks concluded that there are three "inspector profiles" that vary across the different state inspectorates. Inspectors with a social profile focus more on solutions to problems in society, inspectors with a compliance profile focus on the effects on those under supervision and inspectors with a product profile focus on numbers of inspections, infringements or penalties. The support for carrying out impact assessment is greater among inspectors with a social or compliance profile than among inspectors with a product profile [Klerks \& Robben, 2012].

Finally, the risk-based method might also play a negative role when incorporating evaluation into routine work processes. Since the $2^{\text {nd }}$ Framework Vision on Supervision the method for enforcement has been increasingly risk-based, with inspectors intervening where there is the greatest risk of non-compliance. This risk-based method at executive level is at odds with the random measurements or the use of control groups, which are (sometimes) necessary for evaluation of supervision. [Welp, 2012; Winter, 2012]. However, also at strategic level, risks are weighed up to decide where to deploy capacity: whereabouts in the chain, or in which target group, are the risks of noncompliance the greatest, and what supervisory intervention is likely to have the greatest impact? This requires insight into the degree of compliance and into the impact of supervisory interventions, which justifies random measurements or the use of control groups.

In resume, certain factors might help to implement structural evaluation of supervision, like the availability of methodological knowledge, the culture of testability, a positive attitude to impact assessment and the way in which the risk-based procedure is interpreted.

\section{Vulnerabilities}

Finally, we discuss the obstacles that may result from public accountability. There is a risk of losing credibility if supervision has had too little or no effect among supervisory bodies hold themselves to public account [Winter, 2012]. Furthermore, another risk occurs if the assessment appears to occur with low reliability. A study showed that 
there were wide variations in the judgments of inspectors and that the validity and reliability of judgments were problematical. The IGZ was awarded the Vide publication prize (2009) for the study, for its courage in rendering public account. However, it resulted in increased legal proceedings against this inspectorate [Robben, 2010]. Van Twist, however, stresses that, as well as risks, visibility can also offer opportunities for improving effectiveness. Twist indicated that the reports on on-site inspections and penalties of the smoking ban in the hospitality sector, although the compliance was fairly poor, probably have increased the perceived risk of being caught and might have led to an increase in spontaneous compliance [Twist, Klijn \& Steen van der, 2013].

Another barrier in public accountability is dealing with confidential and sensitive data. Depending on the area of supervision and the legal framework, it may not be possible to publish (personal) data - for example, in the case of the financial supervision of the Dutch Central Bank (DNB)- or data that is sensitive to the stock exchange [Ottow \& Robben, 2012; Welp, 2012].

Summarized, there are two considerations inspectorates take into account before performing public accountability; these are the risk of losing credibility and the use of confidential and sensitive data.

\subsection{Discussion}

In this chapter we focus on evaluation and impact assessment by supervisory bodies and on the accountability of the supervision carried out. We have two questions "why has there been an increasing interest in impact assessment of supervision in recent decades?" and "how do supervisory bodies respond in practice?"

The answer to the first question is that supervisory bodies have to pay greater attention to evaluation to account for the results achieved and to gain insight into the impact of supervision. One of the reasons issued the public accountability to explain the allocation of resources and the impact achieved. This is probably due to the political pressure to minimize the burden of business and the cost of supervision and the grown expectation of the society to inspectorates to guarantee maximum safety and the highest quality in services. Another reason is the government requiring inspectorates to measure effects of supervision. And an internal reason is due to the shrinking budgets whereby supervisory bodies need to work ever more efficiently and effectively. Knowledge is required about the impact of previous supervisory interventions to make strategic decisions and deploy their limited capacity where it is expected to have the greatest impact. This also provides the basis for more 'evidence-based' supervision and further professionalization of supervision. 
In answer to the second question of how supervisory bodies respond in practice, we have seen that this has led to further cooperation, the development of instruments, and the need to use a more scientific approach in order to be able to answer questions as reliably as possible. However, despite the fact that impact assessment is on the agenda and supervisory bodies are well aware of the need for transparency about the impact of supervision, just a few experiments are being carried out. Supervisory bodies are still struggling with the practicalities and the incorporation of evaluation of supervision into the primary work process. Apart from the issue of how much funding will be available for impact assessment of supervision in times of austerity, there are a number of practical problems that stand in the way of progress.

The first barrier we described is that inspectorates are mainly focused on methods demonstrating the causality of the added value of supervision, which is often methodologically not feasible. However, we argue that to incorporate evaluation into routine work processes, it is advisable not to focus exclusively on the issue of causality, but to adopt a broader approach to research on evaluation. Various forms of evaluation are possible that contribute to the professionalization of supervision.

We have placed these forms of evaluation in the supervision cycle (Figure 1) applied by most of the supervisory bodies [Jansen \& Smits, 2011; CCV, 2011; Verdonk, Rijswijk, Dekker, Faber \& Visser, 2013]. This approach is comparable to policy evaluation, which also has several variants [Klein Haarhuis \& Niemeijer, 2008]. Next, we have elaborated these forms, with a description and the deliverable of the forms and the aim of using them indicating their objective, such as management, learning and improving or accountability (Box 3). This might make it easier for supervisory bodies to decide when, to what end and what form of evaluation is required, and which research methods are suitable. 
Figure 1: Various forms of evaluation linked to the supervisory cycle [Jansen \& Smits, 2011; Verdonk et al., 2013].

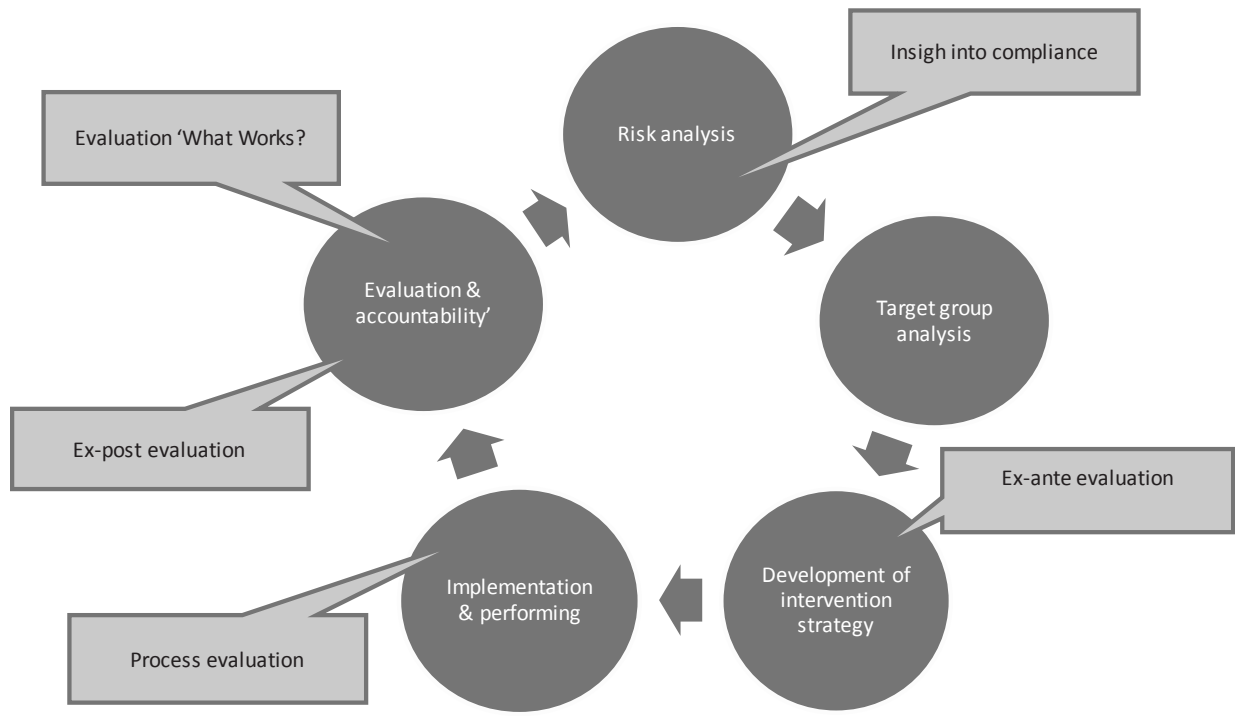

The condition to work with various evaluation forms is that supervisory bodies need adequate methodological knowledge, experience and skills in order to properly weigh up the designs options. We have concluded that this is not the case in all inspectorates, which is one of the organisational characteristics to work on. This knowledge must be ensured through training or retraining, recruitment policy or hiring in. The organisation also needs to be set up in such a way that the methodological knowledge is made available to carry out or supervise the evaluations. Depending on the organisation this can be done through concentration of duties (research department), collaboration (between expert(s) and staff), hiring in or outsourcing of research. Another factor is the degree of independence of the researchers. This can play a role in important investigations, such as 'what works' evaluations to support external accounting. Independence can be guaranteed by placing the evaluation within a separate department, working with external experts, for example through the Academic Collaborative Centres, or outsourcing evaluations. In addition (scientific) verification can take place through publication in official journals (peer review). 
Box 3: Elaboration of evaluation forms with a description, the deliverables and the aims.

\begin{tabular}{|c|c|c|c|}
\hline $\begin{array}{l}\text { Form of } \\
\text { evaluation }\end{array}$ & Description & Deliverable & Aim or motivation \\
\hline $\begin{array}{l}\text { Insight into } \\
\text { compliance }\end{array}$ & $\begin{array}{l}\text { Research of the degree of } \\
\text { compliance } \\
\text { Qualitative: } \\
\text { Measuring compliance } \\
\text { Analysis of retrospective } \\
\text { inspection data. } \\
\text { Qualitative: } \\
\text { Estimation of compliance. }\end{array}$ & $\begin{array}{l}\text { Insight into degree of } \\
\text { compliance of relevant } \\
\text { target groups. }\end{array}$ & $\begin{array}{l}\text { - Input for risk analyses } \\
\text { - Setting priorities }\end{array}$ \\
\hline $\begin{array}{l}\text { Ex-ante } \\
\text { evaluation }\end{array}$ & $\begin{array}{l}\text { Establishing the objective or } \\
\text { impact of the supervision, } \\
\text { based on the most promising } \\
\text { supervisory intervention, } \\
\text { tailored to the motives for } \\
\text { (non)-compliance of the } \\
\text { priority target group. }\end{array}$ & $\begin{array}{l}\text { Substantiated description } \\
\text { of planned commitment } \\
\text { and resources and the } \\
\text { intended aim or impact of } \\
\text { the selected intervention. }\end{array}$ & $\begin{array}{l}\text { - Strategic decisions on } \\
\text { use of capacity } \\
\text { - Ex ante accountability } \\
\text { for options chosen }\end{array}$ \\
\hline $\begin{array}{l}\text { Process } \\
\text { evaluation }\end{array}$ & $\begin{array}{l}\text { Research of implementation } \\
\text { Qualitative: } \\
\text { Monitoring of completed } \\
\text { activities. } \\
\text { Qualitative: } \\
\text { Research of successes, } \\
\text { constraints and any interim } \\
\text { adjustments. }\end{array}$ & $\begin{array}{l}\text { Qualitative: Overview of } \\
\text { planned and completed } \\
\text { activities (P\&C cycle). } \\
\text { Qualitative: summary of } \\
\text { successes, constraints and } \\
\text { deviations. }\end{array}$ & $\begin{array}{l}\text { - Ex post accountability } \\
\text { - Learning \& improving }\end{array}$ \\
\hline $\begin{array}{l}\text { Ex-post } \\
\text { evaluation } \\
\text { (target range) }\end{array}$ & $\begin{array}{l}\text { Evaluation of intended aim } \\
\text { and whether the expected } \\
\text { effect was achieved, plus } \\
\text { more detailed analysis to } \\
\text { clarify the result and make } \\
\text { recommendations for the } \\
\text { future. }\end{array}$ & $\begin{array}{l}\text { Description of whether and } \\
\text { why the intended aim / } \\
\text { effect was or was not } \\
\text { achieved and recommen- } \\
\text { dations for the future. }\end{array}$ & $\begin{array}{l}\text { - Ex post accountability } \\
\text { - Learning \& improving }\end{array}$ \\
\hline $\begin{array}{l}\text { Evaluation of } \\
\text { 'what works' }\end{array}$ & $\begin{array}{l}\text { Research of contribution of } \\
\text { supervisory intervention to } \\
\text { compliance and/or to solving } \\
\text { the societal problem. }\end{array}$ & $\begin{array}{l}\text { Insight into the methodol- } \\
\text { ogy of a specific superviso- } \\
\text { ry intervention. } \\
\text { Insight into the contribu- } \\
\text { tion of supervision to } \\
\text { compliance or to the } \\
\text { solution of the societal } \\
\text { problem. }\end{array}$ & $\begin{array}{l}\text { - Ex post accountability } \\
\text { - Learning \& improving } \\
\text { - Basis for evidence- } \\
\text { based supervision }\end{array}$ \\
\hline
\end{tabular}


Another relevant characteristic is its culture of testability and the attitudes of employees. Both influence the way evaluation of supervision is applied or embedded. To spread the culture of testability by the management and fostering a positive attitude by employees might increase support for impact measurement.

And finally, we concluded that the way in which the supervisory body interprets the risk-based procedure can play a role. We recommend that a risk-based method would be a good balance into the effort used at strategic level; to weigh up risks, to measure compliance, to develop risk profiles and to evaluate supervisory interventions, and at executive level to target inspections on non-compliant companies. The effort on strategic level does not automatically require inspection capacity, as that will depend on the needed information. Some information can only be obtained from inspectors, through specialist knowledge or by access to certain data, while other information can be gathered by means of (anonymous) observations, surveys (chapter 3 ) or from existing (external) data. Knowledge of both the subject matter and methodology are needed to be able to weigh up the best way of gathering the information.

Box 4: Example of a risk-based approach in monitoring of the smoke-free workplace.

By way of illustration: just after the introduction of the workplace-smoking ban in 2004 compliance monitoring was carried out biennial in which telephone surveys were used to measure compliance and the motivation to comply in various target groups. Next the officials determined which group had the biggest compliance problem and should be prioritised. A supervisory intervention was developed and carried out for this target group. To assist in risk-based operation at executive level, existing inspection data, complaints and information from other supervisory bodies were used. Using this method the compliance monitoring identified a steeper rise in compliance in the relevant target group compared with other target groups.

The final barrier we have found is that there are two considerations to take into account, about the risk of losing credibility and the use of confidential and sensitive data, before inspectorates perform public accountability. The risk of losing credibility is played out in the context of "neo-liberalism"; reducing the burden of regulation and supervision and undesirable paternalism, whereby businesses and the public call for fewer rules and less government interference. The tide of public opinion is also veering towards mistrust, which is probably related to the current recession and financial crisis. The result is that people are less accepting of things going wrong. Citizens (and the media) feel they should not have to weigh up risks themselves, but expect the supervisory bodies to do it for them, as well as taking measures to remove the risks. This explains why people look for someone to blame following an incident, when the supervisory bodies often come under fire. Politicians compound this problem by demanding 
far-reaching investigations into responsibilities, setting extra rules or demanding higher penalties, all of which sends out a strong signal to the public that this cannot be allowed to go on.

The question the supervisory bodies should ask themselves is whether the expectations of the public, press and politicians are realistic, and whether they could really be met, particularly in view of shrinking budgets. Inspectorates could make it clearer what they can and cannot do, and what may or may not be expected of them. A change could be effected whereby the supervisory bodies inform the public and politicians of the risks, what the supervisory bodies are doing about them, but also indicating what people could do themselves, and explaining that supervisory bodies cannot remove all risks or guarantee there are no further incidents. Such openness would, to an extent, reduce the external pressure that builds up after an incident (Grave de F., 28 March 2013, Masterclass Toezicht en effectmeting, Nyenrode business University). The WRR also recommends a move in this direction, and calls it "reflective supervision". The WRR does however set limits to such transparency and public accountability. There must be scope both for the supervisory bodies to explain their actions, and for Parliament to take the matter due consideration, without immediately falling back into the culture of blame that is prevalent today [WRR, 2013]. For evaluation of supervision this means that the supervisory bodies make and then follow up a strategic assessment about the form evaluation of supervision should take. After all one cannot expect a detailed evaluation or impact assessment of every supervisory intervention in relation to everything to which standards apply.

Finally, we may conclude that evaluation of supervision is a strategic tool that can make a positive contribution to the development of the supervision. It becomes increasingly clear which interventions deliver more or less, the circumstances under which they work, and what uncertainties or difficulties remain. This leads to a realistic assessment of the contribution supervisory bodies make to increasing compliance, the achievement of societal goals and the prevention of incidents. This knowledge can be used to account for the activities carried out, and to communicate with the public or clients about the future. Within supervisory organisations this knowledge is useful in setting priorities and improving supervision. 

CHAPTER 8

General discussion, including valorization 



\subsection{Introduction}

The purpose of this thesis is to describe the impact of two legal provisions from the Tobacco Act, namely the workplace-smoking ban and the tobacco sales ban to minors. We will assess both the implementation of the legislation (compliance assessment), i.e. the extent to which the parties responsible for compliance adhere to the rules and which factors influence this compliance, and the impact of the legislation (policy impact assessment), this concerns the societal problem that is to be solved. The last theme of this thesis, is the changing role of supervisory bodies.

In this chapter we will discuss these themes and give the significance of the findings. These significances can also be read as valorization of this thesis.

\subsection{Compliance assessment}

This thesis examined employers' compliance with the workplace-smoking ban legislation. Chapter 2 described how compliance developed over the years and which changes in awareness and motivational factors have occurred. The method used to measure compliance is validated in Chapter 3.

\subsubsection{Main conclusions from the compliance studies of the workplace-smoking ban}

Chapter 2 reveals that after an initial stagnation of several years (84.9\% in 2004, 83.9\% in 2006), compliance increased to $95.8 \%$ in 2008 . In addition, the $20 \%$ compliance gap that existed in 2004 between the industrial sector (75\%) and the public sector (94\%) had largely disappeared in 2008. Further analysis revealed that among the industrial sector the perceived risk of being caught and the perceived social pressure to comply with the ban, which were clearly low in 2004, have increased during the acceleration in compliance. It is plausible that the increased enforcement pressure and the general intensification of the governmental policy have contributed to this better compliance.

The question is whether an increased perceived risk of enforcement and greater social pressure also have led to better compliance in cases other than the workplacesmoking ban. This would be probably depend on the baseline situation. In general, efforts to promote compliance should be based on the (non)-compliance motives of the target audience [CCV, 2010]. Therefore we recommend that a study into these motives needs to be carried out before devising and implementing an enforcement approach. 
In the validation study (Chapter 3), we compared self-reported compliance (telephonic survey) with on-site inspections of the same workplace location. The outcomes showed a large agreement between the two methods and no significant differences in compliance rates, which indicated that our measurement of compliance via selfreporting was a valid method to assess compliance with the workplace-smoking ban. We also tested the predictive value of the self-reports and a surprising outcome was the negative predictive value, where over half of the companies that reported noncompliance were found to be compliant during the subsequent inspection. This compliance-promoting effect may be a beneficial side-effect of the self-reporting that occurred at baseline.

Two comparisons of the outcome of this study with other outcomes indicate the context in which this conclusion about self-reporting should be interpreted. First of all, a comparison between the compliance data in 2004 (Chapter 2) and employees reporting about exposure to tobacco smoke (Chapter 4) showed that despite a $85 \%$ compliance rate, $52 \%$ of employees still reported exposure. Although this $52 \%$ largely concerned 'occasional' exposure (30\%), which suggests that the infringements were mainly of an incidental nature, it still means that compliance with the workplace-smoking ban does not offer complete protection against tobacco smoke at the workplace. Secondly, there are indications that with other legislation (the sales ban to minors) the validity of 'self-reporting compliance" is less clear. In $200386 \%$ of tobacco sellers reported that they never sold cigarettes to under-16s, despite young people claiming that their attempts to buy cigarettes are almost always successful (91-96\%) [Bieleman, Kruize \& Zimmerman, 2010]. Research into the sale of alcoholic beverages reveals similar discrepancies between self-reports of sellers and young people, and reports about attempts to buy [Bieleman, Kruize, \& Zimmerman, 2012; Hoof van \& Krokké, 2011]. Our conclusion that self-reporting is valid can therefore not be generalised to all situations. Our reasoning is that the use of self-reports is particularly valid when compliance is relatively high and the probability of socially correct answers is low. This happens more often when respondents do not feel threatened by the question [Verstraete, 2008]. Where the acceptance of infringements is low (e.g. with investigations into fraud, incorrect antibiotics use or the illegal sale of tobacco), the chance of a socially correct answer will be greater. This means that self-reported compliance is useful if the degree of compliance is relatively high and the legislation accepted. In other situations we recommend to validate the self-reporting compliance or to use other methods like on-site inspections, (anonymous) observations or existing (external) data to measure compliance (Chapter 7). 


\subsubsection{Significance of the findings for the application of compliance assessments}

If we ask ourselves what these results mean for supervisory bodies, the following considerations can be mentioned. First of all, it is important to obtain the earliest possible insight into the degree of compliance, the possible existence of low compliance risk groups and the motives for (non-)-compliance. The use of questionnaires for this purpose is possible under certain conditions and saves costs and may also promote compliance. Next, risk groups can be influenced to increase their compliance. Knowledge about the motives for (non-)compliance is necessary to develop the most promising enforcement approach to increase compliance and reduce the risks. Finally, it should be remembered that implementation of legislation might take time and that periodic studies into compliance and impacts are necessary to enable reflection and adjustments.

This last point touches on the subject discussed in Chapter 7. There is political pressure to keep the costs of supervision as low as possible. Supervisory bodies must carry out their supervision as effectively and efficiently as possible, and society wants all risks to be eliminated. Given the $95.8 \%$ compliance rate for the workplace-smoking ban and the absence of low compliance risk groups, it is necessary to weigh up the costs (deployment of supervisory capacity and burden of supervision) against the benefits (expected effect and reduction of employee's risk). However, if the compliance rate is judged to be acceptable, it is still important to continue monitoring the situation. Because a deterioration can always occur, in which case the deployment of supervisory capacity would need to be reconsidered. Monitoring of the workplace-smoking ban is possible by conducting periodic (self-reporting) compliance measurements at employers and by recording and examining signals of non-compliance, for instance via complaints. However, it might be possible to use external data with questions about exposure to tobacco smoke caused by employees to do secondary analysis. The advantage is that this method saves costs and the question gives sufficient insight into the progress of compliance without imposing any supervisory burden on companies. One example of secondary analysis concerns NIPO surveys ${ }^{1}$ which asked about the length of time that employees were exposed to tobacco smoke at the workplace. It was found that the length of time that non-smoking employees were exposed to tobacco smoke during working hours decreased from 6\% in 2005 (1 year after the workplace-smoking ban) to $3.1 \%$ in 2009 .

\footnotetext{
${ }^{1}$ We like to thank G. Nagelhout to provide the NIPO data for secondary analysis.
} 


\subsection{Policy impact assessment}

This thesis involved the performance of three policy impact assessments, of which two concerned the workplace-smoking ban (Chapter 4 and 5) and one the introduction of the tobacco sales ban to minors (Chapter 6).

\section{The workplace-smoking ban}

The societal objective of the legislation on the right to a smoke-free workplace is twofold, namely to protect non-smokers against exposure to colleagues' tobacco smoke and to discourage smokers from using tobacco by restricting the times and places where smoking is allowed. Chapter 4 ascertains whether the introduction of the smoke-free workplace has led to reduced exposure to tobacco smoke, while Chapter 5 assesses whether the introduction of the smoke-free workplace has brought about a decrease in the prevalence of smoking.

\subsubsection{Main conclusions from the policy impact assessments on the workplace- smoking ban}

The main conclusion from the study about the exposure to tobacco smoke (Chapter 4) is that the introduction of the law has decreased the exposure to tobacco smoke among non-smoking employees from $70.7 \%$ to $51.9 \%$, which is still rather high. The restricted effectiveness in protecting non-smoking employees might be due to allowing designate smoking rooms. Countries not allowing smoking rooms reported lower exposure than countries allowing them [Edwards et al., 2008; Fong et al., 2006; Galán et al., 2007; Haw \& Gruer, 2007; Heloma \& Jaakkola, 2003]. Another reason might be the exception for the hospitality, it would be likely that impact of smoke-free legislation in all workplaces at once would be larger [Nagelhout, 2012]. It was expected that the decrease among the risk groups (men and low-skilled workers) would be greater than among other target groups, but this was not the case: $60 \%$ of non-smoking men and $62 \%$ of non-smoking low-skilled workers reported continuing exposure after the law entered into force. This might be explained by the fact that men and low-educated employees are overrepresented at worksites known to be least compliant with the smoking ban, e.g. building trade, industry and agriculture [Bieleman \& Kruize, 2007].

The study into the prevalence of smoking (Chapter 5) showed that the introduction of the workplace-smoking ban, in combination with two tobacco tax increases has led to a decrease in the number of daily cigarettes among smoking employees (from 15.0 to 14.2 cigarettes/day) and to a decrease in the number of daily smokers (from $27.5 \%$ to $24.3 \%)$. Remarkably, the separate effect of the workplace-smoking ban was lower than 
in comparable studies in other countries [Chapman et al., 1999; Fichtenberg \& Glantz, $2002^{b}$ ]. However, the combined effect of the workplace-smoking ban and tobacco tax increases was greater than the reported effect of the tobacco tax increases alone [Hopkins et al., 2001; Levy, Chaloupka \& Gitchell, 2004]. That a combination of measures can have a greater impact than separate measures is also demonstrated by other studies where combined interventions involving a smoking ban and price increases also led to a greater effect [Emont, Choi, Novotny \& Giovino, 1993; Stephens, Pederson, Koval \& Kim, 1997; Stephens, Pederson, Koval \& Macnab, 2001].

Smokers who were not directly confronted with the workplace-smoking ban, i.e. non-employees, and who only suffered the tobacco tax increase, showed no changes in smoking behaviour. If the groups from this quasi experimental study were equivalent, this would entail that the effect among employees was entirely attributable to the workplace-smoking ban. However, the absence of an effect among non-employees can be plausibly assumed to be largely attributable to the fact that before the tobacco tax increase the smoking prevalence among the non-employee group was lower than among the employee group ( $21.1 \%$ versus $27.5 \%)$.

\subsubsection{Significance of the impact assessment studies into the effect of the workplace-smoking ban}

In Chapter 1 we outlined that the effects of legislation take place according to the effect chain. Figure 1 shows the effect chain for the workplace-smoking ban (Figure 1). This thesis comprises three separate studies into the various effect indicators: employer compliance, the exposure among non-smoking employees, and the smoking behaviour among smoking employees.

Figure 1: Effect chain of the workplace smoking ban.

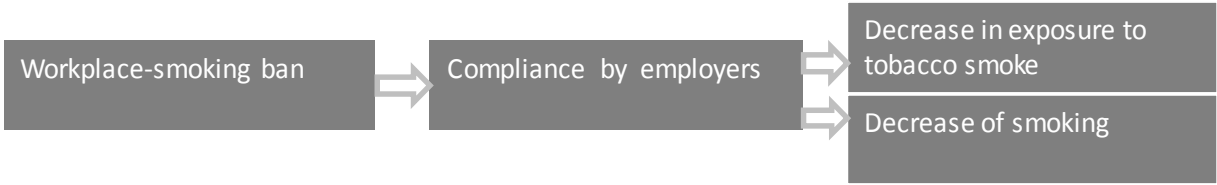

If we fill the results of the three studies into the effect chain, we can conclude that all effect indicators develop in the expected direction; the compliance by companies increased, the employees' exposure to tobacco smoke decreased, as did the prevalence of smoking among employees. However, as we outlined in chapter 1 , that there might be also external factors, such as other bans that came into act in that time, influencing the compliance or societal goals. First, we have to notice that during the introduction of the workplace-smoking ban a mass-media campaign 'recht op een rookvrije werk- 
plek (right to a smoke-free workplace)' took place to support the implementation, which we could not control for. The ban on advertisement and sponsoring in 2002 is however unlikely to have effects on compliance or smoking, because it is known that this ban influences mainly the positive user imagery, the curiosity and the normative beliefs of tobacco use [Wilson et al., 2012]. More important were the tax-increases, one and fifteen months after the introduction in 2004 , of about $24 \%$. We found in our study (Chapter 5) a larger decrease in overall consumption (price elasticity of -0.68 ) than would be expected from the tax increases separate (price elasticity of -0.4) [Wilson et al., 2012; Fichtenberg \& Glantz, 2002].

In two studies we also demonstrated the existence of risk groups. The lowest compliance rates were measured in the industrial sector with, respectively, 75\% (2004) and $70 \%$ (2006), while the highest exposure among employees after the introduction of legislation was reported among men (60\%) and low-skilled workers (62\%). These outcomes were consistent with each other, as men and low-skilled workers are overrepresented in the industrial sector. In due course, compliance in the industrial sector increased to $94 \%$ in 2008 , almost eliminating the gap with other sectors. Secondary analysis of the NIPO surveys ${ }^{2}$ showed that, although there was a decrease in the percentage of time during which, respectively, non-smoking male and non-smoking low-educated workers were exposed to tobacco smoke during working hours, there were still (small) differences (a decrease from 7\% (male) and 4.3\% (female) in 2005 to respectively $3.6 \%$ and $2.5 \%$ in 2009 and a decrease from $8.9 \%$ (low-educated), 6.5\% (middle-educated) and $2.8 \%$ (high-educated) to respectively $5.0 \%, 3.9 \%$ and $1.3 \%$.)

All in all it can be concluded that the impact of the workplace-smoking ban has been in the desired (and expected) direction, although some other factors, i.e. taxincreases have helped to achieve these.

\section{Tobacco sales ban to minors}

The societal objective of the introduction of the tobacco sales ban to minors is to make it more difficult for young people to buy tobacco, ultimately leading to a decrease in the prevalence of smoking among young people and an increase in the age at which people start smoking. Chapter 6 explores whether the introduction of the age limit of sixteen in 2003 has led to a decrease in the purchase of tobacco products by under$16 s$.

\footnotetext{
${ }^{2}$ We like to thank G. Nagelhout to provide the NIPO data for secondary analysis.
} 


\subsubsection{Main conclusions from the policy impact assessment on tobacco sales ban}

The main conclusion from this study is that the percentage of adolescents in the 13 to 15 age category buying tobacco decreased from $26.3 \%$ before the introduction of the legislation (1999) to $10.8 \%$ after the introduction (2003). This group of buyers consists both of smokers and non-smokers. The legislation has a completely different effect on smoking buyers than on non-smoking buyers. Since the introduction, the probability of young smokers purchasing tobacco themselves has tripled among all age categories. By contrast, the probability of non-smoking adolescents purchasing tobacco had decreased strongly $(\mathrm{OR}=0.17)$. This picture was confirmed by the number of weekly purchases. The purchasing frequency has risen significantly (2.3 - 4.7 times more) among smokers, but has remained unchanged among non-smoking buyers.

\subsubsection{Significance of impact assessment study into the introduction of tobacco sales ban}

The effect found in this study, i.e. a decrease in the percentage of adolescents buying tobacco, have to be seen in a broader context. Namely, in 2002 also the advertisement ban came into act. Although there is limited evidence of the effect of this ban in reducing smoking among youth, we know that tobacco advertising and promotion increases the likelihood that adolescents will start to smoke [Lovato, Watts \& Stead, 2011; Wilson et al., 2012]. However, the ban in the Netherlands would be less effective because it is not a comprehensive ban, because exceptions were made allowing to advertise inside the tobacconist and in our study there are no different patrons found in the various points of sale [Staatsblad van het Koninkrijk der Nederlanden, 2002]. Another effective measure to discourage youths of smoking are price increases, but these did not occur between 1999 and 2003. This leads to the conclusion that the tobacco sales ban may have contributed to making it more difficult for adolescents to buy tobacco, and thus contributes towards the achievement of the societal objective of this law. The second finding was that the composition of the group of buyers had changed: after the introduction, there were more smoking buyers and fewer non-smoking buyers. This leads to two conclusions. The first is that the effect of the legislation among adolescents who already smoked was not large; actually in-depth analysis showed that they had started to buy tobacco more frequently. To increase the effect of the measure on this target group, stronger compliance among sellers should be enforced, so that this group of smokers also encounters obstacles. Additionally other means could be employed as well, such as increasing the tobacco price or to repeal the exemption of advertisement among tobacconists. The second conclusion is that the decrease in the percentage of adolescents buying tobacco was mainly attributable to non-smoking adolescents who no longer bought tobacco. It can be assumed that these buying non- 
smoking youths were at point of on-set smoking. This finding correspondents with the legislator's second objective, namely to discourage people from starting smoking. The Dutch National School Surveys of the Trimbos Institute showed that the percentage of non-smoking young people aged 12 to 16 in secondary education increased from $46 \%$ in 1999 to $56 \%$ in 2003 and that since then this trend has continued to 63\% (2007) and $67 \%$ (2011) [Verdurmen, et al., 2012]. Secondary analysis of these data, by K. Monshower of the Trimbos Institute, showed a reversal in declining age at which young people start smoking their first cigarette after 2003 (12.6(1992); 12.5(1996); $12.4(1999) ; 12.3(2003) ; 12.8(2007) ; 13.0(2011))$. It is very plausible that the introduction of the age limit made a strong contribution to the sharp rise in non-smoking young people and the reversal in age of on-set smoking, particularly as no other new interventions aimed at young people were implemented between 1999 and 2003. The continuation of this trend may also be caused by the price increases in 2004 and 2005 and are known to have a large effect on tobacco use by young people [Mackenbach \& McKee, 2013; Wilson et al., 2012].

On 1 January 2014 the age limit of tobacco sales was raised to 18. If the effects are in line with the findings from our study, these will be less spectacular than in 2003 . This has to do with the composition of the age group that has been added to the legislation. Our study showed that the decline in buying was strongest among non-smokers. We think it likely that among the present 16-17 year old a far larger proportion of buyers is (already) a smoker than in our study among the 13-15 year old buyers. Therefore we expect that there might be some lag into the effect of the new minimum age for buying tobacco on the prevalence of smoking among the 16 and 17 year olds.

\subsection{The significance for the supervision}

In this section we set out the insights that the studies included in this thesis have yielded for the supervision. The section is organised as follows. First, we give a summary of how the supervision has been influenced in the past decades, the current expectations of the supervision, and the role that supervision impact assessments play in supervisory practice (Chapter 7). Next, we describe the answers that this thesis gives to the questions about the organisation and accountability of supervision. Finally, we will make some recommendations.

\subsubsection{Developments in and expectations of supervision}

Over the past decades an enforcement paradox has arisen in the Netherlands. The prevailing perception among politicians and society is that supervision imposes a bur- 
den for businesses, restrictions on freedom and costs of supervision. Measures to counter this include a reduction of the regulatory burden, mergers between supervisory bodies and cost-cutting at inspectorates. At the same time, society's expectations of the supervisors are high, and possibly even higher than before. When it comes to public services, citizens and politicians demand maximum safety and the highest quality of public services, and hold supervisors responsible for this. When incidents occur, supervisors are considered partly to blame, as they should have foreseen the problem and taken pre-emptive action. Moreover, serious incidents are often followed by calls for more supervision.

Supervisors are aware of this paradox and realise more than ever that anything less than full accountability to their superiors, politicians and citizens is unacceptable. Evaluation of supervision is important to demonstrate the added value of supervision ('what problems does it solve and what problems are avoided?') as well as to make strategic choices and deploy the limited supervisory capacity where the greatest effect is expected to be achieved.

However, despite the increased cooperation between (government) inspectorates and the intensified collaboration with the world of research in order to develop greater knowledge on supervision and the evaluation of its impacts, certain factors still impede the structural embedment of the evaluation of supervision in the primary work process of supervisors.

\subsubsection{Findings from this thesis in relation to supervision}

Based on the studies performed for this thesis, we are able to draw a number of conclusions regarding two questions, namely how can supervision be more effectively organised and how can accountability of supervision contribute to the high expectations of the society?

\section{More effective supervision}

Our study into compliance with the workplace-smoking ban revealed a lower compliance rate for a specific risk group, the industrial sector. It also showed that targeted enforcement among this group had led to increased compliance, while the perceived risk of being caught and the reported social pressure also increased. From this, we can conclude that a risk-based approach aimed at the target group's non-compliance motives is effective. It follows that knowledge about the degree of compliance, the (non) compliance motives and effects of supervisory interventions is necessary to make choices and deploy capacity where the greatest impact is to be expected. Moreover, a risk-based approach helps to reduce the burden of supervision on companies that are sufficiently compliant and do not belong to risk groups. 
Research is essential to obtain knowledge about compliance, motives and effects. The validation study shows that compliance measurement via self-reporting can be a valid method under certain conditions to establish these aspects. This method saves costs compared to the use of inspectors and may even promote compliance. The monitoring of final output indicators, such as the degree of exposure caused by employees, gives also insight into compliance and risk groups. By looking for relevant indicators for the degree of compliance and by using cost-saving research methods, it is possible to obtain more insight into risk groups and monitor effects with limited resources. However, these choices do require the presence of sufficient methodological knowledge at inspectorates as well as the allocation of part of the supervisory budget to research. Yet, in order to be able to validate self-reported data with actual data, actual monito-ring will remain an essential part of the supervision tasks.

\section{Accountability \& expectations}

In response to the question whether the performed studies in this thesis have contributed to the accountability of supervision, we can say that both the introduction of the workplace-smoking ban and the introduction of the tobacco sales ban are likely to have contributed towards the achievement of the policy objectives. The added value of the supervisor's intervention received less explicit attention in these studies, but it is plausible that the combination of legislation, supervision and mentioned other policy measures have led to this positive outcome of less exposure, reduction in the prevalence of smoking and fewer adolescents buying tobacco. Other studies into the effects of the introduction of health policies, such as alcohol, food and road safety, also indicate frequently positive results [Mackenbach \& McKee, 2013]. If we link these results to the expectations of society and politicians in terms of maximum safety and highest quality, we can conclude that these expectations are largely fulfilled.

One issue that merits attention is the length of time it takes for policies to have a noticeable effect. The results of the studies into the workplace-smoking ban indicate that the effects may sometimes occur after a longer period of time. The elimination of the compliance shortage of the industrial sector risk group, for instance, took a period of 4 years. On the other hand, there are exceptions such as the implementation of the smoking ban in the restaurants in the Netherlands or in the bars in Scotland, where compliance effects occurred after several months [Voedsel en Warenautoriteit, 2008; Intraval \& Voedsel en Warenautoriteit, 2009; Semple et al., 2007].

\subsubsection{Recommendations for the supervision}

The above considerations lead to a number of recommendations for the development and accountability of supervision. 
Well-informed choices are necessary to set up effective supervision and limit the burden of supervision. These can be made if research provides reliable information on risks, risk groups, the degree of compliance, (non-)compliance motives and the effectiveness of interventions. In this way, capacity is deployed where the greatest impacts are expected and the burden of supervision is limited among groups that are sufficiently compliant. To carry out the above research, inspectorates need to have sufficient knowledge of research methods as well as connections with the research world, because only then can new research insights be translated into instruments that optimise the supervision and only then can relevant research questions be formulated on the basis of supervisory practice.

Regarding the duty of accountability, it is clear that greater accountability is demanded from supervisors than before. However, as society's expectations are so high, and possibly too high, supervisors must manage these expectations in order to create a more realistic playing field. Capacity constraints force supervisors to make choices. It is important to communicate and motivate the choices made, so that the expectations of the parties involved (e.g. government, consumers and the supervised) be placed in a realistic perspective. In addition, it is sometimes advisable to undertake communication efforts in order to make citizens or other target groups aware of the risks and the contributions they themselves can make towards the mitigation of these risks. Alongside the communication of risks and the deployment of capacity, it is also important to communicate about the areas of supervision where compliance is high and safety or quality are sufficiently assured. This helps to give society a more balanced view. One suggestion in this connection is to carry out a trend analysis over several years, as improvements are often a slow and protracted process. Clearly, studies into and communication about the achieved effects also belong to the supervisor's set of instruments, as these produce valuable control information, even if the effects are disappointing.

Finally, incidents will always occur. It is advisable for the supervisor to clarify and explain its supervisory choices, methods and implementation to society as promptly as possible. This, in combination with the above-mentioned expectations management and risk communication, should in due course lead to greater understanding for the supervisor. 

Summary 
SUMMARY 


\section{Introduction}

From the 1950s onwards, it became generally known that smoking and passive smoking are harmful to one's health. In response, various governments adopted policy measures to discourage smoking and to reduce the health damage caused by (passive) smoking. The policy measures consist largely of legislation, e.g. provisions for the labelling and composition of tobacco products, bans on advertising and sponsorship, smoking bans, sales restrictions and taxes; however, other measures, such as general information and 'quit smoking' support programs, are also available.

In this thesis we focus on two legal provisions that emerged from the Dutch Tobacco Act, i.e. the workplace-smoking ban (excluding the hospitality sector), and the tobacco sales ban to minors. We investigated the effects of this legislation from two perspectives: 'compliance assessment', and 'policy impact assessment'. Legal provisions require that the parties involved (e.g. employers in the case of the workplace-smoking ban, and tobacco sellers in the case of checking the purchaser's age) comply with the law before an impact on the policy level can be expected. The third theme of this thesis is 'supervision'; the rationale for this is that the supervisory bodies are responsible for supervising the parties involved, with the aim to promote compliance.

These three themes are addressed in this thesis as follows:

1. Compliance assessment i.e. the extent to which the parties involved comply with the rules and how compliance behaviour can be influenced. Chapter 2 investigates the course of compliance among employers after the introduction of the workplace-smoking ban in 2004, and Chapter 3 examines the validity of self-reported measurements of compliance.

2. Policy impact assessment i.e. the extent of compliance with the policy goal of the legislation, i.e. this concerns the (societal) problems which need to be solved. Chapter 4 explores whether exposure to tobacco smoke among employees and atrisk groups decreased after introduction of the workplace-smoking ban. Chapter 5 focuses on the impact on smoking behaviour after implementation of the workplace-smoking ban and tax increases, and Chapter 6 investigates changes in the purchasing behaviour of young people who buy tobacco.

3. Supervision is an issue that has become increasingly important. The question arises whether the studies presented in this thesis offer (new) insights for improvement and justify the need for supervision. Chapter 7 describes the role of supervisory bodies in relation to the growing interest in evaluation and impact assessment, and implementation in practice. 


\section{Compliance assessment}

In Chapter 2 we examined the course of compliance after the introduction of the workplace-smoking ban in 2004. This study focused on differences in compliance over time and between occupational sectors, and describes the background variables related to the awareness and motivation to implement this ban. Telephone interviews were conducted with company employees across industry, and public and service sectors, in 2004, 2006 and 2008. Results show that, four years after introduction of the law, compliance rates increased (after an initial stagnation) from 85\% (2004) to $96 \%$ (2008). Differences in compliance between the sectors with the highest compliance (public sector) and the lowest compliance (industry) decreased from about 20\% to nearly $4 \%$ (2008). Simultaneous with the stronger increase in compliance within the industry sector, in that sector there was also a stronger increase in risk perception of enforcement and social influence. The conclusion was drawn that a high compliance rate was reached after four years. Also, during the entire period, a stronger increase in compliance was seen in the industry sector. This was probably due to the intensification of enforcement activities and additional measures (e.g. extension of the smoking ban to the hospitality sector) which may have increased awareness of enforcement and social support.

The study in Chapter 3 tests the validity of the compliance measures by comparing self-reported compliance (telephonic survey) with on-site inspections at the same workplace location $(n=360)$. The data showed a strong agreement between these two methods. This indicates that the measurement of compliance via self-reporting is a valid method to assess compliance with the workplace-smoking ban. After we also tested the predictive value of the self-reports, a surprising outcome was the negative predictive value. Over half of the companies that reported non-compliance were found to be compliant during the subsequent inspection. This compliance-promoting effect may be a beneficial side-effect of self-reporting. Moreover, the use of self-reports tends to reduce the burden of physical inspection on location.

\section{Impact assessment of the workplace-smoking ban}

The implementation of the workplace-smoking ban has two main objectives, both of which are investigated in this thesis. The legislature aims to protect non-smokers from exposure to tobacco smoke from smoking colleagues and also to discourage smoking by restricting the times and places where smoking is allowed.

Chapter 4 assesses the degree of exposure to tobacco smoke faced by nonsmoking employees. The expectation was that the decline of exposure among at-risk groups (i.e. males and lower educated employees) would be larger than in other groups. The study showed a decrease in the reported exposure among all employees 
(71\% to $52 \%$ ) and among the at-risk groups. However, even after the ban, males and lower educated employees still reported the highest level of exposure, i.e. $60 \%$ and $62 \%$, respectively. The conclusion is that, although half of the non-smoking employees still reports exposure, introduction of the ban resulted in better protection against tobacco smoke. In addition, some differences in gender and level of education remain regarding the extent of exposure.

The study in Chapter 5 explores how the combination of the workplace-smoking ban and two tax measures influenced smoking behaviour. For respondents with paid work these combined measures led to a decrease in the number of cigarettes smoked per day and in the prevalence of their daily smoking. For smokers not (directly) exposed to the workplace-smoking ban, respondents without paid work, and only exposed to the tax increases, no significant effect was found on any of the outcome parameters. The conclusion is that the combined policy measures influenced the smoking behaviour of respondents with paid work in a positive way, and that the impact of the combination of the workplace-smoking ban and tax increases is higher than the effect of the two separate measures alone, as was found in other studies.

\section{Impact assessment of the sales ban to minors}

The societal objective of the introduction of the tobacco sales ban to minors is to make it more difficult for young people to buy tobacco. Hopefully, this will ultimately lead to a decrease in the prevalence of smoking among young people and an increase in the age at which people start smoking.

Chapter 6 explores whether the introduction of the age limit of 16 years in 2003 led to a decrease in the purchase of tobacco products by the under $16 \mathrm{~s}$. The study shows that the percentage of adolescents (aged 13- 15 years) buying tobacco decreased from $26.3 \%$ (1999) before the ban to $10.8 \%$ (2003) after the legislation. Further analysis showed that this group of buyers consisted of both smokers and nonsmokers, and that the impact of the legislation for each group was different. After the ban, the proportion of smokers among buyers almost tripled (O.R. 2.9), while the likelihood of non-smokers buying tobacco showed a strong decrease (O.R. 0.17). This pattern was also observed in the number of weekly tobacco purchases. The frequency of buying increased in smoking buyers and remained the same in non-smoking buyers. The variety of commercial outlets in which purchases were made increased among both smoking and non-smoking purchasers of tobacco.

This leads to the conclusion that the tobacco sales ban may have contributed to making it more difficult for adolescents to buy tobacco and thus contributes to the achievement of the societal objective of this law. More specifically two conclusions can be drawn. The first is that the effect of the legislation among adolescents who already smoked was not large; in-depth analysis showed that in fact they had started to buy 
tobacco more frequently. To increase the effect of this ban, stronger compliance among sellers should be enforced so that this group of smokers also encounters more obstacles. The second conclusion is that the decrease in the percentage of adolescents buying tobacco was mainly attributable to non-smoking adolescents who no longer purchased tobacco. This finding corresponds with the second objective of the legislation, i.e. to discourage people from starting smoking. This is confirmed by other studies reporting that the percentage of non-smoking young people aged $12-16$ years in secondary education increased, as did the age at which they started smoking. It is likely that the introduction of this legislation contributed to these results.

\section{Supervision}

Chapter 7 describes the role of supervisory bodies in relation to the growing interest in evaluation and impact assessment, barriers in practice, as well as the need for supervisory bodies to account for the added value of surveillance.

Over the past decades, an enforcement paradox has arisen. In the absence of incidents, supervision is seen as 'a burden' for businesses; however, as soon as an incident occurs, the supervisory body is blamed for not preventing it and demands are made for increased supervision. The background of this paradox is as follows: on the one hand the prevailing perception among politicians and society is that supervision imposes a burden on businesses, that freedoms are being restricted, and that the costs of supervision are high; government takes steps to combat this by, e.g., reducing the regulatory burden and mergers, and cutbacks directed at inspectorates. On the other hand, society's expectations are high when it comes to the safety and/or quality of their public services.

Supervisory bodies are aware of this paradox and realise more than ever that they have to account for how supervision is carried out and the impact that is achieved by this supervision. In addition, inspectorates have to make strategic decisions to deploy their limited capacity to where it is expected to have the greatest impact. To achieve this, the evaluation of supervision is needed.

However, despite this need and the activities undertaken by inspectorates (e.g. increased cooperation between (government) inspectorates and intensified collaboration with research institutes to increase knowledge on supervision and the evaluation of its impact), there is no structural embedding of evaluation in the primary work of the process of supervisors. In addition to the cutbacks in capacity and financing, factors that may act as barriers include the methodology applied, the organisational characteristics of the inspectorates, and the possible vulnerability in relation to accountability. 


\section{Significance for supervision}

In the general discussion (Chapter 8 ) the findings of the various studies are summarised according to the main themes of the work in this thesis. Then, the significance of the findings are reported and (partly) highlighted from the perspective of 'supervision'.

When considering what the results of these studies mean for supervisory bodies in relation to the performance of compliance assessment, we conclude that it is important to obtain insight into the level of compliance, the risk groups involved, and the motives behind (non-)compliance. For this purpose, the use of self-reports appears to be valid under certain conditions; this method saves costs and may also promote compliance. To increase compliance, an enforcement approach needs to be developed based on the motives of the target group. It will probably take some time before the effects of compliance can be observed, whereby periodic monitoring of the level of compliance and its effects is advisable, also in order to make necessary adjustments.

When considering the significance of the results for policy evaluation we conclude that, after the introduction of the workplace-smoking ban, employees are better protected from tobacco smoke. In addition, with regard to the extent of exposure, some differences still exist in relation to gender and a person's level of education. The conclusion regarding smoking behavior is that the combination of the workplace-smoking ban and tax increases has led to a decline in the number of daily smokers and a decrease in the intensity of smoking. Moreover, the impact of these policy measures combined is greater than the effects reported by others for the two measures applied individually. The introduction of the tobacco sales ban has made it more difficult for young people to purchase tobacco and, moreover, the (still) non-smoking youth have been the most discouraged to buy tobacco. 

Samenvatting 



\section{Inleiding}

Sinds de tweede helft van de twintigste eeuw is bekend dat roken en meeroken schadelijk zijn voor de gezondheid. In reactie hierop nemen overheden van landen beleidsmaatregelen om het roken te ontmoedigen en de gezondheidsschade ten gevolge van het (mee)roken terug te dringen. De beleidsmaatregelen bestaan grotendeels uit wetgeving, (bv. eisen aan de etikettering en samenstelling van tabaksproducten, een verbod op reclame en sponsoring, rookverboden, verkoopbeperkingen en accijnsverhogingen), maar daarnaast zijn er ook andere maatregelen zoals voorlichting en programma's om rokers te ondersteunen met stoppen.

In dit proefschrift staan twee wettelijke bepalingen centraal; de invoering van de rookvrije werkplek in 2004 en de invoering van de leeftijdsgrens van 16 jaar bij de verkoop van tabak in 2003. We onderzochten de effecten van deze bepalingen vanuit twee thema's: naleefevaluatie en beleidsevaluatie. Wettelijke bepalingen vereisen immers dat de onder toezicht staanden, zoals werkgevers bij de rookvrije werkplek en tabaksverkopers bij de controle op de leeftijdsgrens, de wet naleven alvorens een effect op beleidsniveau verwacht mag worden. Het derde thema van dit proefschrift is toezicht, omdat toezichthouders belast zijn met het toezicht op de actoren en het doel hebben de naleving te bevorderen en in geval van overtredingen sancties kunnen opleggen.

Deze thema's komen in dit proefschrift als volgt aan bod:

1. Naleefevaluatie betreft de mate waarin onder toezicht staanden zich aan de regels houden en hoe naleefgedrag kan worden beïnvloed. In hoofdstuk 2 onderzoeken we het verloop van de naleving na de invoering van de rookvrije werkplek in 2004 bij werkgevers en in hoofdstuk 3 testen we de validiteit van de zelf gerapporteerde naleefmetingen.

2. Beleidsevaluatie richt zich op het beleidsdoel van de wetgeving; dit betreft het (maatschappelijk) probleem dat opgelost moet worden. Hoofdstuk 4 onderzoekt of de blootstelling bij werknemers en bij risicogroepen daalt na de invoering van de rookvrije werkplek en in hoofdstuk 5 onderzoeken we het effect op het rookgedrag na de invoering van de rookvrije werkplek en de accijnsverhogingen. In hoofdstuk 6 verkennen we het aankoopgedrag van tabak door jongeren na invoering van de leeftijdsgrens.

3. Toezicht is een onderwerp wat de laatste decennia sterk in ontwikkeling is. De vraag is in hoeverre de uitgevoerde onderzoeken in dit proefschrift (nieuwe) inzichten geven ten behoeve van het verbeteren en verantwoorden van het toezicht. In hoofdstuk 7 beschrijven we de rol van toezichthouders in relatie tot de groeiende aandacht voor toezichtsevaluatie en de uitvoering in de praktijk. 


\section{Naleefevaluatie}

We onderzochten in hoofdstuk 2 het verloop van de naleving na de invoering van de rookvrije werkplek in 2004 bij werkgevers. De studie was gericht op verschillen in naleving over de tijd en tussen sectoren en beschreef achtergrondvariabelen met betrekking tot bewustwording en motivatie om de wet na te leven. Er zijn telefonische interviews gehouden met werkgevers uit de industriële sector, de overheid en de dienstverlenende sector in 2004, 2006 en in 2008. Hieruit bleek dat de naleving vier jaar na invoering, na een initiële stagnatie van enkele jaren, was gestegen van $85 \%$ in 2004 tot $96 \%$ in 2008 . Het verschil bij de sectoren tussen de hoogste naleving (overheid) en de laagste naleving (industrie) daalde van $20 \%$ tot slechts $4 \%$ in 2008 . Gelijktijdig bleek dat de snellere stijging van de naleving bij de industrie gepaard ging met een stijging van pakkansbeleving en een toename van de sociale druk. De eindconclusie was dat na vier jaar een hoge naleving in alle sectoren was bereikt. Binnen deze periode was er een sterkere stijging van de naleving bij de industriële sector. Deze stijging werd waarschijnlijk veroorzaakt door de intensivering van de handhaving en de invoering van aanvullend beleid, zoals de uitbreiding van het rookverbod naar de horeca, wat vermoedelijk geleid heeft tot een verhoogde pakkansbeleving en intensivering van sociale druk.

In hoofdstuk 3 hebben we de validiteit van de naleefmetingen getest door de zelf gerapporteerde naleving (telefonische enquêtes) te vergelijken met officiële inspectiegegevens van dezelfde werkplek locatie. De resultaten lieten een hoge overeenkomst zien tussen de twee methoden. Dit gaf aan dat het meten van naleving via zelfrapportage een valide methode was om de naleving op de rookvrije werkplek vast te stellen. We hebben ook de voorspellende waarde van de zelfrapportages getest en de verrassende uitkomst was de negatieve voorspellende waarde van de zelfrapportage. Ruim de helft van de bedrijven die niet-naleving rapporteerden bleken tijdens de daarop volgende inspectie namelijk wel na te leven. Dit naleefbevorderend effect kan een gunstig neveneffect zijn van zelfrapportage. Bovendien helpt deze manier van meten om de toezichtlast te verlagen.

\section{Beleidsevaluatie rookvrije werkplek}

De invoering van de rookvrije werkplek heeft twee beleidsdoelen die in dit proefschrift beiden onderzocht zijn. De wetgever wil niet-rokers beschermen tegen de blootstelling aan tabaksrook van collega's en wil rokers ontmoedigen door het roken te beperken in tijd en plaats.

In hoofdstuk 4 is de mate van blootstelling aan tabaksrook door niet-rokende werknemers onderzocht. De verwachting was dat de daling van blootstelling bij risicogroepen (mannen en laaggeschoolden) groter zou zijn dan bij andere doelgroepen. Uit 
het onderzoek bleek zowel een daling van de gerapporteerde blootstelling bij alle werknemers (71\% naar 52\%) als bij de risicogroepen. Echter, ook na de invoering van de wetgeving rapporteerden mannen en laaggeschoolden nog de hoogste blootstelling, respectievelijk $60 \%$ en $62 \%$. De conclusie is dat, hoewel de helft van de nietrokende werknemers nog steeds blootstelling rapporteert, er na de invoering een betere bescherming is tegen tabaksrook. Daarnaast bestaan er nog steeds verschillen in geslacht en in opleiding ten aanzien van de mate van blootstelling.

De studie in hoofdstuk 5 onderzocht wat het effect was op het rookgedrag ten gevolge van de invoering van de rookvrije werkplek in combinatie met twee accijnsverhogingen. Bij werknemers hebben deze gecombineerde maatregelen geleid tot een daling van het aantal dagelijkse sigaretten bij rokers en tot een daling van het aantal dagelijkse rokers. Bij rokers die niet (direct) zijn blootgesteld aan de rookvrije werkplek, de niet-werkenden, en alleen een accijnsverhoging hebben ondergaan zijn geen veranderingen vastgesteld van het rookgedrag. De conclusie is dat de gecombineerde beleidsmaatregelen het rookgedrag van werkenden positief hebben beïnvloed en dat het effect van de combinatie van de rookvrije werkplek met accijnsverhogingen groter is dan in andere onderzoeken voor de afzonderlijke maatregelen wordt gevonden.

\section{Beleidsevaluatie leeftijdsgrenzen tabak}

Het instellen van de wettelijke leeftijdsgrens bij de verkoop van tabaksproducten heeft als maatschappelijk doel het moeilijker maken voor jongeren om tabak te kopen. Uiteindelijk moet dit leiden tot een daling van de rookprevalentie bij jongeren en een stijging van de leeftijd waarop gestart wordt met roken.

Hoofdstuk 6 onderzoekt of de invoering van de leeftijdsgrens van 16 jaar in 2003 heeft geleid tot een daling van tabaksaankopen bij jongeren onder de 16 jaar. Uit de studie bleek dat het percentage jongeren in de leeftijdscategorie dertien tot vijftien jaar dat tabak kocht is gedaald van $26 \%$ vóór de invoering van de wet (1999) naar $11 \%$ na de invoering (2003). Verdere analyse toonde aan dat deze groep kopers bestond uit rokers en uit niet-rokers, waarbij het effect van de wetgeving per groep anders was. $\mathrm{Na}$ het verbod was het percentage rokers onder de kopers bijna verdrievoudigd (O.R. 2.9), terwijl de kans dat niet-rokers tabak kopen sterk was afgenomen (O.R. 0.17). Dit patroon werd ook zichtbaar in het aantal wekelijkse aankopen, waarbij de frequentie gestegen was bij rokende kopers en gelijk was gebleven bij niet-rokende kopers. De variatie in commerciële verkooppunten waar aankopen werden gedaan is toegenomen zowel onder rokende als onder niet-rokende kopers van tabak.

Dit leidt tot de conclusie dat invoering van de leeftijdsgrens voor tabaksaankoop het waarschijnlijk moeilijker heeft gemaakt voor jongeren om tabak te kopen, waarmee het bijdraagt aan het maatschappelijke doel van deze wet. Meer specifiek kunnen er twee conclusies worden getrokken. Ten eerste is het effect bij de (al) rokende jon- 
geren niet groot en zou de effectiviteit van deze maatregel verhoogd kunnen worden door een sterkere naleving af te dwingen bij de verkopers, waardoor ook deze rokende groep belemmeringen ondervindt. Ten tweede is de daling van het percentage jongeren dat tabak koopt met name te danken aan (nog) niet-rokende jongeren die geen tabak (meer) kopen. Dit is in lijn met het tweede doel van de wetgever, ontmoedigen van het starten met roken. Dit werd bevestigd door andere onderzoeken waaruit bleek dat het percentage niet-rokende schoolgaande jongeren van 12 tot 16 jaar is toegenomen na 2003, evenals de leeftijd waarop gestart werd met roken. Het is zeer aannemelijk dat de invoering van de leeftijdsgrens hieraan heeft bijgedragen.

\section{Toezicht}

In hoofdstuk 7 beschrijven we de rol van toezichthouders in relatie tot de groeiende aandacht voor toezichtsevaluatie, de knelpunten in de praktijk en de noodzaak voor toezichthouders om zich te verantwoorden voor de toegevoegde waarde van het toezicht.

De laatste decennia is een handhavingsparadox ontstaan. Bij afwezigheid van incidenten wordt toezicht gezien als last voor het bedrijfsleven, maar zodra er een ongeval of ernstige gebeurtenis plaatsvindt, wordt de toezichthouder verantwoordelijk gehouden en eist men meer toezicht. Dit komt door de heersende perceptie onder politici en de maatschappij dat het toezicht een last is voor bedrijven, dat vrijheden worden beperkt en dat de kosten van het toezicht hoog zijn. De overheid neemt maatregelen om dit tegen te gaan, zoals vermindering van de regeldruk en fusies en bezuinigingen bij toezichthouders. Tegelijkertijd zijn verwachtingen van de maatschappij hoog gespannen als het gaat om veiligheid of kwaliteit van de openbare diensten.

Toezichthoudende organisaties zijn zich bewust van deze paradox en beseffen zich dat ze zich moeten verantwoorden voor het uitgevoerde toezicht en het bereikte resultaat. Daarnaast zullen toezichthouders strategische keuzes moeten maken om de beperkte capaciteit daar in te zetten waar het grootste effect zal worden verwacht. Voor beiden is evaluatie van het toezicht noodzakelijk.

Echter, ondanks deze noodzaak en de ondernomen activiteiten van toezichthouders, zoals de toegenomen samenwerking tussen (overheids) inspecties en de geïntensiveerde samenwerking met de wetenschap om meer kennis over het toezicht en de evaluatie van de effecten te ontwikkelen, is er nog geen structurele inbedding van de evaluatie van het toezicht in het primaire werkproces van toezichthouders. Factoren die mogelijk belemmerend werken naast de afweging hoeveel geld en capaciteit er beschikbaar is in tijden van bezuinigingen hebben te maken met de methodologie, de organisatorische kenmerken van toezichthouders en de mogelijke kwetsbaarheid bij openbare verantwoording. 


\section{Betekenis voor het toezicht}

In de algemene discussie (hoofdstuk 8) worden de conclusies van de verschillende hoofdstukken samengevat onder de verschillende thema's. Vervolgens wordt de betekenis van de bevindingen gerapporteerd en (mede) belicht uit het oogpunt van toezicht.

Als we ons de vraag stellen wat de resultaten betekenen voor het toezicht in relatie tot het uitvoeren van naleefevaluatie kunnen we aangeven dat het belangrijk is om inzicht te hebben in de mate van naleving, in risicogroepen en in motieven voor (niet-) naleving. Het gebruik van zelfrapportage hierbij is onder bepaalde voorwaarden mogelijk. Dit bespaart kosten en lijkt naleefbevorderend te werken. Om de naleving te verhogen kan daarna een handhavingsaanpak worden ontwikkeld die aansluit bij de motieven van de doelgroep. Het bereiken van een effect kan tijd kosten, waarbij periodieke onderzoeken naar de naleving en effecten aan te raden zijn om bijsturing mogelijk te maken.

Als het gaat om wat de resultaten aangaande beleidsevaluatie betekenen is de conclusie dat er na de invoering van de rookvrije werkplek een betere bescherming is van de werknemers tegen tabaksrook. Daarnaast bestaan er nog steeds verschillen in geslacht en in opleiding ten aanzien van de mate van blootstelling. De conclusie ten aanzien van het rookgedrag is dat het effect van de combinatie van de rookvrije werkplek met accijnsverhogingen heeft geleid tot een daling van het aantal dagelijkse rokers en een daling in de intensiteit van het roken en dat het effect van deze gecombineerde beleidsmaatregelen groter is dan de effecten die in andere onderzoeken voor de afzonderlijke maatregelen wordt gevonden. De invoering van de leeftijdsgrens heeft het moeilijker gemaakt voor jongeren om tabak te kopen, waarbij de (nog) nietrokende jongeren het meest werden ontmoedigd om tabak te kopen. 



\section{References}



Algemene Rekenkamer (ARK). (1990). Verslag van de Algemene Rekenkamer over 1989 - deel 2 onderzoek naar inspecties (Research on inspectorates) (21481 nr.2). Tweede Kamer der Staten Generaal (19891990). 's-Gravenhage, SDU uitgevers.

Algemene Rekenkamer (ARK). (2002). Handhaving door rijksinspecties (Enforcement by governmental inspectorates) (28271 nr.2). Tweede Kamer der Staten Generaal (2001-2002). 's-Gravenhage, SDU uitgevers.

Algemene Rekenkamer (ARK). (2005). Handhaven en gedogen (Enforce and tolerate) (30050 nr.2). Tweede Kamer der Staten Generaal (2004-2005). 's-Gravenhage, SDU uitgevers.

Algemene Rekenkamer (ARK). (2008). Handhaven en gedogen - Rapport: Terugblik 2008 (Enforcement and Tolerance - report: A look back at 2008) (30050 nr.5). Tweede Kamer der Staten Generaal (2007-2008). 's-Gravenhage, SDU uitgevers.

Algemene Rekenkamer. (2013). Toezicht bij de Nederlandse Voedsel en Warenautoriteit na de fusie (26991 nr. 386). Tweede Kamer der Staten Generaal (2013-2014). 's-Gravenhage, SDU uitgevers.

Allwright, S., Paul, G., Greiner, B., Mullally, B.J., Pursell, L., Kelly, A. et al. (2005). Legislation for smoke-free workplaces and health of bar workers in Ireland: Before and after study. British Medical Journal, 331(7525), 1117-1120.

Altman, D.G. \& Bland, J.M. (1994). Diagnostic tests 2: Predictive values. British Medical Journal, 309(6947), 102.

Astma Fonds, KWF Kankerbestrijding, Nederlandse Hartstichting and Stivoro. (2007) Dossier over de gevolgen van roken en het tabaksontmoedigingsbeleid (Report about the consequences of smoking and the policy of discouragement of smoking). Astmafonds.

Bagott M., Jordan C., Wright C. \& Jarvis S. (1998). How easy is it for young people to obtain cigarettes, and do test sales by trading standards have any effect? A survey of two schools in Gateshead. Child: Care Health \& Development, 24, 207-216.

Barnoya, J, \& Glantz, S.A. (2005). Cardiovascular effects of secondhand smoke: Nearly as large as smoking. Circulation, 111(20), 2684-98.

Bieleman B. \& Kruize A. (2004). Monitor tabaksverstrekking jongeren 2003 (Monitoring tobacco sales to youth 2003). Groningen: Intraval 2004.

Bieleman B. \& Kruize A. (2007). Monitor naleving rookvrije werkplek 2006 (Monitor compliance smoke free workplace). Groningen-Rotterdam: Intraval.

Bieleman B., Kruize .A \& Zimmerman C. (2010). Monitor tabaksverstrekking 2009, naleving leeftijdsgrens 16 jaar: tweejaarlijkse metingen 1999-2009 (tobacco distribution survey 2009, compliance of the age limit of 16 years: biennial measurements 1999 - 2009). Groningen-Rotterdam: Intraval.

Bieleman B., Kruize A. \& Zimmerman C. (2012). Monitor alcoholverstrekking jongeren 2011, naleving leeftijdsgrenzen 16 en 18 jaar: tweejaarlijkse metingen 1999-2011 (alcohol distribution youth survey 2011, compliance of the age limits of 16 and 18 years: biennial measurements 1999 - 2011). Groningen-Rotterdam: Intraval.

Borland, R., Pierce, J.P., Burns, D.M., Gilpin, E., Johnson, M. \& Bal, D. (1992). Protection from environmental tobacco smoke in California: The case for a smoke-free workplace. JAMA, 268(6), 749-752.

Borland, R., Yong, H.H., Siahpush, M., Hyland, A., Campbell, S., Hastings, G., et al. (2006). Support for and reported compliance with smoke-free restaurants and bars by smokers in four countries: Findings from the International Tobacco Control (ITC) Four Country Survey. Tobacco Control, 15(Suppl 3), iii34-iii41.

Boseley, S. (2012, April 5). Cigarette and tobacco displays banned in supermarkets. The Guardian.

Bouma, J. (2013, June 7). Documenten over tabakslobby in Nederland openbaar gemaakt. Trouw.

Brownson, R.C., Davis, J.R., Jackson-Thompson, J. \& Wilkerson, J.C. (1995). Environmental tobacco smoke awareness and exposure: Impact of a statewide clean indoor air law and the report of the US Environmental Protection Agency. Tobacco Control, 4, 132-138.

Brownson, R.C., Eriksen, M.P., Davis, R.M. \& Warner, K.E. (1997). Environmental tobacco smoke: Health effects and policies to reduce exposure. Annual Review of Public Health, 18, 163-185. 
Castrucci B.C., Gerlach K.K., Kaufman N.J. \& Orleans C.T. (2002). Adolescents' acquisition of cigarettes through noncommercial sources. Journal of Adolescent Health, 31(4), 322-326.

CBS StatLine. (2009). Maandelijkse cijfers werkloze, werkzame- en nietberoepsbevolking (monthly figures of unemployed, employed and non workforce. Retrieved November 11, 2009 from Centraal Bureau voor de Statistiek Web site: http://statline.cbs.nl/statweb.

CBS StatLine. (2010). ICT gebruik van personen naar persoonskenmerken (ICT use of persons related to personal characteristics). Retrieved 2010 from Centraal Bureau voor de Staitstiek Web site: http://statline.cbs.nl/statweb.

Centrum voor Criminaliteitspreventie en Veiligheid. (2010). Programmatisch handhaven, gids voor departementen en inspecties (Programmatic supervision, guide for departments and inspections). Utrecht: CCV.

Chaloupka F.J. \& Wechsler H. (1997). Price, tobacco control policies and smoking among young adults. Journal of Health Economics 16(3), 359-373.

Chan, Y. H. (2003). Biostatistics I 04: Correlational Analysis. Singapore Medical Journal, 44(12), 614-619.

Chapman, S., Borland, R., Scollo, M., Brownson, R.C., Dominello, A. \& Woodward, S. (1999). The impact of smoke-free workplaces on declining cigarette consumption in Australia and the United States. American Journal of Public Health, 89(7), 1018-1023.

Coghlin, J., Hammond, S.K. \& Gann, P.H. (1989). Development of epidemiologic tools for measuring environmental tobacco smoke exposure. American Journal of Epidemiology, 130(4), 696-704.

Cummings K.M., Sciandra E., Peckacek T.F., Orlandi M. \& Lynn W.R. (1992). Where teenagers get their cigarettes: A survey of the purchasing habits of 13-16 year olds in 12 US communities. Tobacco Control, 1(4), 264-267.

Cummings, K.M., Markello, S.J., Mahoney, M., Bhargava, A.K., McElroy, P.D. \& Marshall, J.R. (1990). Measurement of current exposure to environmental tobacco smoke. Archives of Environmental Health, 45(2):74-79.

Cummings, K.M., Morley, C.P., Horan, J.K., Steger, C. \& Leavell, N.R. (2002). Marketing to America's youth: Evidence from corporate documents. Tobacco Control, 11(suppl1), 15-17.

De Beyer, J. \& Waverly Brigden, L. (2003). Tobacco Control Policy: Strategies successes and setbacks. Washington: World Bank \& Research for International Tobacco Control.

Department for Business, Innovation and Skills, Better Regulation Delivery Office. (2013). Conference Report, Inspection Reform: The change that matter (3.0). BRDO.

Diepen van M. (2007). Onderzoek zelfregulering rookbeleid in de horeca en cultuursector: resultaten 2006: $2 e$ monitor (Research self-regulation smoking policy in the hospitality and culture sector: Results 2006: $2^{\text {nd }}$ monitor) (E6542), Amsterdam TNS-NIPO.

DiFranza J.R. \& Coleman M . (2001). Sources of tobacco for youths in communities with strong enforcement of youth access laws. Tobacco Control, 10(4), 323-328.

DiFranza J.R. (2003). Adolescents' acquisition of cigarettes through noncommercial sources. Journal of Adolescent Health, 32(5), 331-332.

Dijksma, S.A.M. \& Schippers, E.I. (2013). Brief aan de Voorzitter van de Tweede Kamer der Staten-Generaal betreft stand van zaken voedselincidenten (food incidents) (DGA-PAV/13042661). Ministerie van Economische Zaken.

Dishoeck. A., Oude Wesseling, S.F., Lingsma, H.F., Steyersberg, E.W., Robben, P.B.M. \& Mackenbach, J.P. (2013). Transparantie: is het effect van toezicht te meten?, haalbaarheid van effectmeting door de inspectie (Transparency: can the effect of supervision be measured?, feasibility of impact measurement by the inspectorate). Nederlands Tijdschrift voor Geneeskunde, 157:A1676.

Doll, R. \& Hill, A.B. (1950). Smoking and carcinoma of the lung: Preliminary report. British Medical Journal, 2(4682), 739-748.

Doll, R. \& Hill, A.B. (1956). Lung cancer and other causes of death in relation to smoking: A second report on the mortality of British doctors. British Medical Journal, 2(5001), 1071-1081. 
Eadie D., Heim D., Macaskill S., Ross A., Hastings G. \& Davies J. (2008). A qualitative analysis of compliance with smoke-free legislation in community bars in Scotland: Implications for public health. Addiction 103(6), 1019-1026.

Eagan, T.M., Hetland, J. \& Aarø, L.E. (2006) Decline in respiratory symptoms in service workers five months after a public smoking ban. Tobacco Control, 15(3),242-246.

Edwards, R., Thomson, G., Wilson, N., Waa, A., Bullen, C., O'Dea, D. et al. (2008). After the smoke has cleared: Evaluation of the impact of a new national smoke-free law in New Zealand. Tobacco Control, 17(1), e2.

Ellingsen, D.G., Fladseth, G., Daae, H.L., Gjølstad, M., Kjaerheim, K., Skogstad, M. et al. (2006). Airborne exposure and biological monitoring of bar and restaurant workers before and after the introduction of a smoking ban. Journal of Environmental Monitoring, 8(3), 362-368.

Emmons, K.M., Abrams, D.B., Marshall, R., Marcus, B.H., Kane, M., Novotny, T.E. et al. (1994). An evaluation of the relationship between self-report and biochemical measures of environmental tobacco smoke exposure. Preventive Medicine, 23(1), 35-39.

Emont, S.L., Choi, W.S., Novotny, T.E. \& Giovino, G. A. (1993). Clean indoor air legislation, taxation, and smoking behaviour in the United States: An ecological analysis. Tobacco Control, 2, 13-17.

Eriksen M \& Chaloupka F. (2007). The economic impact of clean indoor air laws. CA: A Cancer Journal for Clinicians. 57(6), 367-378.

European Commission. (2011). Excise duty tables: part III-Manufactured tobacco. (REF 1033). Brussels: European commission.

European Commission. (2013). Excise duty tables, part III-Manufactured tobacco. (REF 1038). Brussels: European commission.

European Network for Smoking Prevention. (2007). European trends toward smoke-free provisions. Retrieved 2007, April from: http://www.ensp.org/files/legislation_on_smokefree_workplaces_200704.pdf

European Parliament and the Council. $\left(1989^{\mathrm{a}}\right)$. Council Directive 89/552/EEC of 3 October 1989 on the coordination of certain provisions laid down by law, regulation or administrative action in Member States concerning the pursuit of television broadcasting activities (L 298/23). Official Journal of the European Communities.

European Parliament and the Council. $\left(1989^{\mathrm{b}}\right)$. Council Directive 98/622/EEC of 13 November 1989 on the approximation of laws, regulations and administrative provisions of the Member States concerning the labelling of tobacco products (L 359/1). Official Journal of the European Communities.

European Parliament and the Council. (1990). Council Directive 90/239/EEC of 17 May 1990 on the approximation of the laws, regulations and administrative provisions of the Member States concerning the maximum tar yield of cigarettes (L 137/36). Official Journal of the European Communities.

European Parliament and the Council. (1992). Council Directive 92/41/EEC of 15 May 1992 amending Directive 89/622/EEC on the approximation of the laws, regulations and administrative provisions of the Member States concerning the labelling of tobacco products ( $L$ 158/30). Official Journal of the European Communities.

European Parliament and the Council. (1998). Directive 1998/43/EC of the European parliament and of the council of 6 July 1998 on the approximation of the laws, regulations and administrative provisions of the Member States relating to the advertising and sponsorship of tobacco product (L 213/9). Official Journal of the European Communities.

European Parliament and the Council. (2001). Directive 2001/37/EC of the European parliament and of the council of 5 June 2001 on the approximation of the laws, regulations and administrative provisions of the Member States concerning the manufacture, presentation and sale of tobacco (194/26). Official Journal of the European Communities. 
European Parliament and the Council. (2003). Directive 2003/33/EC of the European parliament and of the council of 26 May 2003 on the approximation of the laws, regulations and administrative provisions of the Member States relating to the advertising and sponsorship of tobacco products (L 152/16). Official Journal of the European Communities.

European Parliament and the Council. (2014). Directive 2014/40/EU of the European parliament and of the council of 3 April 2014 on the approximation of the laws, regulations and administrative provisions of the Member States concerning the manufacture, presentation and sale of tobacco and related products and repealing Directive 2001/37/EC (L 127/1). Official Journal of the European Communities.

Evans, W.N., Farrelly, M.C. \& Montgomery, E. (1999). Do workplace smoking bans reduce smoking? American Economic Review, 89, 728-747.

Ezzati, M. \& Lopez, A.D. (2004). Regional, disease specific patterns of smoking-attributable mortality in 2000. Tobacco Control, 13(4), 388-395.

Farrelly, M.C., Evans, W.N., Skekas, A.E. (1999). The impact of the workplace smoking bans: Results from a national survey. Tobacco Control, 8, 272-277.

Farrelly, M.C., Nonnemaker, J.M., Chou, R., Hyland, A., Peterson, K.K. \& Bauer, U.E. (2005). Changes in hospitality workers' exposure to secondhand smoke following the implementation of New York's smokefree law. Tobacco Control, 14(4), 236-241.

Farrington, D.P., Gottfredson, D.C., Sherman, L.W., \& Welsh, B.C. (2002). Maryland Scientific Methods Scale. In Sherman L.W., Farrington D.P., Welsh B.C. \& MacKenzie D.L., (Eds), Evidence-Based Crime Prevention, (pp. 13-21) London: Routledge.

Fichtenberg, C.M. \& Glantz, S.A. $\left(2002^{\mathrm{a}}\right)$. Youth access interventions do not affect youth smoking. Pediatrics, 109(6), 1088-1094.

Fichtenberg, C.M. \& Glantz, S.A. $\left(2002^{\text {b }}\right)$. Effect of smoke-free workplaces on smoking behaviour: Systematic review. British Medical Journal, 325, 188-194.

Field A. (2005). Discovering statistics using SPSS (2nd ed.). London: SAGE Publications LTD.

Fong, G.T., Hammond, D. \& Hitchman, S.C. (2009). The impact of pictures on the effectiveness of tobacco warnings (Bulletin of World Health Organization vol.87:640-643). Geneva: WHO.

Fong, G.T., Hyland, A., Borland, R., Hammond, D., Hastings, G., McNeill, A. et al. (2006). Reductions in tobacco smoke pollution and increases in support for smoke-free public places following the implementation of comprehensive smoke-free workplace legislation in the Republic of Ireland: Findings from the ITC Ireland/UK Survey. Tobacco Control, 15(Suppl.3), iii51-58.

Forster J.L. \& Wolfson M. (1998). Youth access to tobacco: Policies and politics. Annual Review of Public Health, 19, 203-35.

Freeman, B., Chapman, S. \& Rimmer, M. (2008) The case for the plain packaging of tobacco products. Addiction, 103(4), 580-590.

Galán, I., Mata, N., Estrada, C., Díez-Gañán, L., Velázquez, L., Zorrilla, B. et. al. (2007). Impact of the "Tobacco control law" on exposure to environmental tobacco smoke in Spain. BMC Public Health, 7, 224.

Gallus, S., Schiaffino, A., La Vecchia, C., Townsend, J. \& Fernandez, E. (2006). Price and cigarette consumption in Europe. Tobacco Control, 15(2), 114-119.

Gelder, B.M. van, Poos, M.J.J.C. \& Zantinge, E.M. (2011). Wat zijn de mogelijke gezondheidsgevolgen van roken? Retrieved September 22, 2011, from RIVM Web site: http://www.Nationaal kompas.nl\NationaalKompasVolksgezondheid\Gezondheidsdeterminanten\Leefstijl\Roken.

Gerlach K.K., Shopland D.R., Hartman A.M., Gibson J.T. \& Pechacek T.F. (1997). Workplace smoking policies in the United States: Results from a national survey of more than 100,000 workers. Tobacco Control 6, 199-206.

Gezondheidsraad. (1990). Beoordeling van de schadelijkheid van omgevingsrook voor de gezondheid ( $\mathrm{nr}$. 1990/18). Den Haag: Gezondheidsraad.

Gezondheidsraad. (2003). Volksgezondheidsschade door passief roken (nr.2003/21). Den Haag: Gezondheidsraad. 
Gezondheidsraad. (2011). Op weg naar evidence based toezicht: het onderzoek naar effecten van toezicht door de Inspectie voor de Gezondheidszorg (Towards evidence-based supervision: Study on the impact of supervision by the Health Care Inspectorate). (nr.2011/03). Den Haag: Gezondheidsraad.

Gilpin, E.A., Farkas, A.J., Emery, S.L., Ake, C.F. \& Pierce, J.P. (2002). Clean indoor air: Advances in California, 1990-1999. American Journal of Public Health, 92(5), 785-791.

Gonzalez, M. \& Glantz, S.A. (2011). Failure of policy regarding smoke-free bars in the Netherlands. European Journal of Public Health, 23(1), 139-145.

Goodin M. \& McAllister I. (1997). Evaluating compliance with Australia's first smoke-free public places legislation. Tobacco Control, 6, 326-31.

Guindon, G.E., Tobin, S. \& Yach, D. (2002). Trends and affordability of cigarette prices: ample room for tax increases and related health gains. Tobacco Control, 1, 35-43.

Gwet, K. L. (2008). Computing inter-rater reliability and its variance in the presence of high agreement. British Journal of Mathematical and Statistical Psychology, 61, 29-48.

Hammond, D. (2011). Health warning messages on tobacco products: A review. Tobacco Control, 20(5), 327337.

Hammond, S.K. (1999). Exposure of U.S. workers to environmental tobacco smoke. Environmental Health Perspective, 107(suppl.2), 329-340.

Hampton, P. (2005). Reducing administrative burdens: Effective inspection and enforcement. London: HM Treasury.

Haw, S.J. \& Gruer, L. (2007). Changes in exposure of adult non-smokers to secondhand smoke after implementation of smoke-free legislation in Scotland: National cross sectional survey. British Medical Journal, 335, 549-552.

Hefler, M. (2013, Febuary 19). New Zealand government to introduce tobacco plain packaging [web log post]. Retrieved from http://blogs.bmj.com/tc/2013/02/19/new-zealand-government-to-introducetobacco-plain-packaging.

Heloma, A. \& Jaakkola, M.S. (2003). Four-year follow-up of smoke exposure, attitude and smoking behaviour following enactment of Finland's national smoke-free work-place law. Addiction, 98(8), 1111-1117.

Hibell B., Andersson B., Bjarnason T., Ahlström S., Balakireva O., Kokkevi A. et al. (2003). The Espad report 2003, Alcohol and other drug use among students in 35 European countrie. Stockholm: Espad.

Hilton S., Semple S., Miller B.G., MacCalman L., Petticrew M., Dempsey S. et al. (2007). Expectations and changing attitudes of bar workers before and after the implementation of smoke-free legislation in Scotland. BMC Public Health, 7, 206.

Hinds M.W. (1992). Impact of a local ordinance banning tobacco sales to minors. Public health reports 107(3), 355-358.

Holbrook, A. L., Green, M. C., \& Krosnick, J. A. (2003). Telephone versus Face-to-Face interviewing of national probability samples with long questionnaires: Comparisons of respondent satisficing and social desirability response bias. Public Opinion Quarterly, 67, 79-125.

Hoof J. van \& Krokké J. (2011). Alcoholverkoop aan jongeren, een landelijk nalevingsonderzoek (alcohol sales to youth, a nationwide compliance survey). Enschede: Twente University.

Hopkins, D.P., Briss, P.A., Ricard, C.J., Husten, C.G., Carande-Kulis, V.G., Fielding, J.E. et al. (2001). Reviews of evidence regarding interventions to reduce tobacco use and exposure to environmental tobacco smoke. American Journal of Preventive Medicine, 20(Suppl.2), 16-66.

Hurd, A. L., Mayer, J. A., Woodruff, S. I., Belch, G. E. \& Patel, M. R. (2006). Comparing two methods of measuring legislation compliance among indoor tanning facilities. Journal of the American Academy of Dermatology, 54, 433-439.

Hyland, A., Higbee, C., Borland, R., Travers, M., Hastings, G., Fong, G.T, et al. (2009). Attitudes and beliefs about secondhand smoke and smoke-free policies in four countries: Findings from the International Tobacco Control Four Country Survey. Nicotine \& Tobacco Research, 11(6), 642-649. 
Inspectie voor de Gezondheidszorg (IGZ) Healt Care Inspectorate (2010). Jaarplan rijksinspecties ziekenhuizen (annual plan state inspectorates in hospitals) Retrieved September 28, 2011, from http://www.igz.nl/Images/Jaarplan\%20rijkinspecties\%20ziekenhuizen\%202011tcm294-300052.pdf.

Inspectieraad. (2012). Werkprogramma Samenwerkende Rijksinspecties (Work Programme for Collaborating Government Inspectorates) 2012-2013. 's-Gravenhage: Inspectieraad.

International Agency for Research on Cancer (IARC) - World Health Organization. (2009). IARC handbooks of cancer prevention, tobacco control, vol. 13: Evaluating the effectiveness of smoke-free policies. Geneva: WHO Press.

Intraval \& nieuwe Voedsel en Waren Autoriteit. (2011). Inventarisatie naleefniveau rookvrije horeca winter 2010/2011 (Inventarisation of the degree of compliance smoke free hospitality winter 2010/2011).

Intraval \& Voedsel en Warenautoriteit. (2009). Inventarisatie naleefniveau rookvrije horeca (Inventarisation degree of compliance smoke free hospitality). Intraval \& VWA.

Jacobson, P.D. \& Wasserman, J. (1997). Tobacco Control Law: Implementation and enforcement. Washington: Rand.

Jacobson P.D., Wasserman J. \& Anderson J.R. (1997). Historical overview of tobacco legislation and regulation. Journal of Social Issues 53(1), 75-95.

Jamrozik K. Population strategies to prevent smoking. (2004). Britisch Medical Journal, 328(7442), 759-762.

Jansen, M. \& Smits, A. (2011). Effecten van toezicht en handhaving meten: een handreiking (Measuring effects of supervision and enforcement: A guide). Utrecht: Centrum voor Criminaliteitspreventie en Veiligheid

Jason L.A., Pokorny S.B., Muldowney K.\& Velez M. (2005). Youth tobacco sales-to-minors and possessionuse-purchase laws: A public health controversy. Journal of Drug Education.35(4), 275-290.

Jenkins R.A. \& Counts R.W. (1999) Occupational exposure to environmental tobacco smoke: Results of two personal exposure studies. Environmental Health Perspect, 107 (Suppl.2), 341-348.

Jones S.E., Sharp D.J., Husten C.G. \& Crossett L.S. (2002) Cigarette acquisition and proof of age among US high school students who smoke. Tobacco Control 11, 20-25.

Joossens, L. \& Raw, M. (2006). The Tobacco Control Scale: A new scale to measure country activity. Tobacco Control, 15(3), 247-253.

Joossens, L. \& Raw, M. (2011). The Tobacco Control Scale 2010 in Europe. Brussels: Association of European Cancer Leagues.

Joossens, L. \& Raw, M. (2014). The Tobacco Control Scale 2013 in Europe. Brussels: Association of European Cancer Leagues.

Klein Haarhuis, C.M. \& Niemeijer, E. (2008) Wet en werkelijkheid, bevindingen uit evaluaties van wetten (Law and reality: findings of evaluation of legislation).( $n r .267$ onderzoek en beleid). Den Haag: Wetenschappelijk Onderzoek- en Documentatiecentrum \& Boom Juridische uitgevers.

Klerks, M.C.J.L. \& Robben, P.B.M. (2012) De inspecteur over de effecten van het toezicht: een onderzoek onder de inspecteurs van twaalf rijksinspecties (The inspector on the impact of supervision: A survey of inspectors from twelve inspectorates). Tijdschrift voor Toezicht, (3), 19-30.

Knol, K., Hilvering, C., Wagener, D.J.TH. \& Willemsen, M.C. (2005). Tabaksgebruik: gevolgen en bestrijding. Utrecht: Lemma bv.

Lantz P.M., Jacobson P.D., Warner K.E., Wasserman J., Pollack H.A., Berson J., et al. (2000). Investing in youth tobacco control: A review of smoking prevention and control strategies. Tobacco Control, 9(1), 47-63.

Law Enforcement Expertise Centre. (2004). The 'Table of Eleven': A versatile tool. The Hague: Ministry of Justice.

Lee, J.G., Hendriksen, L., Myers, A.E., Dauphinee, A.L. \& Ribisl, K.M. (2014). A systematic review of store audit methods for assessing tobacco marketing and products at the point of sale. Tobacco Control 23(2), 98-106.

Levy, D.T., Chaloupka, F. \& Gitchell, J. (2004). The effects of tobacco control policies on smoking rates: A tobacco control scorecard. Journal of Public Health Management and Practice,10(4), 338-353. 
Levy, D.T., Romano, E. \& Mumford, E. (2005). The relationship of smoking cessation to sociodemographic characteristics, smoking intensity, and tobacco control policies. Nicotine \& Tobacco Research, 7(3), 387-396.

Lewit E.M., Hyland A., Kerrebrock N. \& Cummings K.M. (1997). Price, public policy, and smoking in young people. Tobacco Control 6(suppl.2), S17-24.

Linden, G. (2006, march 7). E-mailing and chatting, most popular activities on the Internet. Web magazine. Retrieved from: www.cbs.nl/en-GB/menu/themas/bedrijven/publicaties/artikelen.archief/2006/20061893.wm.htm. Statistics Nederland (CBS)

Lovato, C., Watts, A. \& Stead, L.F. (2011). Impact of tobacco advertising and promotion on increasing adolescent smoking behaviours (Review). Cochrane Database Systematic Review. 10.

Mackenbach, J.P. \& McKee, M. (2013). Successes and Failures of Health Policy in Europe: Four decades of divergent trends and converging challenges. Berkshire: Open University Press.

McMullen, K.M., Brownson, R.C., Luke, D. \& Chriqui, J. (2005). Strength of clean indoor air laws and smoking related outcomes in the USA. Tobacco Control, 14(1), 43-48.

Mertens, F. (2011). Inspecteren, toezicht door inspecties. Den Haag, SDU-uitgevers.

Miller C., Wakefield M., Kriven S. \& Hyland A. (2002). Evaluation of smoke-free dining in South Australia: Support and compliance among the community and restaurateurs. Australian and New Zealand Journal of Public Health, 26 (1), 38-44.

Ministerie van Binnenlandse Zaken en Koninkrijksrelaties. (2012). De staat van het rijkstoezicht 2011 (The state of government supervision 2011) (interne notitie). Ministerie BZK.

Monk, J. (2012). Reform of regulatory enforcement and inspections in OECD countries. OECD.

Monshouwer K., Dorsselaer S. van, Gorter A., Verdurmen J. \& Vollebergh W. (2004). Jeugd en riskant gedrag: kerngegevens uit het peilstationonderzoek 2003, roken, drinken, drugsgebruik en gokken onder scholieren vanaf tien jaar [Youth and risk behaviour: data from the Netherlands 2003, smoking, drinking, drugs use and gambling among schoolchildren of 10 years old]. Utrecht: Trimbos-instituut.

Montini T. \& Bero L.A. (2008). Implementation of a workplace smoking ban in bars: The limits of local discretion. BMC Public Health, 8, 402.

Morawski, M., Leeuw, F.L. \& Ottow, A.T. (2013). Trends in toezicht: middelen en prestaties (Trends in supervision: resources and performance). Tijdschrift voor toezicht, 2, 43-51.

Mosher J.F. (1995). The merchants, not the customers: Resisting the alcohol and tobacco industries' strategy to blame young people for illegal alcohol and tobacco sales. Journal of Public Health Policy, 16, 412432.

Moskowitz, J.M., Lin, Z. \& Hudes, E.S. (1999). The impact of California's smoking ordinances on worksite smoking policy and exposure to environmental tobacco smoke. American Journal of Health Promotion, 13(5), 278-281.

Moussa, K., Lindström, M. \& Ostergren, P.O. (2004). Socioeconomic and demographic differences in exposure to environmental tobacco smoke at work: The Scania Public Health Survey 2000. Scandinavian Journal of Public Health, 32(3), 194-202.

Mudde A.N., Willemsen M.C., Kremers S., de Vries H. (2000). Meetinstrumenten [Measuring-instruments]. Den Haag: Stivoro.

Mullooly, J.P., Schuman, K.L., Stevens, V.J., Glasgow, R.E. \& Vogt, T.M. (1990). Smoking behavior and attitudes of employees of a large HMO before and after a work site ban on cigarette smoking. Public Health Report, 105(6), 623-628.

Nagelhout, G.E. (2012). It has been done elsewhere, it can be done everywhere, impact of smoke-free legislation on smoking. (Doctoral dissertation). Universtiteit van Maastricht, the Netherlands. Retrieved from: http://arno.unimaas.nl/show.cgi?fid=26377.

Nagelhout, G.E., Willemsen, M.C. \& Vries de, H (2011). The population impact of smoke-free workplace and hospitality industry legislation on smoking behavior. Findings from a national populations survey. Addiction, 106, 816-823. 
Nagelhout. G.E., Putte van den, B., Vries de, H., Crone, M., Fong, G.T. \& Willemsen, M.C. (2012). The influence of newspaper coverage and a media campaign on smokers' support for smoke-free bars and restaurants and on secondhand smoke harm awareness: Findings from the International Tobacco Control (ITC) Netherlands Survey. Tobacco Control, 21, 24-29.

Naidoo J. \& Platts C. (1985). Smoking prevention in Bristol, getting the maximum results using the minimum resources. Health Education Journal, 44, 39-42.

Nederlands School Public Health (NSPH). (1998). Tabaksontmoedigingsbeleid, gezondheidseffectrapportage. Utrecht: NSPH.

Nederlandse Nietrokersvereninging CAN v. de Staat der Nederlanden, ECLI:NL:GHDHA:2013:BZ4871 (2013), Gerechtshof Den Haag.

Ogilvie D., Gruer L. \& Haw S. (2005). Young people's access to tobacco, alcohol, and other drugs. British Medical Journal, 331, 393-396.

Organisation for Economic Cooperation and Development (OECD). (2014). Regulatory enforcement and inspections, OECD, Best practice principles for regulatory policy. OECD.

Opstelten I.W. (2011). Brief aan de Voorzitter van de Tweede Kamer der Staten-Generaal betreft beleidsreactie op het Inspectie OOV-rapport naar "de brand bij Chemie-Pack in Moerdijk (policy response to the inspection report on the fire at Chemie-Pack in Moerdijk)" en het Al-rapport "Veilig werken door hulpverleningsdiensten" (Safe operation by aid services) (2011-2000036262). Ministerie van Veiligheid en Justitie.

Ottow, A.T. \& Robben, P.B.M. (2012). De toezichthouder als koorddanser (The supervisor as tightrope walker). Tijdschrift voor Toezicht, 3, 32-35.

Patten, C.A., Pierce, J.P., Cavin, S.W., Berry, C.C. \& Kaplan, R.M. (1995). Progress in protecting non-smokers from environmental tobacco smoke in California workplaces. Tobacco Control, 4, 139-144.

Paynter, J. \& Edwards, R. (2009). The impact of tobacco promotion at the point of sale: A systematic review. Nicotine \& Tobacco Research, 11(1), 25-35.

Pechtold A. \& Brinkhorst L.J. (2006) Brief aan de voorzitter van de Tweede Kamer der Staten-Generaal, betreft voortgang uitvoering Kaderstellende Visie op Toezicht en uitvoering motie-Aptroot 30300 XIII $n r .29$, (BZK/DGMOS). Ministerie van Binnenlandse Zaken en Koninkrijksrelaties.

Pickett, M.S., Schober, S.E., Brody, D.J., Curtin, L.R. \& Giovino, G.A. (2006). Smoke-free laws and secondhand smoke exposure in US non-smoking adults, 1999-2002. Tobacco Control, 15(4), 302-307.

Pierce, J.P. \& León, M. (2008). Effectiveness of smoke-free policies. Lancet Oncology, 9(7), 614-615.

Pierce, J.P., Shanks, T.G., Pertschuk, M., Gilpin, E., Shopland, D., Johnson, M. et al. (1994). Do smoking ordinances protect non-smokers from environmental tobacco smoke at work? Tobacco Control, 3, 15-20.

Pirkle, J.L., Bernert, J.T., Caudill, S.P., Sosnoff, C.S. \& Pechacek, T.F. (2006). Trends in the exposure of nonsmokers in the U.S. population to secondhand smoke: 1988-2002. Environmental Health Perspective 114(6), 853-858.

Pirkle, J.L., Flegal, K.M., Bernert, J.T., Brody, D.J., Etzel, R.A. \& Maurer, K.R. (1996). Exposure of the US population to environmental tobacco smoke: The Third National Health and Nutrition Examination Survey, 1988 to 1991. JAMA, 275(16), 1233-1240.

Pollay, R.W. (2000). Targeting youth and concerned smokers: Evidence from Canadian tobacco industry documents. Tobacco Control, 9, 136-147.

Pro Facto. (2010). 'Toezicht en effectmeting: Het Kan!, researchsynthese van onderzoek naar de effectiviteit van toezichtinterventies (Supervision and impact measurement: It can be done!, synthesis of research into effectiveness of supervisory interventions). Den Haag: Ministerie van Justitie, Wetenschappelijk Onderzoek- en Documentatiecentrum.

Pucci, L.G. (1991). Implementing restrictive smoking policies: An overview of worksite intervention studies. European Journal of Public Health, 1(2), 105-109. 
Putte S.J.H.M. van den, Yzer M.C., Berg B.M. ten \& Steevels R.M.A. (2005). Nederland start met stoppen / Nederland gaat door met stoppen - Evaluatie van de STIVORO campagnes rondom de jaarwisseling 2003 - 2004. (The Netherland starts to quit / the Netherlands continues quiting - Evaluation of the STIVORO campaigns around the turn of the year 2003-2004). Amsterdam:Ascor.

Reedijk, K. \& Verdonk-Kleinjan, W. (2013). Academie voor Toezicht: verkenning in opdracht van de Inspectieraad (Academy for Supervision: Exploratory report on the behalf of the Inspection Board). Den Haag: Inspectieraad.

Reynolds, P. (1999). Epidemiologic evidence for workplace ETS as a risk factor for lung cancer among nonsmokers: Specific risk estimates. Environmental Health Perspective, 107(Suppl.6), 865-872.

Richardson, L., Hemsing, N., Greaves, L., Assanand, S., Allen, P., McCullough, L., et al. (2009). Preventing smoking in young people: A systematic review of the impact of access interventions. International Journal of Environmental Research and Public Health, 6(4), 1485-1514.

Rimpelä A.H. \& Rainio S.U. (2004). The effectiveness of tobacco sales ban to minors: The case of Finland. Tobacco Control 13(2), 167-174.

Rijn, M.J. van. (2013 $\left.{ }^{\mathrm{a}}\right)$ Brief aan de voorzitter van de Tweede Kamer der Staten-Generaal, betreft toezeggingen AO 28 februari (VGP/3160038). Ministerie van Volksgezondheid, Welzijn en Sport.

Rijn, M.J. van. $\left(2013^{b}\right)$. Brief aan de voorzitter van de Tweede Kamer der Staten-Generaal, betreft nota n.a.v. verslag Tabakswet verhoging minimumleeftijd (126135-105670-VGP). Ministerie van Volksgezondheid, Welzijn en Sport.

Robben, P.B.M. (2011). Evalueren en verbeteren van toezicht (Evaluating and Improving Supervision). Tijdschrift voor toezicht, 2, 72-74.

Robben, P.M.B. (2010). Toezicht in een glazen huis: effectiviteit van het toezicht op de kwaliteit van de gezondheidszorg (Supervision in a glass house: Effectiveness of supervision on the quality of health care). Rotterdam: Instituut Beleid \& Management Gezondheidszorg.

Sargent J.D. \& DiFranza J.R. (2003). Tobacco control for clinicians who treat adolescents. CA Cancer Journal of Clinicians, 53(2), 102-123.

Schippers E.I. (2013). Brief aan de Voorzitter van de Tweede Kamer der Staten-Generaal betreft Tuchtrecht en casus voormalig Jansen Steur (disciplinary law and the case of the former Jansen Steur) (MEVA-U3150929). Ministerie van Volksgezondheid, welzijn en Sport.

Schol, M.J., \& Winter, H.B. (2012). Toezichthouder: beroep, professie, of specialisatie?, studie naar de identiteit en professionalisering van de beroepsgroep (Supervisor: career, profession or specialisation?, Study on the identity and professionalisation of supervisory staff. Groningen: Profacto.

Scollo M., Lal A., Hyland A. \& Glantz S. (2003) Review of the quality of studies on the economic effects of smoke-free policies on the hospitality industry. Tobacco Control, 12(1), 13-20.

Segaar D, \& Willemsen M.C.. (2003) Tabaksrook in de werkomgeving - resultaten van het PARA-meter onderzoek onder werknemers (Tobacco smoke in the work environment - results of the PARAmeter research among employees). Den Haag: Stivoro.

Semple, S., Creely, K.S., Naji, A. Miller, B.G., Ayres, J.G. (2006). Secondhand smoke levels in Scottish pubs: The effect of smokefree legislation. Tobacco Control 16, 127-132.

Shafey, O., Dolwick, S., \& Guindon, G.E. (2003). Tobacco Control Country Profiles (2nd edition). Atlanta: American Cancer Society, World Health Organization, International Union Against Cancer.

Siegel, M. (2002). The effectiveness of state-level tobacco control interventions: A review of program implementation and behavioral outcomes. Annual Review of Public Health, 23, 45-71.

Skogstad, M., Kjaerheim, K., Fladseth, G., Gjølstad, M., Daae, H.L., Olsen, R., et al. (2006). Cross shift changes in lung function among bar and restaurant workers before and after implementation of a smoking ban. Occupational Environmental Medicine, 63(7), 482-487.

Spijkerman, R., Knibbe, R., Knoops, K., Mheen, D. van de \& Eijnden, R. van den (2009). The utility of online panel surveys versus computer-assisted interviews in obtaining substance-use prevalence estimates in the Netherlands. Addiction. 104(10), 1641-1645. 
Spijkers E, Laan van der R \& Bieleman B. (1999). Tabaksverstrekking aan jongeren 1999: onderzoek naar de naleving van de leeftijdsgrens van 16 jaar uit het Convenant Verkooppunten Tabak [Providing tobacco to minors 1999: Investigation to compliance with the age limit of 16 years from the Covenant Point of sale Tobacco]. Groningen-Rotterdam: Intraval.

Staatsblad van het Koninkrijk der Nederlanden. (1989). Maatregelen ter beperking van het tabaksgebruik, in het bijzonder ter bescherming van de niet-roker (Tabakswet). (18 $749 \mathrm{nr}$ 236) Den Haag: Staatsblad.

Staatsblad van het Koninkrijk der Nederlanden. (2002). Wet van 18 april 2002 tot wijziging van de Tabakswet. (nr. 201), Den Haag: Staatsblad.

Staatsblad van het Koninkrijk der Nederlanden. (2010). Wet van 13 december 2010 tot wijziging van de Wet op de accijns in verband met de implementatie van de Richtlijn 2010/12/EU van de Raad van 16 februari 2010 tot wijziging van Richtlijnen 92/79/EEG, 92/80/EEG en 95/59/EG wat betreft de structuur en de tarieven van de accijns op tabaksfabrikanten en Richtlijn 2008/118/EG (PbEU L 50) (Implementatie wijziging tabaksaccijns) (nr. 841), Den Haag: Staatsblad.

Staatsblad van het Koninkrijk der Nederlanden. (2011). Besluit van 14 juni 2011, houdende wijzigingen van het Besluit uitvoering rookvrije werkplek, horeca en andere ruimten. (nr. 337), Den Haag: Staatsblad.

Staatsblad van het Koninkrijk der Nederlanden. (2012). Wet van 12 juli 2012 tot wijziging van enkele belastingwetten en enige andere wetten (Wet uitwerking fiscale maatregelen Begrotingsakkoord 2013) (nr. 321), Den Haag: Staatsblad.

Stichting Red de Kleine Horeca Ondernemer v Staat der Nederlanden, ECLI:NL:RBSGR:2008:BD6680 (2008) Rechtbank's-Gravenhage.

Stead, L.F. \& Lancaster, T. (2008). Interventions for preventing tobacco sales to minors (review). Cochrane Database Systematic Reviews 1.

Steenland, K. (1999). Risk assessment for heart disease and workplace ETS exposure among nonsmokers. Environmental Health Perspective, 107(Suppl.6), 859-863.

Stephens, T., Pederson, L.L., Koval, J.J. \& Kim, C. (1997). The relationship of cigarette prices and no-smoking bylaws to the prevalence of smoking in Canada. American Journal of Public Health, 87(9), 1519-1521.

Stephens, T., Pederson, L.L., Koval, J.J. \& Macnab, J. (2001). Comprehensive tobacco control polities and the behaviour of Canadian adults. Tobacco control, 10(4), 317-322.

Stivoro. (2012). Trendpublicatie percentage rokers. Percentage rokers in de Nederlandse bevolking 1958 2011, (trendreport percentage smokers. Percentage smokers in the Dutch population 1958-2011). Den Haag: Stivoro.

Sundh M. \& Hagquist C. (2004). The importance of a minimum age law for the possibility of purchase of tobacco by adolescents: A study based on Swedish experiences. Scandinavian Journal of Public Health $32,68-74$.

Sweet, M. (2013). New Zealand moves towards plain packaging of cigarettes. Britsch Medical Journal, 346, f1425.

Thomas, S., Fayter, D., Misso, K., Ogilvie, D., Petticrew, M., Sowden, A. et al. (2008). Population tobacco control interventions and their effects on social inequalities in smoking: Systematic review. Tobacco Control, 17(4), 230-237.

Timmerman, J.P.H.K., Tromp, E. \& Waveren van, R.C. (2012). Eindevaluatie Meerjaren-programma Effecten van toezicht (Final report on evaluation of the Multi-annual program on the impact of supervision) (nr.2293). Amsterdam: Regioplan beleidsonderzoek.

TNS-NIPO. (2006) Roken jeugd 2005 (Youth smoking 2005). (Intern rapport) Amsterdam: TNS-NIPO.

Townsend, J. (1996). Price and consumption of tobacco. British Medical Bulletin, 52(1), 132-142.

Townsend, J., Roderick, P. \& Cooper, J. (1994). Cigarette smoking by socioeconomic group, sex, and age: Effects of price, income, and health publicity. British Medical Journal, 309(6959), 923-927.

Tweede Kamer der Staten-Generaal. (1996). Tabaksontmoedingsbeleid (24 743, vergaderjaar 1995-1996), Den Haag: Sdu Uitgevers. 
Tweede Kamer der Staten-Generaal. (2001). Kaderstellende visie op toezicht (Framework Vision on Supervision). (27831, nr.1. vergaderjaar 2000-2001), 's-Gravenhage, SDU uitgevers.

Tweede Kamer der Staten-Generaal. $\left(2005^{\mathrm{a}}\right)$. Preventiebeleid voor de volkgezondheid (22 894, nr.61, vergaderjaar 2004-2005), Den Haag: Sdu Uitgevers.

Tweede Kamer der Staten-Generaal. $\left(2005^{\mathrm{b}}\right)$. Preventiebeleid voor de volkgezondheid - bijlage Evaluatie tabaksontmoediging (22 894, nr.61, vergaderjaar 2004-2005), Den Haag: Sdu Uitgevers.

Tweede Kamer der Staten-Generaal. $\left(2005^{c}\right)$. Preventiebeleid voor de volkgezondheid - bijlage VWA Evaluatie van de handhavingservaring van de Tabakswet 2002-2004, een kwantitatieve en kwalitatieve analyse( Evaluation of the enforcement experience of the Tobacco Act 2002-2004, a quantitative and qualitative analysis), (22 894, nr.61, vergaderjaar 2004-2005), Den Haag: Sdu Uitgevers.

Tweede Kamer der Staten-Generaal. $\left(2005^{c}\right)$. Kaderstellende visie op toezicht (Framework Vision on Supervision). (27831, nr.15. vergaderjaar 2005-2006), 's-Gravenhage, SDU uitgevers.

Tweede Kamer der Staten-Generaal (2007). Vaststelling van de begrotingsstaten van het Ministerie van Volksgezondheid, Welzijn en Sport (XVI) voor het jaar 2007, brief van de Minister van Volksgezondheid, Welzijn en Sport. (30 800 XVI, nr. 149, vergaderjaar 2006-2007). Den Haag: Sdu Uitgevers.

Tweede Kamer der Staten-Generaal. (2008). Trendnota Arbeidszaken Overheidspersoneel (Trends in Labour Affairs in the Public Service). (31201 nr.25. vergaderjaar 2008-2009), 's-Gravenhage, SDU uitgevers.

Tweede Kamer der Staten-Generaal. (2011). Kabinetsplan aanpak administratieve lasten (governmentplan approach administrative burden). (29 515, nr.327. vergaderjaar 2010-2011), 's-Gravenhage, SDU uitgevers.

Tweede Kamer der Staten-Generaal (2013). Voedselveiligheid. (foodsafety) (26 991, nr.339. vergaderjaar 2012-2013), 's-Gravenhage, SDU uitgevers.

Tweede Kamer der Staten-Generaal. (2014). Verduidelijking van de rookverboden in de Tabakswet (33 791 nr.98.13, vergaderjaar 2013-2014). ), 's-Gravenhage: Tweede Kamer.

Twist, M.J.W., Klijn, E.H. \& van der Steen, M. (2013). Over hijgerigheid en lange adem (Exploration of the relationship between supervision and the media) (nr. 67), Den Haag: WRR.

U.S. Department of Health and Human Services (1986). The Health consequences of involuntary smoking: $A$ report of the Surgeon General. Rockville, Maryland: U.S. Department of Health and Human Services, Center for Diseases Control and Prevention, National Center for Chronic Disease Prevention and Health Promotion, Office on smoking and Health.

U.S. Department of Health Education and Welfare (1964). Smoking and health: Report of the Advisory Committee to the Surgeon General of the Public Health Service. Washington, DC: U.S. Public Health Service.

Vedder, A. (2013). Factsheet Academische Werkplaats Toezicht (Factsheet on the Academic Collaborative Centre for Supervision).

Verdonk, W., Rijswijk, P., Dekker, P., Faber, O. \& Visser K. (2013). Effect in zicht. (eindopdracht Masterclass Toezicht en effectmeting, Nyenrode Business Universiteit). Utrecht: NVWA.

Verdonk-Kleinjan W.M., Candel M.J., Knibbe R.A., Willemsen M.C. \& Vries H. de. (2011). Effects of a workplace-smoking ban in combination with tax increases on smoking in the Dutch population. Nicotine \& Tobocco Research 13(6), 412-418.

Verdonk-Kleinjan W.M., Rijswijk P.C., Candel M.J., de Vries H. \& Knibbe R.A. (2012). Agreement between selfreports and on-site inspections of compliance with a workplace smoking ban. Nicotine \& Tobacco Research 14(9), 1121-1125.

Verdurmen, J., Monshouwer, K., Dorsselaer van, S., Lokman, S., Vermeulen-Smit, E. \& Vollebergh, W. (2012). Kerngegevens uit het peilstationsonderzoek scholieren, jeugd en riskant gedrag 2011 (Key data from the Dutch national school survey, youth and risky behavior in 2011). Utrecht: Trimbos-instituut.

Verstraete B. (2008). Het sociaal wenselijk antwoorden bij adolescentenenquêtes (The socially desirable responses in adolescents surveys). (Verhandeling voorgedragen tot het behalen van de graad van ManaMa in de Jeugdgezondheidszorg) 
Vries H. de, Kremers S.P., Smeets T., Brug J., Eijmael K. (2008). The effectiveness of tailored feedback and action plans in an intervention addressing multiple health behaviors. American Journal of Health Promotion, 22(6), 417-425.

Vries H. de, Mudde A., Leijs I., Charlton A., Vartiainen E., Buijs G. et al. (2003). The European Smoking Prevention Framework Approach (EFSA): An example of integral prevention. Health Educucation Research, 18(5), 611-626.

Voedsel en Warenautoriteit. (2008). Inspectieresultaten Rookvrije Horeca; juli t/m september 2008 (Inspection results smoke free hospitality; July to September 2008).VWA.

Wakefield, M.A., Hayes, L., Durkin, S., Borland, R. (2013). Introduction effects of the Australian plain packaging policy on adult smokers: A cross-sectional study. Britisch Medical Journal, 3 ,e003175.

Wassink, W.F. (1948). Ontstaansvoorwaarden voor longkanker. Nederlands Tijdschrift voor Geneeskunde, 92(46), 3732-3747.

Wegener DM. (z.d.) De Grote Consumenten Enquête helpt uw rendement te verhogen (the Large Consumer Survey helps to increase your returns). Nieuwegein: Wegener DM.

Wejnert B. (2002). Integrating models of diffusion of innovations: A conceptual framework. Annual Review of Sociology; 28,297-326.

Welp, P. (2012). Effectiviteit van toezicht: tijd voor responsive evaluation (Effectiveness of supervision: Time for responsive evaluation). Tijdschrift van Toezicht, 2, 7-22.

Werkgroep Effectmeting IG-beraad. (2005). Leidraad effectmeting bij Inspecties (Guide to impact measurement in inspectorates). 's-Gravenhage: Ministerie van Justitie, Expertisecentrum Rechtshandhaving.

Wester, J. (1957). Roken en longkanker. Nederlands Tijdschrift voor Geneeskunde, 101, 459-464.

Wetenschappelijke Raad voor het Regeringsbeleid (WRR). (2013). Toezien op publieke belangen, naar een verruimd perspectief op rijkstoezicht (Supervising public interests, towards a broader perspective on government supervision) (no. 89). Amsterdam: Amsterdam University Press.

Willemsen, M.C. \& Zwart de, W.M. (1999). The effectiveness of policy and health education strategies for reducing adolescent smoking: A review of the evidence. Journal of Adolescence 22, 587-599

Willemsen, M.C., Brug, J., Uges, D.R., \& Vos-de Wael, M.L. (1997). Validity and reliability of self-reported exposure to environmental tobacco smoke in work offices. Journal of Occupational Environmental Medicine, 39(11), 1111-1114.

Wilson, L.M., Tang, E.A., Chander, G., Hutton, H.E., Odelola, O.A., Elf, J.L. et al. (2012). Impact of tobacco control interventions on smoking initiation, cessation, and prevalence: a systematic review. Journal of Environmental Public Health. Doi:10.1155/2012/961724.

Winter, H.B. (2012). Meten van de effecten van toezicht 'Yes we can!' (Measure the impact of supervision 'Yes we can!'). Tijdschrift voor Toezicht, 2, 63-80.

World Health Organization. (2003). WHO Framework Convention on Tobacco Control. Geneva: World Health Organization.

World Health Organization. (2008). WHO Report on the global tobacco epidemic, 2008: The MPOWER package. Geneva: World Health Organization.

World Health Organization. (2011). WHO Report on the global tobacco epidemic, 2011: Warning about the dangers of tobacco. Geneva: World Health Organization.

Wortley P.M., Caraballo R.S., Pederson L.L. \& Pechacek T.F. (2002). Exposure to secondhand smoke in the workplace: serum cotinine by occupation. Journal of Occupational Environmental Medicine 44(6):503509.

Wynder, E.L. \& Graham, E.A. (1950). Tobacco smoking as a possible etiologic factor in bronchiogenic carcinoma; A study of six hundred and eighty-four proved cases. Journal of American Medical Association, 143(4), 329-336.

Zhong, L., Goldberg, M.S., Parent, M.E. \& Hanley, J.A. (2000). Exposure to environmental tobacco smoke and the risk of lung cancer: A meta-analysis. Lung Cancer, 27(1):3-18. 
Dankwoord 
Graag wil ik langs deze weg iedereen bedanken die, in welke fase dan ook, mij heeft geïnspireerd en/of een bijdrage heeft geleverd aan de uitvoering van mijn promotieonderzoek. Het is voor mij een zoektocht geweest met mijlpalen en successen, maar ook met tegenslagen en een constante strijd om de balans te vinden tussen werk, promotie en privé.

Bijzondere dank ben ik verschuldigd aan Ronald die het aandurfde om ruim 10 jaar geleden de taak van promotor op zich te nemen om met mij, zonder wetenschappelijke achtergrond, dit traject te doorlopen. Vanaf dag één heeft Ronald mij het vertrouwen gegeven dat ik dit traject tot een goed einde zou brengen en ik ben blij dat ik dit vertrouwen heb kunnen waarmaken. Ronald, bedankt voor alle tijd die je in mijn begeleiding hebt gestoken om mij te adviseren bij de onderzoeken, te discussiëren over de betekenis van mijn bevindingen en voor het becommentariëren van de vele versies van mijn artikelen. Hein, mijn tweede promotor wil ik ook bedanken. Ondanks de beperkte tijd vond je altijd wel een mogelijkheid om waardevolle feedback te geven en mij naar het grotere geheel te laten kijken. Met zijn drieën spraken we ook vaak over het vak toezicht en mijn werk bij de NVWA. We spraken over de verschillen en overeenkomsten tussen de wetenschap en de praktijk van toezicht en over hoe we de verbinding konden versterken. Tot slot wil ik hier benoemen dat ik tijdens onze afspraken in Maastricht door jullie altijd geïnspireerd werd en met nieuwe positieve energie thuis kwam. Ik zal de discussies missen!

Ook wil ik Frans Tan en Math Candel bedanken die mij hebben geadviseerd bij het uitvoeren van de statistische analyses. Jullie hebben mij erg geholpen om de 'pas opgedane' kennis ook in de praktijk goed toe te passen. En natuurlijk Marc Willemsen die de databestanden van Stivoro beschikbaar heeft gesteld om beleidseffecten te kunnen analyseren.

Verder wil ik Mieke Derickx bedanken die, naast Ronald en Hein, één van de constante factoren voor mij was op de universiteit en altijd een luisterend oor had.

Ook wil ik een aantal collega's van de NVWA bedanken, waarbij ik wil beginnen met Paul Beljaars, mijn toenmalige afdelingshoofd. Als Paul mij destijds niet de vraag had gesteld 'waarom ga je niet promoveren in plaats van je energie te steken in een masterstudie?' was ik wellicht nooit aan dit traject begonnen. Inmiddels is Paul al vele jaren met pensioen en heeft hij zich vermoedelijk nooit gerealiseerd dat deze korte vraag zoveel impact heeft gehad op mijn verdere loopbaan. Dank hiervoor Paul! Ook Hans Beelen, mijn teamleider destijds, heeft mij in de eerste jaren gestimuleerd om te beginnen aan dit traject en ging vaak mee naar Maastricht, om in de startfase de onderzoeken te bespreken. Uiteraard wil ik de NVWA bedanken voor de mogelijkheid die ik heb gekregen om dit promotieonderzoek uit te voeren en de benodigde opleidingen 
te volgen, zoals de verschillende modules aan de Universiteit van Maastricht en het Postdoctoraal onderwijs epidemiologie aan het EMGO-instituut. Daarnaast wil ik de NVWA ook bedanken voor het gebruik van de (inspectie)data en de extra vragen die ik kon laten meelopen met de bestaande externe onderzoeken die werden uitgevoerd. Samen met Boudewijn Kustner en Marian Gacsbaranyi waren we een 'drie-eenheid' die de onderzoeken op het gebied van tabak en alcohol initieerde en coördineerde. Vaak werden deze uitgevoerd door bureau Intraval. Samen met Bert en Annelies keken we hoe zowel de NVWA-vragen als 'mijn promotie vragen' te combineren waren in een onderzoek. Ik denk met plezier terug aan de doorgaans constructieve en gezellige gesprekken. Voor een aantal onderzoeken heb ik gebruik gemaakt van inspectiegegevens. NVWA-teamleiders en inspecteurs dank voor jullie bijdrage.

Ook waren er verschillende masterstudenten die ik begeleid heb en die onderdelen van mijn onderzoek hebben uitgevoerd. Pieter Rijswijk, tevens collega, wil ik apart noemen en waarderen voor zijn analysewerk en het meeschrijven. Het zijn twee mooie artikelen geworden! (hoofdstuk 2 en 3).

Sinds 2010 werk ik binnen de NVWA niet meer voor het domein tabak, maar houd ik mij bezig met toezichtsontwikkeling in het algemeen. Samen met Andries, Cees en Ad werk(t)en we aan de inbedding van handhavingsregie; ook wel programmatisch handhaven genoemd.

Via deze werkzaamheden kwam ik in contact met Paul Robben, waarmee ik enkele jaren heb samengewerkt aan het meerjarenprogramma 'Effecten van toezicht' in opdracht van de Inspectieraad, samen met Hiba, Marielle K. en Ron. Binnen dit programma discussieerden we over de vraag hoe effectmeting een prominentere plaats kon krijgen in de toezichtspraktijk. Eén van de activiteiten was het ontwikkelen en geven van workshops over effectmeting. Hierbij werkten we samen met het CCV (Annemarie, Marielle J. \& Karin).

Om effectmeting beter in te bedden binnen de NVWA, volgden we, op verzoek van Freek van Zoeren, met een paar collega's (Karin, Olchert, Peter \& Pieter) de Masterclass 'Toezicht en effectmeting' aan de Nyenrode Business Universiteit.

Bovenstaande werkzaamheden hebben mij geïnspireerd om mijn proefschrift te verbreden (hoofdstuk 7). Graag wil ik jullie (en alle andere collega's waar ik mee heb samengewerkt in het kader van effectmeting) bedanken voor de discussies en de gezellige tijd.

Door de jaren heen heb ik zowel door functiewisselingen als door reorganisaties verschillende leidinggevenden gehad: Hans Beelen, Joop Blenkers, Henk de Groot, Anja Martens, Laurens Smit, Richard van Buuren en Gezinus van der Vlag. Wat jullie gemeen hebben is dat jullie allen begrip hadden voor mijn ambitie en mij stimuleerden om 
door te gaan en het promotietraject af te maken. Nu is het af! Ik wil jullie nogmaals danken voor jullie vertrouwen.

Wat mij ook altijd gesteund heeft is de interesse van mijn collega's. Zij vroegen regelmatig hoe ver ik was met mijn proefschrift. Bijvoorbeeld de collega's van de afdeling Signalering Zuid, de afdeling Samengestelde Producten, ITAT, Concernstrategie, het Analyse team, het team 'Alcohol \& Tabak, Horeca \& Ambacht en Dierproeven', het Ontwerpteam Verbeterplan Vlees en nog vele anderen. Dank voor deze belangstelling!

En dan mijn twee paranimfen, Marian Gacsbaranyi en Mieke Derickx. Fijn dat jullie deze bijzondere dag met mij samen willen beleven.

Tot slot wil ik ook mijn ouders en schoonouders bedanken, die het hele traject altijd op de voet hebben gevolgd en super trots zijn. Daarnaast dank ik ook vrienden en familie voor de belangstelling naar mijn onderzoek. Het laatste jaar heb ik minder tijd voor jullie gehad, maar dit gaat veranderen en ik ga ook weer hardlopen!

Als laatste een bijzonder woord van dank voor Nico. Je was er altijd, nam veel uit handen, leefde mee als ik het weer eens 'te druk' had en vond het niet erg als we een afspraak moesten verzetten. Bovendien heb je geweldig geholpen om alles op tijd af te krijgen. Je zegt altijd dat ik het zelf heb gedaan, maar zonder jouw onvoorwaardelijke steun en je vertrouwen in mij was dit nooit gelukt! 
Curriculum vitae 
Wendy Verdonk-Kleinjan was born on the 9th of November 1967 in Delft, the Netherlands. After graduating from secondary school (HAVO) in 1985 in Voorburg, she studied Nutrition and Dietetics at the Haagse Hoge School, were she received her Bachelor degree in 1989.

After a year of traveling she joined the (former) Netherlands Food and Consumer Product Safety Authority (Nederlandse Voedsel en Warenautoriteit; NVWA) where she worked as a food inspector until 1998. Then she moved to the department of Research and Development of the NVWA, where she worked on the safety and supervision strategies of food supplements, herbal preparations and other health products. In 2002 she became involved in the development of supervision strategies for and research on tobacco legislation in the Netherlands. In that same period she started her PhD project under the supervision of Prof. Dr. R.A. Knibbe of the department of Medical Sociology of Maastricht University (CAPHRI). Meanwhile, she has fulfilled various functions in the Research and Development department within the field of tobacco.

In 2010 she moved to the Staff department where she worked on developing and advising on supervision strategies in general. In addition, she also worked (partly) for the Inspection Council within the multi-annual program 'Supervision with impact'. Currently, she works primarily on advising and conducting impact assessments in the different areas for which the NVWA is responsible for the overall supervision. 
List of publications from this thesis:

Verdonk-Kleinjan W.M., Candel M., Knibbe R.A., Willemsen M.C. \& de Vries H. (2011). Effect of a workplace-smoking ban in combination with tax increases on smoking in the Dutch population. Nicotine and Tobacco Research, 13(6), 412-418.

Verdonk-Kleinjan W.M., Knibbe R.A., Bieleman B., de Groot H.N. \& de Vries H. (2008). The tobacco sales ban and tobacco purchases by adolescents: a general population study in the Netherlands. European Journal of Public Health, 18(5), 498-503.

Verdonk-Kleinjan W.M., Knibbe R.A., Tan F.E., Willemsen M.C., de Groot H.N. \& de Vries H. (2009). Does the workplace-smoking ban eliminate differences in risk for environmental tobacco smoke exposure at work? Health Policy, 92(2), 197-202.

Verdonk-Kleinjan W.M., Rijswijk P.C., Candel M, de Vries H. \& Knibbe R.A. (2012). Agreement between self-reports and on-site inspections of compliance with the workplace-smoking ban. Nicotine \& Tobacco Research, 14(9), 1121-1125.

Verdonk-Kleinjan W.M., Rijswijk P.C., de Vries H. \& Knibbe R.A.(2013). Compliance with the workplace-smoking ban in the Netherlands. Health Policy, 109(2), 200-206. 
